Portland State University

PDXScholar

Civil and Environmental Engineering Faculty

Publications and Presentations

$12-2014$

\title{
Evaluation of Bicyclists Exposure to Traffic-Related Air Pollution along Distinct Facility Types
}

James F. Pankow

Portland State University, pankowj@pdx.edu

Miguel A. Figliozzi

Portland State University, figliozzi@pdx.edu

Alexander Y. Bigazzi

Portland State University, abigazzi@gmail.com

Follow this and additional works at: https://pdxscholar.library.pdx.edu/cengin_fac

Part of the Transportation Commons, and the Urban Studies Commons Let us know how access to this document benefits you.

\section{Citation Details}

Pankow, James, Figliozzi, Miguel, and Bigazzi, Alexander. Evaluation of Bicyclists Exposure to TrafficRelated Air Pollution along Distinct Facility Types. NITC-RR-560. Portland, OR: Transportation Research and Education Center (TREC), 2014. http://dx.doi.org/10.15760/trec.121

This Report is brought to you for free and open access. It has been accepted for inclusion in Civil and Environmental Engineering Faculty Publications and Presentations by an authorized administrator of PDXScholar. Please contact us if we can make this document more accessible: pdxscholar@pdx.edu. 


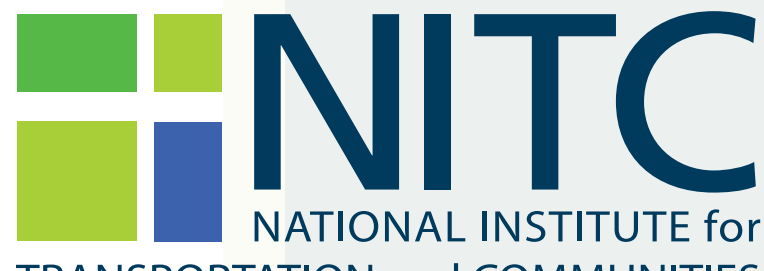

TRANSPORTATION and COMMUNITIES

\section{DRAFT FINAL REPORT}

\section{Evaluation of Bicyclists Exposure to Traffic-Related Air Pollution along Distinct Facility Types}

NITC-RR-560 ם December 2014

NITC is the U.S. Department of Transportation's national university transportation center for livable communities.

H:PREC 


\title{
EVALUATION OF BICYCLISTS EXPOSURE TO TRAFFIC-RELATED AIR POLLUTION ALONG DISTINCT FACILITY TYPES
}

\author{
Draft Final Report
}

NITC-RR-560

\author{
by \\ James Pankow \\ Miguel Figliozzi \\ Alexander Bigazzi \\ Portland State University \\ for \\ National Institute for \\ Transportation and Communities (NITC) \\ P.O. Box 751 \\ Portland, OR 97207

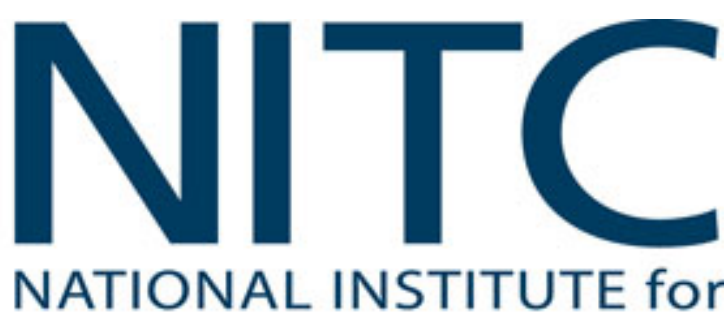

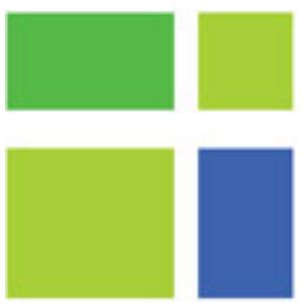

TRANSPORTATION and COMMUNITIES

December 2014 



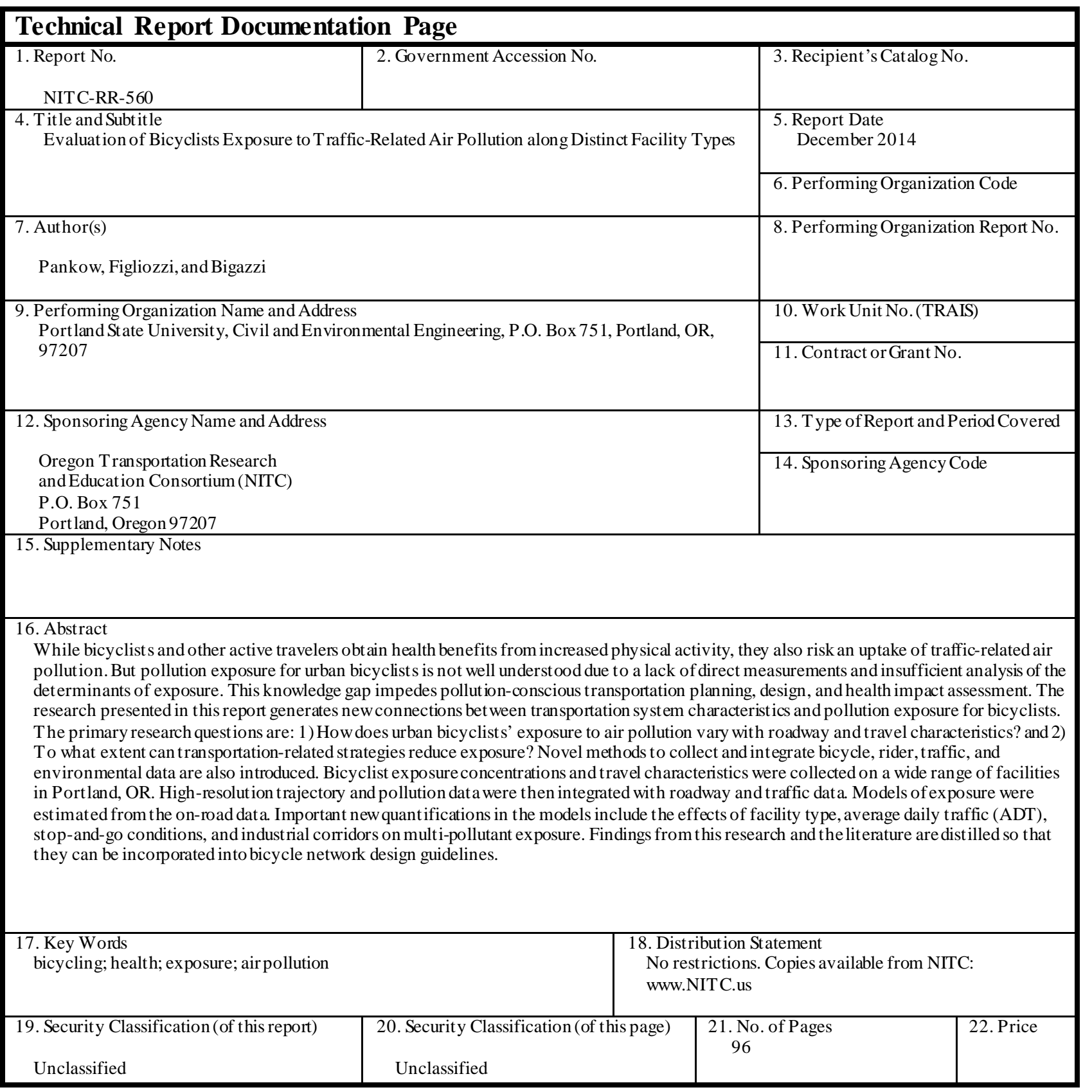




\section{ACKNOWLEDGEMENTS}

The research described in this report was supported by the National Institute for Transportation and Communities (NITC); Metro, Portland's regional government; and the City of Portland. In addition, Alexander Bigazzi was supported by doctoral fellowships from the U.S. National Science Foundation (Grant No. DGE-1057604) and NITC. Wentai Luo and the late Lorne Isabelle assisted with gas sample collection and analysis.

\section{DISCLAIMER}

The contents of this report reflect the views of the authors, who are solely responsible for the facts and the accuracy of the material and information presented herein. This document is disseminated under the sponsorship of the U.S. Department of Transportation University Transportation Centers Program in the interest of information exchange. The U.S. Government assumes no liability for the contents or use thereof. The contents do not necessarily reflect the official views of the U.S. Government. This report does not constitute a standard, specification, or regulation. 


\section{TABLE OF CONTENTS}

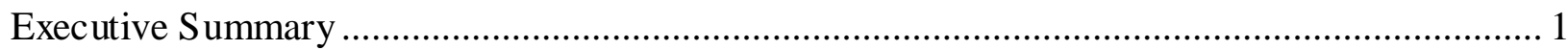

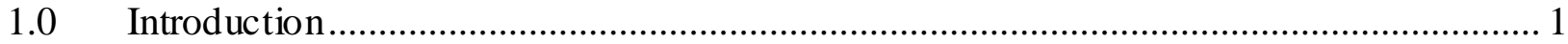

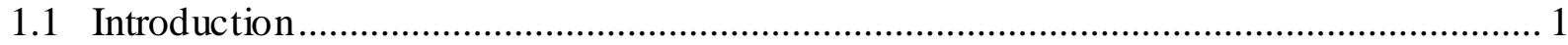

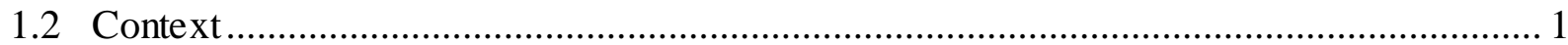

1.2.1 Bicycling and Health............................................................................................ 2

1.2.2 Planning and Managing Bicycle Transportation for Health ..................................... 2

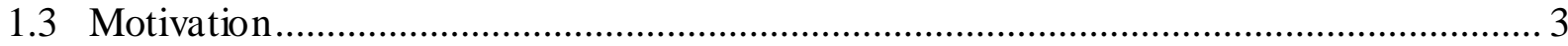

1.4 Objective and Research Questions............................................................................. 4

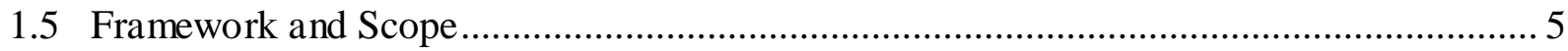

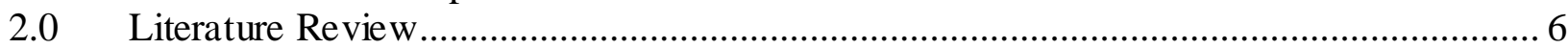

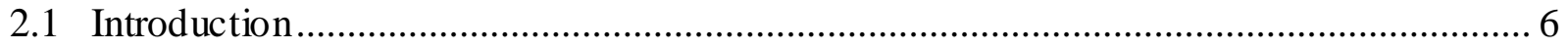

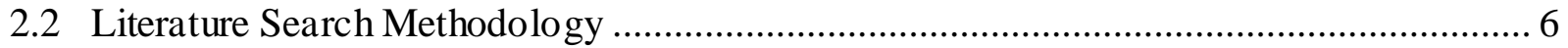

2.3 Bicyclists’ Air Pollution-exposure Concentrations .............................................................. 8

2.3.1 Modal Comparisons of Exposure Concentration....................................................... 10

2.3.2 Factors Affecting Bicyclists' Exposure Concentrations ............................................ 11

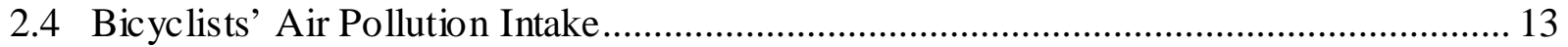

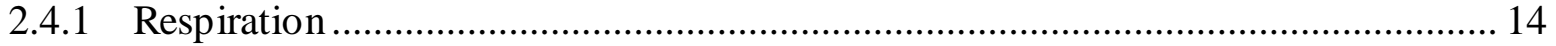

2.4.2 Studies of Bicyclists’ Pollution Intake................................................................. 16

2.4.3 Modal Comparisons of Pollution Intake .............................................................. 18

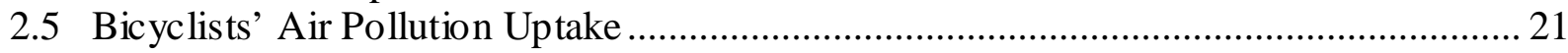

2.6 Health Effects of Bicyclists’ Air Pollution Uptake.......................................................... 23

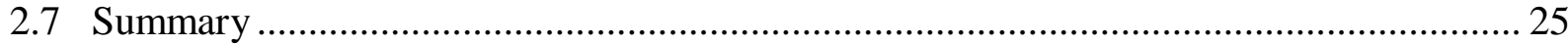

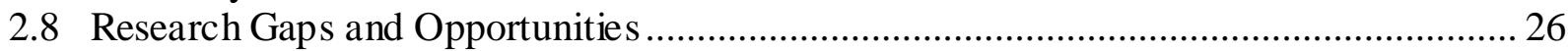

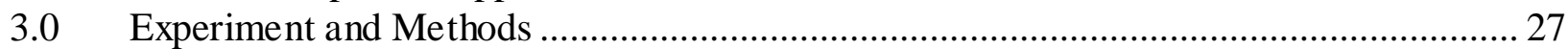

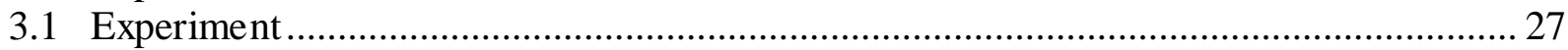

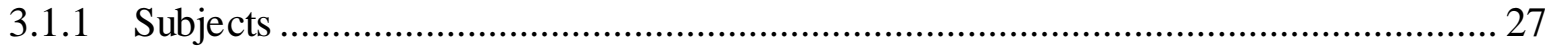

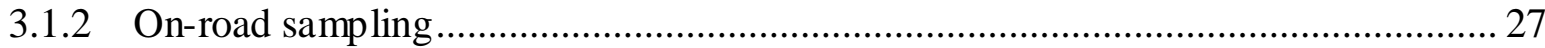

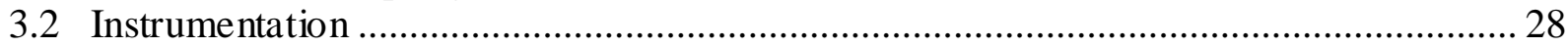

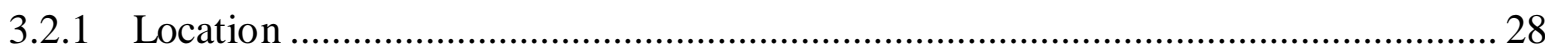

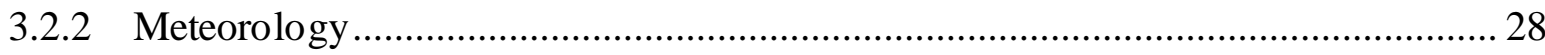

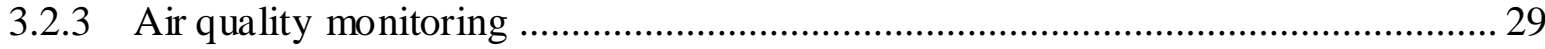

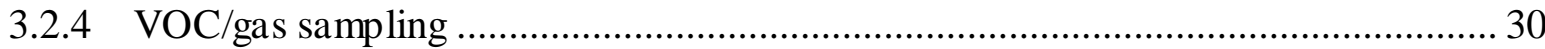

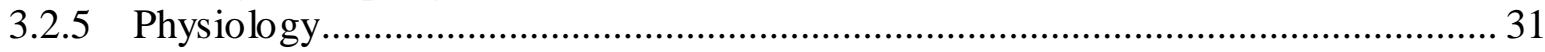

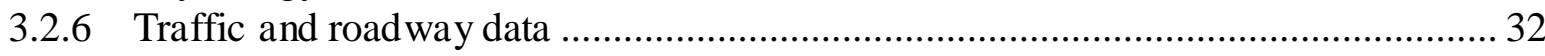

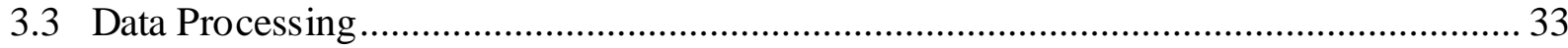

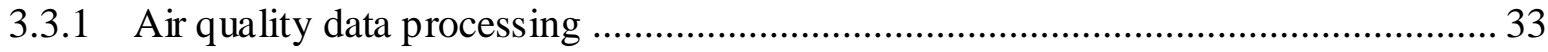

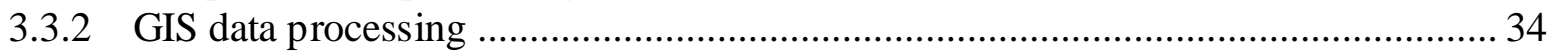

3.3.3 Elevation and grade data ................................................................................... 41

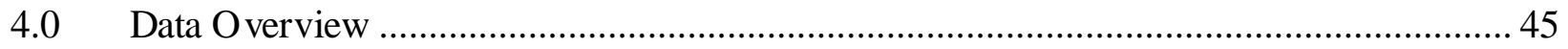

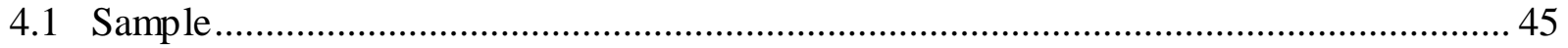

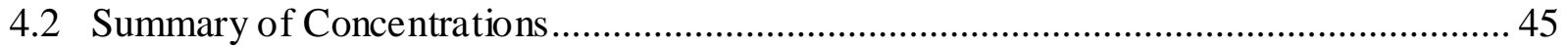

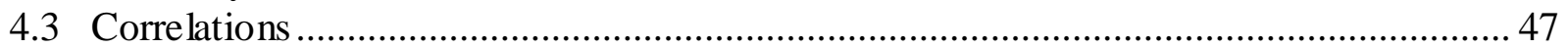

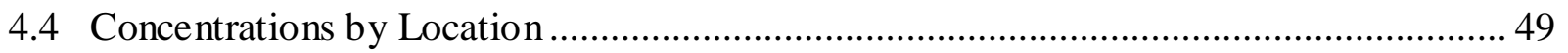

4.5 Exposure Skew..................................................................................................... 52

4.6 Parallel Path Effects .................................................................................................... 53 


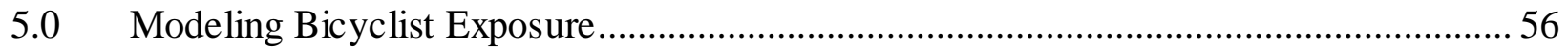

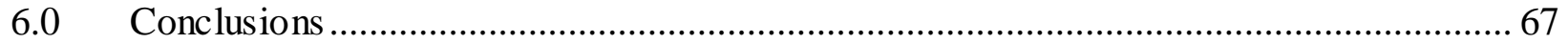

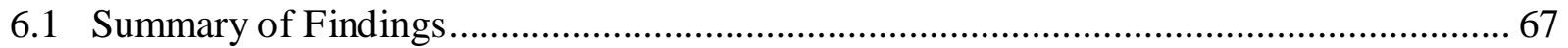

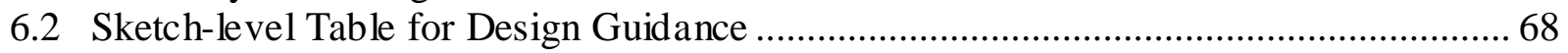

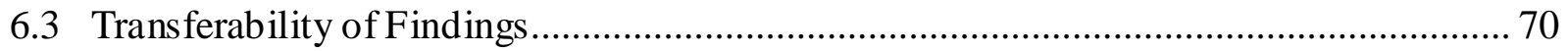

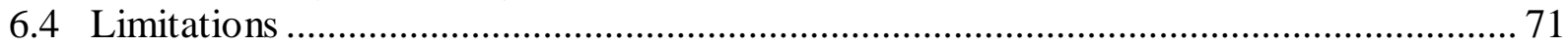

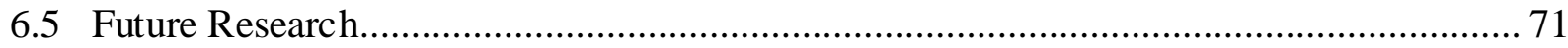

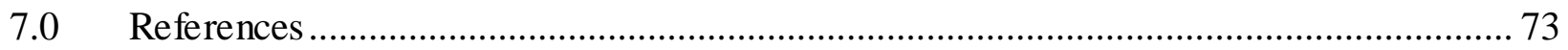

\section{LIST OF TABLES}

Table 1 . Summary of the 42 studies directly measuring on-road bicyclists' exposure

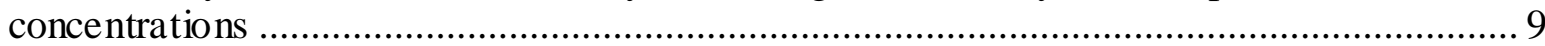

Table 2. Respiration-related parameters measured for bicyclists ................................................... 15

Table 3. Categorization of bicyclists' air pollution exposure, intake, uptake and biomarker studies

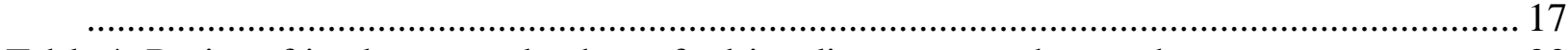

Table 4. Ratios of intake or uptake doses for bicyclists versus other modes................................ 20

Table 5. Factors that increase pollutant uptake................................................................................. 21

Table 6. Summary of routes used in breath sampling .................................................................. 28

Table 7. Gas analysis conditions................................................................................................. 31

Table 8. Validation results comparing 2005 ADT map data with more recent (2008-2012) traffic

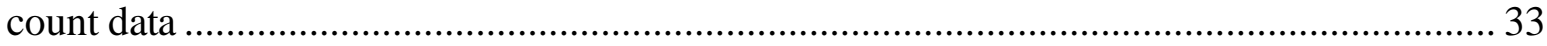

Table 9. Results of initial point-link matching based on proximity .............................................. 35

Table 10. Discontinuity corrections to point-link matches ............................................................ 35

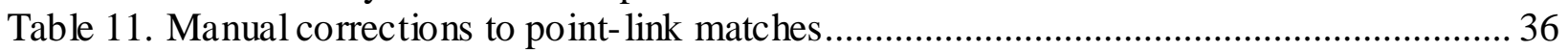

Table 12. Results of point data mapping onto link data sets .......................................................... 36

Table 13. Road-type classifications based on TSP classes ............................................................ 37

Table 14. Distribution of road-type classifications ....................................................................... 37

Table 15. Unique crossing points identified ................................................................................ 40

Table 16. Sampling conditions for 53 on-road segments by three subjects over nine days .......... 45

Table 17. Characterization of ambient concentrations ( $\mathrm{ng} \mathrm{t}^{-1}$ ) for on-road segments..................... 46

Table 18. Characterization of continuous air quality monitoring concentrations........................... 47

Table 19. Spearman correlation coefficients between one-second air quality monitoring data (all

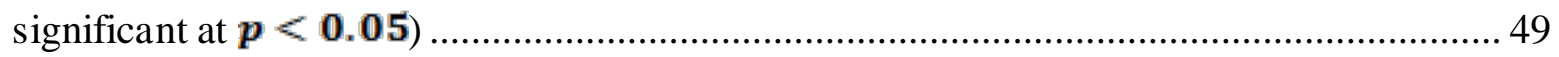

Table 20. Mean on-road concentrations, normalized to concentrations measured at the park ..... 50

Table 21. Gini index of inequality and the minimum portion of the observations representing half

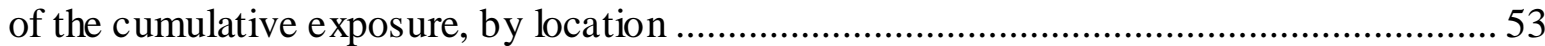

Table 22. Potential explanatory variables for modeling exposure................................................. 57

Table 23. Measured explanatory variables …………………………………………………...... 58

Table 24. Fit characteristics for the SUR system of 10 equations ...................................................61

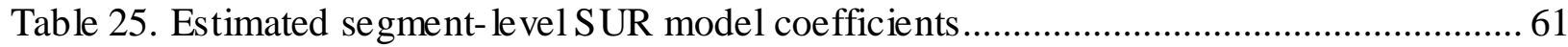

Table 26. Expected effect of path dummy variables on exposure from semi-log SUR model..... 62 Table 27. Changes in SUR model system SSR with individual removal of explanatory variables

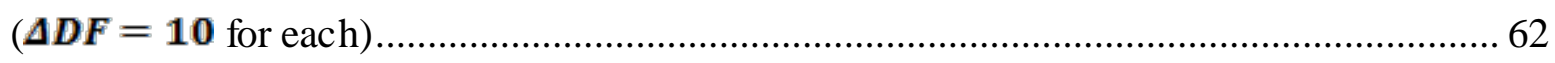


Table 28. Alternative specifications for ADT in the SUR model................................................65

Table 29. Expected effects of facility types on exposure from semi- log SUR model.................... 66

Table 30. Segment-level SUR model coefficients with a differenced (exposure - background)

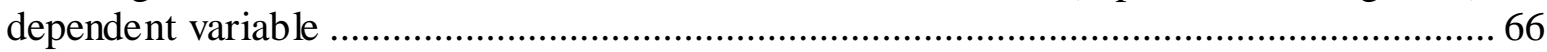

Table 31. Princip les about bicyclist pollution risks for transportation professionals ........................... 69

Table 32. Bikeway design considerations for air pollution risks .................................................. 70

\section{LIST OF FIGURES}

Figure 1. Conceptual Diagram of Exposure Pathway for Traffic-Related Air Pollution ................ 5

Figure 2. Literature Search Summary .................................................................................... 8

Figure 3. Reported Increases in Bicyclists' Exposure Concentrations in "High Traffic" versus

"Low Traffic" Routes and Locations" ................................................................................ 12

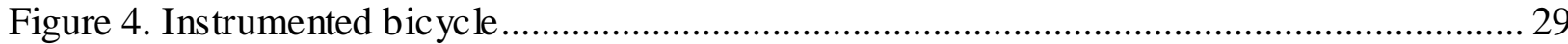

Figure 5. BioHarness Physiology Monitor ............................................................................... 32

Figure 6. Associated road-type classification (a) and ADT (b) for all location data points

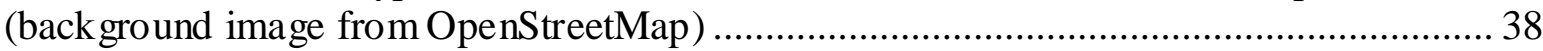

Figure 7. Comparison of ADT and road type for matched-link location data ............................... 39

Figure 8. Identified crossings on local roads and paths (background image from OpenStreetMap)

.

Figure 9. Elevation data from DEM (background image from OpenStreetMap) .......................... 41

Figure 10. Estimated travel grades (background image from OpenStreetMap) .............................. 42

Figure 11. Estimated grade versus travel speed (1-second data) .................................................. 43

Figure 12. Correlation coefficients for ambient concentrations among 26 compounds (* indicates

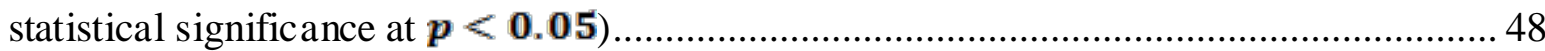

Figure 13. Exposure concentrations by location.......................................................................... 49

Figure 14. Average ambient concentrations by location, normalized to park location ................. 51

Figure 15. On-road measured TVOC concentration as pin height (travel speed as color, where from black/slow to green/fast); 2013-09-11 data collection .................................................. 51

Figure 16. Lorenz curves showing exposure skew by location .................................................... 52

Figure 17. Parallel facility comparisons (images from on-bicycle video data) ..............................5 54

Figure 18. Correlations among 5-second aggregated explanatory variables and BTEX exposure

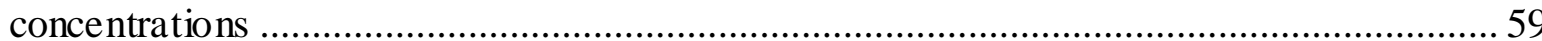

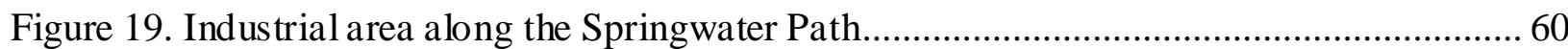

Figure 20. Correlation coefficients of residuals among 10 SUR model equations.............................63

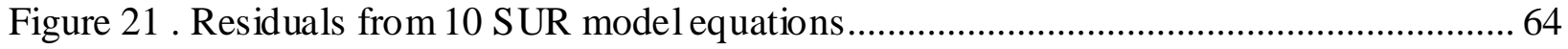




\section{EXECUTIVE SUMMARY}

While bicyclists and other active travelers obtain health benefits from increased physical activity, they also risk an uptake of traffic-related air pollution. But pollution uptake by urban bicyclists is not well understood due to a lack of direct measurements and insufficient analysis of the determinants of exposure (particularly characteristics of the transportation system). This knowledge gap impedes pollution-conscious transportation planning, design, and health impact assessment.

The research presented in this report generates new connections between transportation system characteristics and pollution exposure for bicyclists. The primary research questions are: 1) How does urban bicyclists' exposure to air pollution vary with roadway and travel characteristics? and 2) To what extent can transportation-related strategies reduce exposure? These questions are addressed with an exhaustive review of the literature, an on-road data collection campaign, advanced statistical modeling of the empirical data, and synthesis of findings. Novel methods to collect and integrate bicycle, rider, traffic, and environmental data are introduced.

Bicyclist exposure concentrations, respiratory physiology, and travel characteristics were collected on a wide range of facilities in Portland, OR. High-resolution trajectory and pollution data were then integrated with roadway and traffic data. Summary statistics are presented for bicyclist physiology and exposure to volatile organic compounds (VOCs), carbon monoxide (CO), and fine particulate matter ( $\left.\mathrm{PM}_{2.5}\right)$. Exposure concentrations are highly correlated among aromatic hydrocarbon VOCs. Concentrations of CO and total VOCs are also positively correlated.

As expected, concentrations are generally higher on high-traffic facilities. One notable exception is high VOC exposure on an off-street path that runs through an industrial corridor. Average concentrations of BTEX compounds (benzene, toluene, ethylbenzene, and xylenes) in this study were $50 \%$ to $120 \%$ higher on major arterials than on local roads, in good agreement with past studies. In terms of fractional changes from the reference park location, increases in concentrations were 2.1-3.2 times greater during riding on major arterials than during riding on local roads. Exposure concentrations on parallel high-traffic/low-traffic facility pairs were also directly compared, showing that even minor, one- to two-block detours to parallel low-volume streets can significantly reduce exposure concentrations.

Statistical models of VOC exposure were developed from the on-road data using seemingly unrelated regression equations (SURE) to account for intra-sample correlation. The estimated models show that roadway and travel variables are both important determinants of VOC exposure. Weather and traffic variables explained an approximately equal amount of variance in exposure concentrations for BTEX compounds. BTEX concentrations approximately doubled on high-volume versus low-volume mixed-traffic facilities. ADT seems to be a parsimonious approach to characterize the impact of mixed-traffic facilities on bicyclists' exposure: BTEX 
exposure concentrations increased about $2 \%$ per 1,000 ADT. This quantitative estimate provides a ready tool for analysts to calculate expected differences in exposure levels among routes.

Lastly, findings from the empirical analysis and the literature review are distilled so that they can be incorporated into bicycle network design guidelines. In addition, limitations of this research, transferability of the findings, and future research directions are all discussed. 


\subsection{INTRODUCTION}

\subsection{INTRODUCTION}

Urban transportation systems can affect traveler health in many ways. Bicyclists and other physically active travelers enjoy the health benefits of increased physical activity, but with the major potential drawback of an increased uptake of traffic-related air pollutants (de Hartog et al., 2010). It is clear from past research that exposure to traffic-related air pollution has negative health impacts for urban populations (Health Effects Institute, 2010), and exposure during travel can be especially dangerous because of proximity to sources of pollution. However, the details of exposure concentrations within individual transportation microenvironments are not well established because of the great diversity of environmental, meteorological and traffic factors (Knibbs, Cole-Hunter, and Morawska, 2011; Kaur, Nieuwenhuijsen and Colvile, 2007).

The health risks of pollution exposure during bicycling are particularly uncertain because of varying physical activity levels. Not only are bicyclists' exposure concentrations highly variable, but different levels of physical exertion and individual physiology affect the intake of pollutants because of varying volumes and depths of respiration (Zuurbier et al., 2009; Nadeau et al., 2006). The current state of uncertainty about bicyclists' intake of traffic-related air pollution leaves unsatisfying gaps in health impact assessments and impedes health-conscious transportation planning and management.

\subsection{CONTEXT}

Bicycling is currently a small share of total trips taken in most of North America, but many urban areas are actively promoting increased bicycling as a mode of transportation (J. Pucher, Buehler and Seinen, 2011). Promotional programs and policies often take the forms of new or improved bicycle infrastructure (on-road or at trip-ends); bike-sharing programs; pro-bicycle marketing and education; or restrictions on private automobile usage (City of Portland, 2010; Department for Transport, 2013; J. Pucher, Dill and Handy, 2010). The promotion of bicycling is justified by expected environmental benefits (reduced emissions and fuel consumption); public health benefits (increased physical activity leading to positive health outcomes); and socia/livability benefits (more active public spaces, reduced road and parking land uses, and increased community connectivity) (Gotschi, 2011; J. R. Pucher and Buehler, 2012). Portland, OR, is one of the cities with the most bicycling in the U.S., where bicycling is actively supported with comprehensive public policy (City of Portland, 2010; J. Pucher, Buehler and Seinen, 2011). The Portland Bicycle Plan for 2030 (City of Portland, 2010) aims to achieve a 25\% bicycle mode share in the city, based on recommendations in the city's Climate Action Plan 2009 (City of Portland and Multnomah County, 2009). 


\subsubsection{Bicycling and Health}

Public health benefits are expected from an increase in bicycling, due to increased physical activity and decreased stress. Active commuting (walking and biking) has been associated with an 11\% reduction in cardiovascular risk (Hamer and Chida, 2008), while longer driving commutes are associated with higher obesity and blood pressure - likely due to less physical activity and other aspects of suburban life (Hoehner et al., 2012). But there are potential safety risks associated with crashes during bicycling, too, which are often cited as a caveat to public health benefits (C. C. O. Reynolds et al., 2010).

The other potential mitigation of health benefits from bicycling is an increased absorption of traffic-related air pollution in the body. The intake of air pollution by bicyclists can be increased because of longer exposure duration and higher respiration rates than other modes (Int Panis et al., 2010; Zuurbier et al., 2010), though there is also the potential of lower exposure concentrations for bicyclists (Boogaard et al., 2009; Kaur, Nieuwenhuijsen and Colvile, 2007; Knibbs, Cole-Hunter and Morawska, 2011). The issue of bicyclists' health effects from air pollution is still under debate; as stated by Reynolds et al. (2010) "it is unclear whether active transportation is associated with ... a reduction or increase in air pollution exposure at both the individual and societal level."

The question of the net health effects of bicycling, including physical activity, crashes, and air pollution, has been asked frequently in recent years (de Hartog et al., 2010; Int Panis, 2011; C. C. O. Reynolds et al., 2010; Rojas-Rueda et al., 2011; Teschke, Reynolds et al., 2012). Generally, physical activity benefits are expected to dominate, resulting in a net positive health benefit. When looking at society as a whole a net benefit is likely, but there is more uncertainty on the net health effects for the individual travelers making a transition to bicycling. Part of the continued uncertainty is due to the lack of sound information on bicyclists' intake of pollution under varying circumstances.

\subsubsection{Planning and Managing Bicycle Transportation for Health}

While the net health effects of bicycling are important to consider, transportation planners and managers benefit more from information about how to reduce pollution exposure and intake for travelers, rather than a comparison of the risks between modes. An urban transportation system influences bicyclists through its infrastructure, management and policies. The bicycling environment affects travel decisions (Broach, Dill and Gliebe, 2012; Dill, 2009; Dill and Carr, 2003); crash risks (Ragland et al., 2013; Winters et al., 2013); and likely pollution intake, too - though that is not well quantified (Cole-Hunter et al., 2012; Hertel et al., 2008; Kendrick et al., 2011).

In the "Survey of Best Practices" for "Bikeway Facility Design" used in the development of the Portland 2030 Bicycle Master Plan', bicyclists' exposure to air pollution does not explicitly appear as a design criterion. The Dutch Design Manual for Bicycle Traffic (CROW, 2007) recognizes the pollution benefits of separating bicycles from motor vehicles, stating that "when designing a cycle network, longitudinal or lateral

\footnotetext{
${ }^{1}$ http://www.portlandoregon.gov/transportation/article/334689
} 
combinations of cycle connections with busy flows of motorized traffic should be avoided where possible.” The CROW manual further cites a benefit of separated cycle tracks and bike boxes as "less nuisance from exhaust fumes" but does not provide any quantitative guidance.

Much previous research on travelers' exposure to air pollution is based on modal comparisons (i.e., travel along the same routes or between the same origins), and destinations are compared for different travel modes (O’Donoghue et al., 2007;

McNabola, Broderick and Gill, 2008; Boogaard et al., 2009). These studies are useful for comparing mode-choice effects on pollution exposure because they control for many factors, but they provide little information on which parameters most influence bicyclists' intake of pollution or how best to mitigate exposure. Some recent research has shown that bicycle facility design and route characteristics can affect bicyclists' pollution-exposure concentrations (Cole-Hunter et al., 2013; Hertel et al., 2008; Kendrick et al., 2011; MacNaughton et al., 2014). But apart from a handful of studies, there is little quantitative information on ways to reduce pollution exposure for bicyclists.

Furthermore, while the more robust traveler-exposure studies apply different respiration rates for travelers of different modes (van Wijnen et al., 1995; Zuurbier et al., 2010), respiration is almost never considered as a function of travel or roadway characteristics other than mode (i.e., intra-modal respiration variability is ignored). Two exceptions are McNabola et. al. (2008), who found speed-varying respiration rates for a bicyclist based on laboratory tests (though the respiration model is not related to a transportation network), and Int Panis et. al. (2010), who directly measured on-road respiration (though respiration covariates were not analyzed). The ability of transportation system planners and managers to mitigate pollution uptake for travelers is impeded by a lack of quantitative information on how both exposure concentrations and respiration vary during active travel.

\subsection{MOTIVATION}

Human exposure to traffic-related air pollution is a serious public health problem, with a variety of negative health impacts from long-term exposure (Forastiere and Agabiti, 2013; Health Effects Institute, 2010; Nawrot, Vos et al., 2011; Shah et al., 2012). Commuting represents a disproportionately high portion of daily pollution dose and risk because of high concentrations around roadways (Dons et al., 2012; Fruin et al., 2008; Hill and Gooch, 2010; Nawrot, Perez et al., 2011). A study in Southern California estimated that human mortality due to excessive fine particulate matter (PM2.5) exposure was on par with traffic crash-related deaths (Hall, Brajer and Lurmann, 2008). Still, as described above there is continued uncertainty about the magnitude of health effects from air pollution exposure for bicyclists (de Hartog et al., 2010; A. de Nazelle et al., 2011; Int Panis, 2011). No quantitative guidance is available on bicycle transportation 
planning and management to lower pollution uptake, and yet the public is interested in knowing the health risk of pollution exposure while bicycling².

Bicyclist exposure research is particularly relevant in Portland, which is strongly associated with bicycling in the U.S. Portland has a 6\% bicycle commute mode share, compared with $0.5 \%$ nationally - the highest percent of any large American city - and experienced a $238 \%$ increase in the number of people commuting by bicycle between $2000-2010^{3}$. Portland is the only large American city to be labeled "Platinum" by the League of American Bicyclists, and continues to actively promote bicycling in the city ${ }^{4}$.

Unfortunately, Portland also has elevated concentrations of several hazardous air pollutants, as demonstrated by the Portland Air Toxics Assessment (PATA) (Oregon Department of Environmental Quality, 2012; Rosenbaum, Carr and Cohen, 2004). With benchmarks set at a health risk increase of one mortality in a population of one million, eight studied air toxics are more than 10 times over the benchmark, and six more are 1-10 times over the benchmark. Car and truck emissions are "the largest sources of air toxics," with on-road engines emitting 1,3butadiene, benzene, diesel particulate, arsenic and chromium 6 with regional and neighborhood effects. Portland's benzene levels are predicted to be up to 30 times over benchmarks in 2017, due to the high benzene content of gasoline in the Pacific Northwest (Oregon Department of Environmental Quality, 2011). Because of elevated respiration and close proximity between bicyclists and motor vehicles, these hazardous pollutants are particularly a concern for bicyclists in the city. Lastly, few bicyclist exposure studies have been conducted in the U.S., which has a unique population of bicyclists and different motor vehicle fleet, fuels and transportation systems from Europe (where most other studies were conducted).

\subsection{OBJECTIVE AND RESEARCHQUESTIONS}

The main objective of this research is to determine how exposure to air pollution by bicyclists is affected by transportation system characteristics, in order to provide tools for transportation system planners and managers to more explicitly consider the health risks of air pollution in decision-making, and for active travelers to make more informed choices about their own travel.

The primary research questions that this research aims to address are: 1) How does urban bicyclists' exposure to traffic-related air pollution vary with roadway and travel characteristics? and 2) To what extent can transportation-related strategies reduce bicyclists' pollution exposure? From these research questions, the anticipated outcomes of the research are: 1) Better models of bicyclists' pollution exposure based on roadway characteristics and 2) New information for roadway and network design that considers pollution exposure for bicyclists. These results can lead to better tools for traveler health impact assessments and health-conscious transportation system planning and management.

\footnotetext{
${ }^{2}$ For example, for proposed bicycle facility projects: http://bikeportland.org/2011/04/28/224000-for-sullivans-gulchplan-now-in-city-coffers-52243

3 Portland Bureau of Transportation fact sheet: http://www.portlandoregon.gov/transportation/article/407660

${ }^{4}$ See the Portland Bicycle Plan for 2030: http://www.portlandoregon.gov/transportation/44597
} 


\subsection{FRAMEWORKAND SCOPE}

A conceptual diagram linking traffic-related pollution emissions and health effects is illustrated in Figure 1, adapted from Ott, Steinemann \& Wallace (2007). Motor-vehicle emissions (a) degrade urban air quality (b) in accordance with atmospheric dispersive, chemical and physical processes. Travelers' exposure concentrations (c) then depend on their travel trajectory. The inhalation of traffic-related air pollution (d) depends on travelers' breathing volume while exposed to a pollutant concentration. Uptake of the inhaled pollutants into the body (f) depends on processes in the respiratory tract and other body systems. Finally, the health effects (g) of air pollution uptake doses are a function of the toxicity of the pollutants and physiology of the individual. The processes between inhalation and uptake can be further demarcated as ( $\left.\mathrm{e}_{1}\right)$ intake dose (the amount of pollutant that crosses the body boundary at the mouth and nose); (e2) absorbed dose (the amount of pollutant that is not exhaled but deposited or absorbed); ( $\left.\mathrm{e}_{3}\right)$ effective dose (the bioavailable amount of pollutant that reaches body tissue instead of being expelled from the respiratory tract lining by coughing, sneezing, etc.); and (e4) uptake dose (the amount of pollutant that is incorporated into the body). This research focuses on exposure concentrations (Figure 1-c).

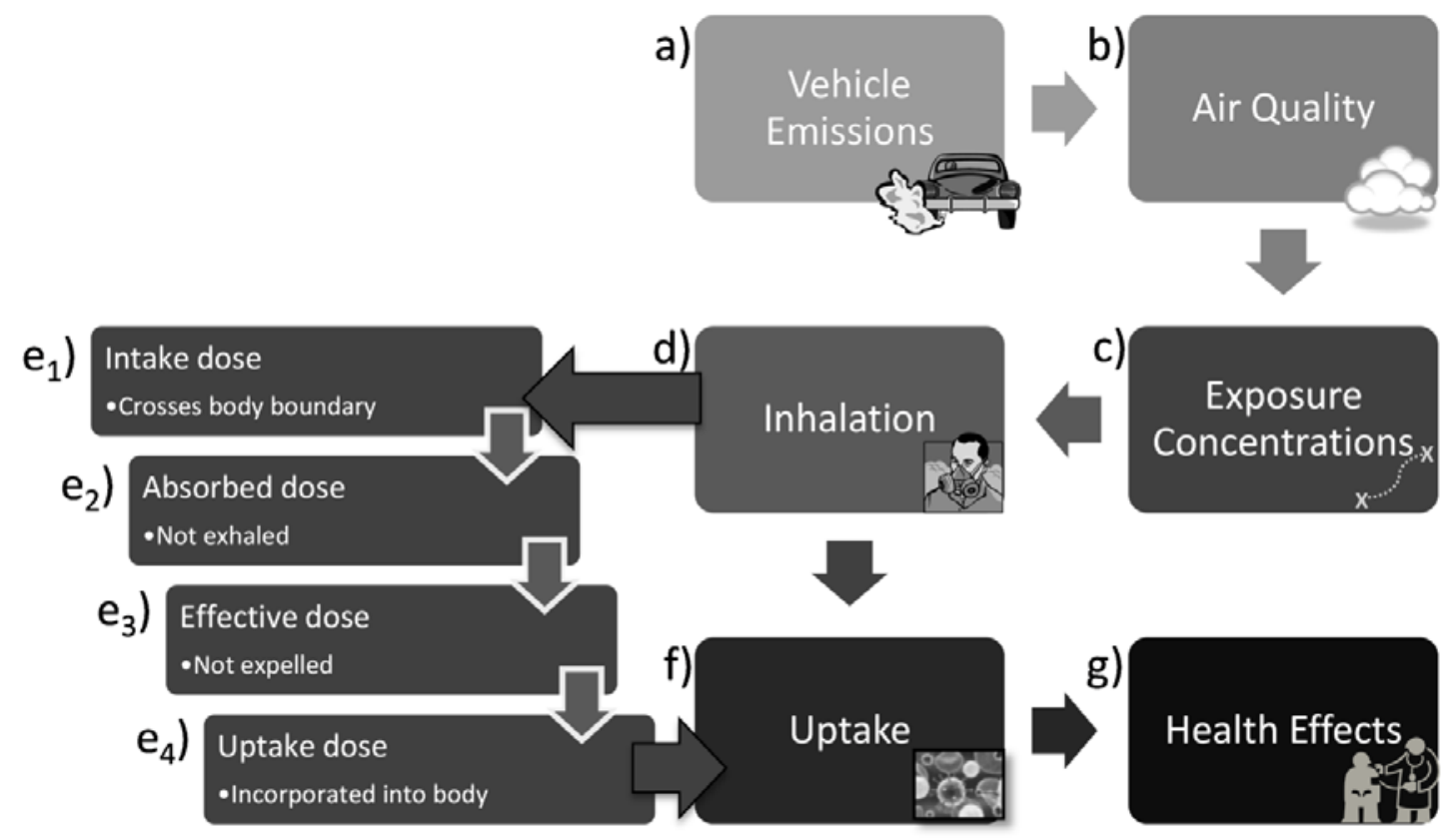

Figure 1. Conceptual diagram of exposure pathway for traffic-related air pollution 


\subsection{LITERATURE REVIEW}

\subsection{INTRODUCTION}

Bicycling as a mode of transportation is enjoying a boost in urban areas around the world through new bike-sharing systems, bicycle-specific roadway facilities, public outreach and incentive programs (J. R. Pucher and Buehler, 2012). The push toward promoting bicycling is motivated by a range of environmental, economic, health and social benefits. Although there are clear health benefits of increased physical activity, bicyclists may experience increased inhalation of traffic-related air pollutants (de Hartog et al., 2010).

Human exposure to traffic-related air pollution has well-established negative health impacts for urban populations (Brook et al., 2010; Forastiere and Agabiti, 2013; Health Effects Institute, 2010; Nawrot, Vos et al., 2011). Air-pollution exposure is particularly high for travelers because of proximity to mobile sources of pollution (Kaur, Nieuwenhuijsen, and Colvile 2007), and air quality is a source of concern for urban bicyclists (Badland and Duncan 2009). However, the health risks of air pollution exposure during travel are not easily characterized because of the numerous individual, environmental and traffic factors involved.

Past reviews of travelers' pollution exposure have been oriented by pollutant (Kaur, Nieuwenhuijsen and Colvile, 2007; Knibbs, Cole-Hunter and Morawska, 2011) and/or focused on in-vehicle exposures (El-Fadel and Abi-Esber, 2009). These reviews focused on exposure concentrations and provide little or no discussion of respiration or its effects on intake and uptake doses. The focus of this review is on bicyclists' exposure to, inhalation of, and uptake of traffic-related air pollution (i.e., steps (c) through (f) in Figure 1). This review is unique in focusing exclusively on bicyclists. ${ }^{5}$

\subsection{LITERATURE SEARCH METHODOLOGY}

A systematic literature search for bicyclist exposure and dose measurements was performed through January 2014 using all 20 possible keyword combinations $\{A+B+C\}$ utilizing the keyword sets $A=$ \{bicycle, bicyclist, cyclist, bike\}, $B=$ \{pollution $\}$ and $C=$ exposure, intake, inhalation, uptake, dose\}. An exhaustive search was performed using the WorldCat ${ }^{\mathrm{TM}}$ catalogue. The number of hits returned for each search phrase ranged from 0 ("bicyclist pollution intake”) to 131 ("bicycle pollution exposure”); 231 unique hits were returned. The same 20 search phrases were used with the Google Scholar ${ }^{\mathrm{TM}}$ search engine. Because of the volume of Google Scholar" ${ }^{\mathrm{TM}}$ hits returned (28,100 for "bicycle pollution exposure” alone), only the first 50 hits per search phrase were processed (sorted by relevance).

\footnotetext{
${ }^{5}$ Note: this section has been published in Transport Reviews as: Bigazzi, A.Y. and Figliozzi, M.A., 2014. Review of Urban Bicyclists’ Intake and Uptake of Traffic-Related Air Pollution. Transport Reviews, 34 (2), 221-245. doi:10.1080/01441647.2014.897772
} 
Of the 231 unique hits returned from the WorldCat ${ }^{\mathrm{TM}}$ database search, a first screening was performed with exclusion based on title review or reference format (theses, conference papers and textbooks were excluded). This screening removed 119 hits, leaving 112 potential papers. A matching exercise was then performed to remove further duplicate papers - resulting in 47 duplicates removed. Another 11 papers were excluded based on abstract review, leaving 54 papers for full-text extraction. The title and abstract review process required that papers describe original studies about on-road bicyclists and environmental air pollution exposures. Reviews, chamber studies using bicycle ergometers, and traveler-exposure studies not including bicyclists were excluded. The citation lists of these 54 papers and the Google Scholar ${ }^{\mathrm{TM}}$ search returns were searched for additional papers that passed the same format, title review and abstract review criteria. The result was 14 additional papers manually added to the full-text body of references, now composed of 68 papers.

The full-text body of 68 references was reviewed for two nested inclusion criteria. The first criterion was the use of spatially explicit concentration data, either measured or modeled. Studies that assumed a generic concentration value (de Hartog et al, 2010) were excluded, and 57 papers met this criterion. The second criterion was the presentation of original exposure concentration data, measured on-road by bicyclists. Studies using modeled concentration data, roadside monitor data, conducting analysis using previously published exposure concentration data, or not reporting central value statistics were excluded; 42 papers met this criterion. If multiple papers reported on the same data set, a single reference was included in this subset. Two studies measured bicyclists' exposures, but were focused on instrument development and did not report central value statistics (Elen et al., 2013; Piechocki-Minguy et al., 2006). The literature search method is summarized in Figure 2. 


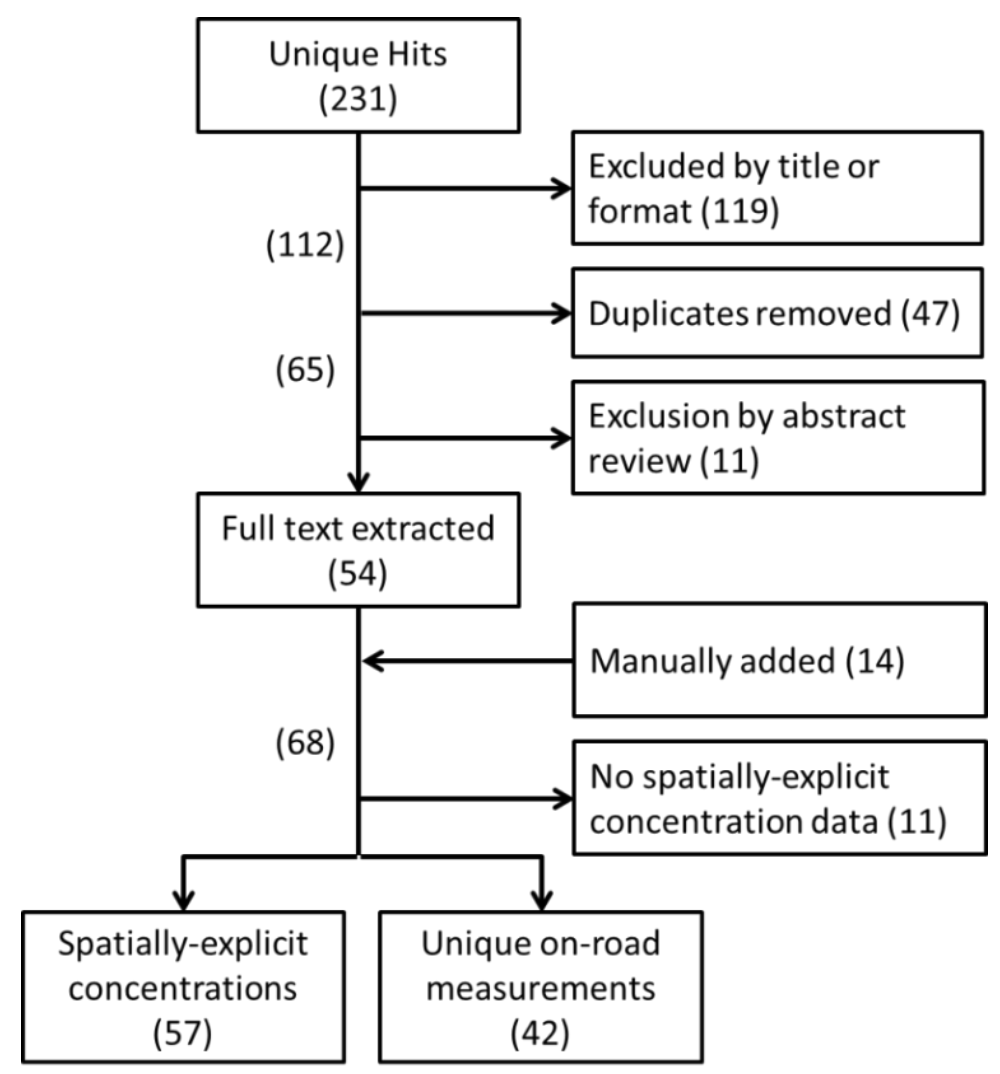

Figure 2. Literature search summary

\subsection{BICYCLISTS'AIR POLLUTION-EXPOSURE CONCENTRATIONS}

The main traffic-related air pollutants linked to health risks for road travelers and measured for bicyclists are carbon monoxide (CO); nitrogen oxides $\left(\mathrm{NO}_{\mathrm{x}}\right)$ - including nitric oxide $(\mathrm{NO})$ and nitrogen dioxide $\left(\mathrm{NO}_{2}\right)$; volatile organic compounds (VOC); and particulate matter (PM) of various sizes and composition: ultrafine particles (UFP), $\mathrm{PM}_{2.5}, \mathrm{PM}_{10}$, and elemental carbon (EC) / black carbon (BC).

A traveler's exposure concentration is the concentration of pollutants in their breathing zone. Concentrations of traffic-related primary pollutants are particularly high near roadways especially for shorter-lived pollutants such as UFP and reactive VOC (Gordon et al, 2012; Karner, Eisinger and Niemeier, 2010). Steep concentration gradients can be seen even on the scale of a few meters (Clifford, Clarke and Riffat, 1997; McNabola, Broderick and Gill, 2009a; Tiwary et al., 2011). Exposure concentrations are sampled using a variety of pollutant-specific devices, each requiring specialized knowledge and careful sampling procedures (Vallero, 2008). Roadside studies of air pollution concentrations are more common than on-road data collections because on-road measurements are more difficult to execute (particularly for pedestrians and bicyclists). But the body of research on active travelers' pollution-exposure concentrations has grown notably in recent years. On-road air-quality sampling has become more precise and more portable because of improvements in measurement technology, power storage, and position tracking systems (Gulliver and Briggs, 2004; Steinle, Reis and Sabel, 2013). 


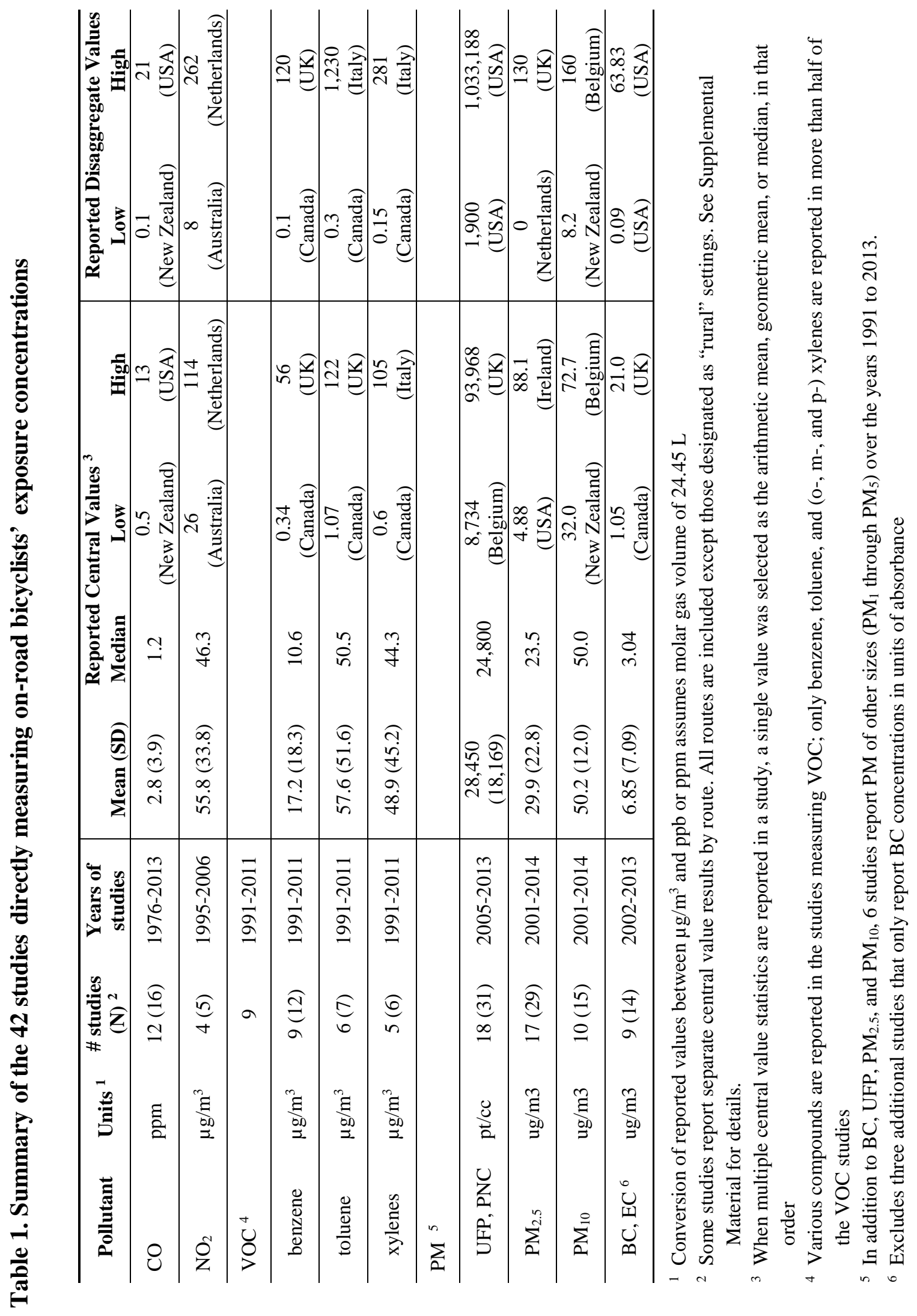


A literature search revealed 42 published studies reporting unique exposure concentration data collected with on-bicycle sampling devices. Table 1 summarizes reported concentrations in all 42 studies, excluding results for "rural" settings. Ranges of reported central value statistics and disaggregate (sample-level) values are presented, including the country where the low and high measurements were taken.

The mean on-road measurements in Table 1 are all well above typical urban background concentrations. Table 1 shows that measured bicyclist exposure concentrations for most pollutants exhibit high variability among studies, with a standard deviation (SD) greater than $50 \%$ of the mean value for all pollutants except $\mathrm{PM}_{10}$, and a $\mathrm{SD}$ greater than the mean for $\mathrm{CO}$, benzene, and BC/EC. Bicyclists' average CO exposure concentrations have been measured in the range of 0.5 to $13 \mathrm{ppm}$, though all studies after 1995 report central value concentrations below 3 ppm.

\subsubsection{Modal Comparisons of Exposure Concentration}

A popular study design for traveler-exposure studies is modal comparisons, in which exposure concentrations are compared for travelers using different transportation modes between the same origin and destination or along identical or parallel routes. Results from modal comparisons of exposure are inconsistent. Bicyclists sometimes have lower exposure concentrations than motorized modes, especially when they use facilities that are separated from traffic (H. S. Adams, Nieuwenhuijsen and Colvile, 2001; H. S. Adams et al., 2002; Boogaard et al., 2009; Chertok et al., 2004; Audrey de Nazelle et al., 2012; Dons et al., 2012; Kaur, Nieuwenhuijsen and Colvile, 2007; Kingham et al., 2013; Kingham et al, 1998; Knibbs, Cole-Hunter and Morawska, 2011; McNabola, Broderick and Gill, 2008; van Wijnen et al., 1995). But modal comparison studies have also found insignificant differences in concentrations by mode, significantly higher bicyclist exposure concentrations than other modes, or inconsistent results by pollutant, location or time of day (Boogaard et al., 2009; Chertok et al., 2004; Audrey de Nazelle et al., 2012; Int Panis et al., 2010; Kaur and Nieuwenhuijsen, 2009; Kingham et al., 2013; Nwokoro et al., 2012; Quiros et al., 2013; Ragettli et al., 2013; Waldman, Weiss and Articola, 1977; Yu et al., 2012). Likely causes of inconsistent results across studies include differences in the proximity and intensity of motor-vehicle traffic, varying availability and use of bicycle facilities, and instrumentation/sampling differences.

Modal comparison exposure studies typically use the same routes or origins and destinations across modes and fix other travel characteristics (e.g., departure time). While potentially informative, these comparisons are not always realistic because pollution exposure is also affected by intrinsic modal travel differences. The more realistic modal comparisons allow self-selected routes or direct active travelers to use representative routes for their mode - but local transportation network characteristics may affect the results. Bicycle travel patterns are different from motorized ones because of distinct traveler characteristics, trip distances and route preferences (Broach, Dill and Gliebe; 2012; Plaut; 2005). Real-world bicycle trips tend to be shorter and in higher-density parts of a city than trips using motorized modes. Bicycle trips are also highly seasonal (Nankervis, 1999), so a different distribution of meteorological conditions could be expected by mode, with a systematic influence on exposure concentrations. Most bicycle 
exposure studies occur during warmer months when a greater proportion of bicycling occurs, but the joint seasonality of mode splits and pollution levels should be considered when comparing travelers' exposures - especially for year-round bicyclists.

Although modal comparisons can be informative, they rarely provide practical insights into how to reduce exposure concentrations, other than mode shifts. Modal comparison studies rarely vary within mode factors (such as route choice), which can be the most important determinants of exposure concentrations during travel (Knibbs, Cole-Hunter and Morawska, 2011).

\subsubsection{Factors Affecting Bicyclists’ Exposure Concentrations}

Multivariate analyses of travelers' exposure concentrations have shown that important factors include wind and weather, traffic and route, and the built environment around the roadway (H. S. Adams, Nieuwenhuijsen and Colvile, 2001; Berghmans et al., 2009; Boogaard et al., 2009; Hatzopoulou, Weichenthal, Dugum et al., 2013; Kaur, Nieuwenhuijsen and Colvile, 2007; Kaur and Nieuwenhuijsen, 2009; Knibbs, ColeHunter and Morawska, 2011; McNabola, Broderick and Gill, 2009b; Quiros et al., 2013). But few studies have looked at bicyclist-specific factors that could influence exposure, such as lateral position in the road, proximity to exhaust pipes, breathing height, and the ability to “dodge between” vehicles (Kaur, Nieuwenhuijsen and Colvile, 2007).

Wind is consistently a significant factor for exposure, decreasing concentrations through dispersion (H. S. Adams, Nieuwenhuijsen and Colvile, 2001; Hatzopoulou, Weichenthal, Dugum et al., 2013; Hong and Bae, 2012; Jarjour et al., 2013; Kaur, Nieuwenhuijsen and Colvile, 2007; Kaur and Nieuwenhuijsen, 2009; Kingham et al., 1998; Knibbs, ColeHunter and Morawska, 2011; McNabola, Broderick and Gill, 2009b). Temperature is less consistently a significant factor, and effects can be difficult to distinguish from humidity because of a strong negative correlation (H. S. Adams, Nieuwenhuijsen and Colvile, 2001; Hatzopoulou, Weichenthal, Dugum et al., 2013; Kaur and Nieuwenhuijsen, 2009; Kaur, Nieuwenhuijsen and Colvile, 2007; Kingham et al., 1998; Knibbs, Cole-Hunter and Morawska, 2011). Time of day is a factor that incorporates influencing effects of local weather and diurnal traffic patterns - particularly relevant for urban areas with diurnal temperature inversions that significantly affect pollutant levels.

After weather, the next most important factors for bicyclists' exposure concentrations can be combined into a single category: separation from motor-vehicle traffic. These factors include the concentration-reducing effects of traveling on low-traffic routes (Hatzopoulou, Weichenthal, Dugum et al, 2013; Hertel et al., 2008), on separated bicycle facilities (Hatzopoulou, Weichenthal, Dugum et al., 2013; Hong and Bae, 2012; Kendrick et al., 2011; Kingham et al., 2013; Kingham et al., 1998; MacNaughton et al., 2014), and during off-peak periods or weekends (Dons et al., 2013; Huang et al., 2012; Kleiner and Spengler, 1976). Lacking more specific data, the influence of motor-vehicle traffic on exposure concentrations is sometimes estimated using a proxy of facility type, time of day, or average daily traffic (ADT) estimates (Boogaard et al., 2009; Cole-Hunter et al., 2012; Hong and Bae, 2012; Jarjour et al., 2013; Ragettli et al., 2013; Weichenthal et al., 2011). 
The influence of motor-vehicle traffic was measured in 14 different studies by comparing bicyclists' exposure concentrations on "high-traffic" and "low-traffic" routes or using a related dichotomy (inner-city/suburban, on-road/off-road, near-road/cycle path). The combined results are shown in Figure 3, with the median and range of reported percent increases on high-traffic versus low-traffic routes. As expected, pollutants that are more dominated by motor-vehicle sources in roadway environments (hydrocarbon VOC, UFP) show larger increases on high-traffic routes.

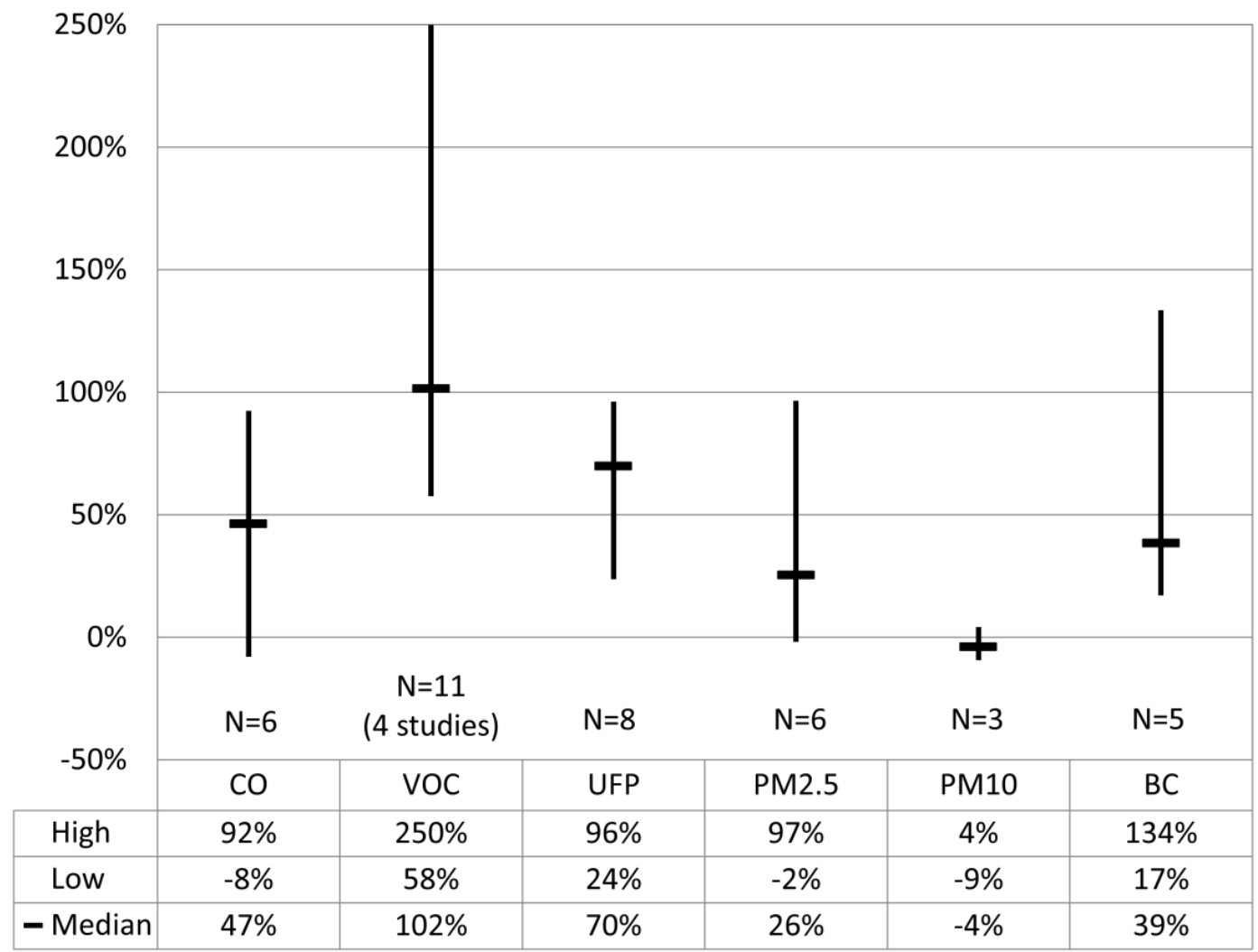

Figure 3. Reported increases in bicyclists' exposure concentrations in "high-traffic" versus "low-traffic" routes and locations*

${ }^{*}$ Urban/rural comparisons are excluded. Where multiple observations are reported per study (e.g., by city or time period), a weighted average by number of samples was used. For VOC, reported BTEX compounds (benzene, toluene, ethylbenzene, and xylenes) are included (11 comparisons for these compounds in four different studies). Sources: CO (Bevan et al., 1991; Jarjour et al., 2013; Kingham et al., 2013; Kleiner and Spengler, 1976; Waldman, Weiss and Articola, 1977; Weichenthal et al., 2011); VOC: (Bevan et al., 1991; Kingham et al., 1998; McNabola, Broderick and Gill, 2008; Weichenthal et al., 2011); UFP: (Cole-Hunter et al., 2013; Cole-Hunter et al., 2012; Jarjour et al., 2013; Kingham et al., 2013; Ragettli et al., 2013; Strak et al., 2010; Weichenthal et al., 2011; Zuurbier et al., 2010); PM$_{2.5}$ (H. S. Adams et al., 2001; Jarjour et al., 2013; Kingham

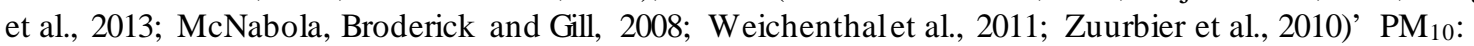
(Kingham et al., 2013; Strak et al., 2010; Zuurbier et al., 2010); BC: (Jarjour et al., 2013; Kingham et al., 1998; Strak et al., 2010; Weichenthal et al., 2011; Zuurbier et al., 2010) 
Explicit traffic variables such as motor-vehicle volume or speed are often not included in bicyclist pollution-exposure analysis because of a lack of concomitant data. When assessed, vehicle volumes, particularly truck or diesel vehicles, generally have a positive influence on pollutant-exposure concentrations, though they are not always significant variables

(Boogaard et al., 2009; Dons et al., 2013; Hatzopoulou, Weichenthal, Dugum et al., 2013; Kaur and Nieuwenhuijsen, 2009; Knibbs, Cole-Hunter and Morawska, 2011; McNabola, Broderick and Gill, 2009b; Quiros et al., 2013). Aggregate traffic variables such as ADT cannot reveal the potentially important influences of varying traffic volumes, speeds, queuing, and fleet composition over the data collection periods. Furthermore, highly aggregate traffic variables are often correlated with geometric roadway characteristics such as the number of lanes, which also influence pollutant concentrations through dispersion.

Traffic data used in bicycle exposure studies to date have been non-specific to the study period, limited in spatial and temporal coverage, and/or highly aggregated (in time and vehicle type). Of the 42 studies included in Table 1, only four report traffic data collected at the locations and time periods of air-quality measurements. Kaur et al. (2005) ${ }^{6}$ and McNabola et al. (2008) ${ }^{7}$ retrieved unclassified hourly vehicle volumes from traffic signal data at major intersections on the study routes. Hatzopoulou et al. (2013) collected intermittent manual vehicle counts using five vehicle classes for 10- to 20-minute periods sequentially at dozens of locations around the on-road measurement area. Quiros et al. (2013) performed intermittent manual vehicle counts for five-minute periods using nine vehicle classes (including bicycles and pedestrians) at a single location on the study corridor.

The next major factors for exposure concentrations, after weather and motor-vehicle traffic, are the study setting and methodology. Comparing measured exposure concentrations across studies reveals wide ranges (Table 1), indicative of different study settings (time frame, city, locational characteristics, etc.) and different experimental methods (instruments, sampling strategy, aggregation, etc.). Potentially important differences among study settings include traffic patterns, weather conditions, vehicle fleets and fuels, urban form, and topography. Boogaard et al. (2009) compare bicyclists' on-road exposure concentrations in 11 Dutch cities over a three-month period (using a consistent methodology), and report coefficients of variability for UFP and $\mathrm{PM}_{2.5}$ of 0.22 and 0.86 among cities. For comparison, the coefficients of variability for UFP and $\mathrm{PM}_{2.5}$ among studies in Table 1 are 0.64 and 0.76 , respectively.

\subsection{BICYCLISTS’ AIR POLLUTION INTAKE}

The mass of air pollutants that cross the body boundary through the mouth and nose is the intake dose (Ott, Steinemann and Wallace, 2007). Estimates of intake dose rates per unit time combine exposure concentrations with a respiration rate; intake dose rates per unit distance also take travel duration into account (as does total intake dose over a journey). Some studies consider only duration (not respiration) by estimating cumulative exposure, such as Nwokoro et al. (2012)

\footnotetext{
6 Traffic data are reported in a companion paper, Kaur and Nieuwenhuijsen (2009).
}

7 Traffic data are only used in a companion paper, McNabola et al. (2009a). 
and Ragettli et al. (2013). Measurement and analysis of bicyclists' pollutant intake facilitates a transition toward a dose-oriented estimation of health effects.

\subsubsection{Respiration}

Respiration rate is commonly expressed as the minute respiratory volume (or minute ventilation, $\dot{V}_{E}$ ), which is the volume of air displaced per minute. Minute respiratory volume is the product of the tidal volume $V_{T}$ and the breathing frequency $f_{r}$ (breaths per minute). Tidal volume $V_{T}$ is the volume of air displaced in a single breath; typical ranges are 1.4 to 2.2 liters (L) for bicyclists and 0.6 to $0.8 \mathrm{~L}$ for persons at rest or in a car (Int Panis et al., 2010). Multiplying $V_{E}$ by the average exposure concentration yields the average pollutant inhalation rate in mass per unit time.

Table 2 summarizes published traveling bicyclists' respiration parameters. Minute ventilation has been reported as 22 to $59 \mathrm{~L} / \mathrm{min}$ for bicyclists - two to five times higher than for travelers in automobiles or at rest. Bernmark et al. (2006) found $V_{E}$ peaks for bicycle messengers of up to $97 \mathrm{~L} / \mathrm{min}$. The ranges of minute ventilations in Table 2 are related to the different average travel speeds and heart rates among the studies (included in Table 2), as well as potentially other experimental differences such as terrain, bicycle weight and condition, weather, and subject fitness. Greater exertion increases $\dot{V}_{E}$ primarily by an increase in $V_{T}$ at lower levels of exercise and by an increase in $f_{r}$ at higher levels of exercise; $f_{x}$ is the dominant factor at $70-80 \%$ of peak exercise level (Weisman, 2003). Trained professional bicyclists can achieve a greater increase in $V_{E}$ through increases in $V_{T}$ than recreational bicyclists (Faria, Parker and Faria, 2005a).

For active travelers such as bicyclists, $\dot{V}_{E}$ will be a function of travel characteristics that determine power requirements. The major determinants of power output during bicycling are energy losses (resistance) and changes in kinetic and potential energy (acceleration and grades, respectively). The largest energy losses are typically aerodynamic drag followed by rolling resistance. Rolling resistance becomes a more important factor at lower speeds and in still air, when drag is less severe (Faria, Parker and Faria, 2005b; Martin et al., 1998; Olds, 2001; di Prampero et al., 1979; Whitt, 1971; Wilson, 2004). Nadeau et al. (2006) measured $\dot{V}_{E}$ of around 12, 23, and $35 \mathrm{~L} / \mathrm{min}$ for bicycle ergometer workloads of 0,50 , and $100 \mathrm{~W}$, respectively, suggesting that the subjects in the studies in Table 2 experienced workloads ranging from around $50 \mathrm{~W}$ to well over $100 \mathrm{~W}$ of power. 
Table 2. Respiration-related parameters measured for bicyclists

\begin{tabular}{|c|c|c|c|c|c|c|c|}
\hline Group & $\begin{array}{c}\text { Minute } \\
\text { ventilation, } \\
V_{E}(\mathrm{~L} / \mathrm{min})\end{array}$ & $\begin{array}{l}\text { Tidal } \\
\text { volume } \\
\text { (L) }\end{array}$ & $\begin{array}{l}\text { Breathing } \\
\text { frequency } \\
\left(\mathrm{min}^{-1}\right)\end{array}$ & $\begin{array}{c}\text { Heart } \\
\text { rate } \\
(\mathrm{bpm})\end{array}$ & $\begin{array}{l}\text { Speed } \\
(\mathrm{kph})\end{array}$ & $\begin{array}{c}\text { Ratio of } \\
\text { bicycle/car } \tilde{V}_{E} 1\end{array}$ & $\begin{array}{c}\text { Reference } \\
\text { and method }{ }^{2}\end{array}$ \\
\hline \multirow{2}{*}{ All } & 23.5 & & & 100 & 12 & 2.0 & 1, estimated \\
\hline & 28.7 & & & & 13.5 & 2.5 & 2 , on-road \\
\hline \multirow{10}{*}{ Male } & 22 & & & 94 & 12 & 1.8 & 1, estimated \\
\hline & 22.7 & & & & 14 & 1.9 & 3, on-road \\
\hline & 25 & 1.25 & 20 & & 8 & 2.1 & 4, lab \\
\hline & 28 & & & & & 2.3 & 5 , lab \\
\hline & 31 & & & 107 & & 2.6 & 6, estimated \\
\hline & 31.4 & & & & 19.5 & 2.6 & 3, on-road \\
\hline & 44.2 & & & 138 & 20 & 3.7 & 7, estimated \\
\hline & 50 & 1.92 & 26 & & 19 & 4.2 & 4, lab \\
\hline & 51.2 & & & & 24 & 4.3 & 3 , on-road \\
\hline & 59.1 & 2.2 & 27.9 & 129.6 & 20.5 & 4.9 & 8, on-road \\
\hline \multirow{5}{*}{ Female } & 22.6 & & & & 14 & 2.1 & 3, on-road \\
\hline & 27.6 & & & 116 & 12 & 2.5 & 1, estimated \\
\hline & 32.8 & & & & 19.5 & 3.0 & 3, on-road \\
\hline & 46.2 & 1.4 & 32.7 & 140 & 19.5 & 4.2 & 8, on-road \\
\hline & 51.8 & & & & 24 & 4.7 & 3, on-road \\
\hline
\end{tabular}

Blank cells are not reported

${ }^{1}$ Reference minute ventilation for car drivers of $12 \mathrm{~L} / \mathrm{min}$ for Males, $11 \mathrm{~L} / \mathrm{min}$ for Females, and $11.5 \mathrm{~L} / \mathrm{min}$ for All, based on (W. C. Adams, 1993; Int Panis et al., 2010; O’Donoghue et al., 2007; van Wijnen et al., 1995; Zuurbier et al., 2009)

2 References: 1 (Zuurbier et al., 2009), 2 (van Wijnen et al., 1995), 3 (W. C. Adams, 1993), 4 (McNabola, Broderick and Gill, 2007), 5 (O’Donoghue et al., 2007), 6 (Bernmark et al., 2006), 7 (Cole-Hunter et al., 2012), 8 (Int Panis et al., 2010)

Methodologies are categorized as: “on-road” (direct on-road measurement of respiration using masks), "lab” (laboratory ergometer-based respiration measurements), and "estimated" (on-road measurement of heart rate and estimation of respiration using laboratory ergometer-based heart rate/ventilation relationships)

Compilations of physical activity data often use MET units to compare energy expenditure with a standardized unit; a MET is defined as MET $=\frac{\dot{e}}{\mathrm{RMR}}$ where $\dot{e}$ is the rate of metabolic energy production and RMR is the resting metabolic rate (Ainsworth et al., 2011a; Ainsworth et al., 2011b; U.S. Environmental Protection Agency, 2009). RMR is an individual-specific value (varying across individuals), often assumed to be $3.5 \mathrm{ml}-$ $\mathrm{O}_{2} / \mathrm{min}$ per $\mathrm{kg}$ body mass - i.e. MET $=\frac{\dot{e}}{K \cdot m}$, where $K$ is a constant and $m$ is body mass. Thus, MET values are directly proportional to energy expenditure for an individual and inversely proportional to an individual's body mass for a given energy expenditure ${ }^{8}$.

\footnotetext{
${ }^{8}$ It should be noted that metabolic energy expenditure during bicycling is the sum of energy expenditure for baseline functions and the rate of external work (Olds, 2001). Assuming that the baseline energy expenditure is roughly equal to the RMR, the MET can be expressed as a function of external power output $p$ as MET $=1+\frac{p}{R M R}$. Thus, MET values increase linearly (but not proportionally) with the external power demands of bicycling.
} 
Resting activities are at a MET of 1, while "general" bicycling is at a MET of 7.5 and bicycling "to/from work, self selected pace" is at MET 6.8 in the "Compendium of Physical Activities" (Ainsworth et al., 2011a; Ainsworth et al, 2011b). The Compendium lists 16 different types of bicycling as activities with energy expenditures ranging from 3.5 MET for "leisure" bicycling at $5.5 \mathrm{mph}$ to $16 \mathrm{MET}$ for competitive mountain bicycle racing. Non-sport bicycling has been estimated to require 3.5 to 9 MET of energy expenditure, with power output of roughly 50 to $150 \mathrm{~W}$, depending on the speed (Bernmark et al., 2006; de Geus et al., 2007; Whitt, 1971). MET values have been employed to estimate bicyclists' respiration for pollution dose assessments using both reference MET values and MET values estimated from accelerometer measurements; average accelerometer-based MET for bicycling was estimated at 6.58 with a corresponding ventilation rate of $41 \mathrm{~L} / \mathrm{min}$ (Audrey de Nazelle et al., 2012). Respiration was estimated from MET values using stochastic relationships between oxygen uptake rates and ventilation rates along with the individuals' body mass (Audrey de Nazelle, Rodríguez and Crawford-Brown, 2009; Johnson, 2002).

\subsubsection{Studies of Bicyclists’ Pollution Intake}

Table 3 characterizes published studies of bicyclists' air pollution exposure, intake, uptake, or biomarkers that use spatially explicit exposure concentration data (modeled or measured). Studies are categorized according to how (and whether) they account for respiration (i.e. intake); uptake of gases or deposition of particles; and health biomarkers. The last two dimensions are discussed in Sections 2.5 and 2.6, respectively. "Constant" respiration refers to studies that apply fixed respiration rates by mode or individual; "variable" respiration refers to studies that use varying respiration rates by trip or at a greater level of detail. The categorization in Table 3 proceeds roughly from least to most comprehensive (A to $\mathrm{M}$ ) in terms of targeting farther along the exposure-health pathway, assessing linkages more directly (e.g., measuring versus assuming), and/or examining more intermediate steps between exposure and uptake or biomarkers. 


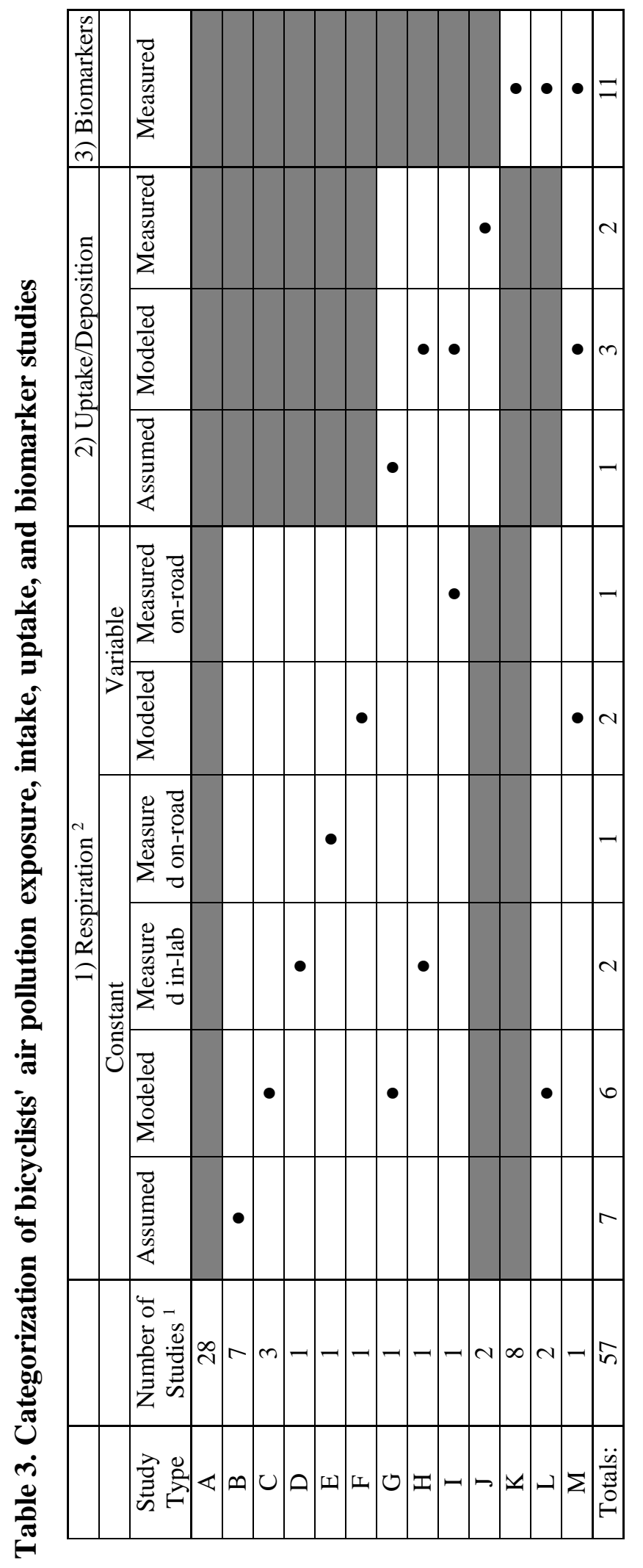

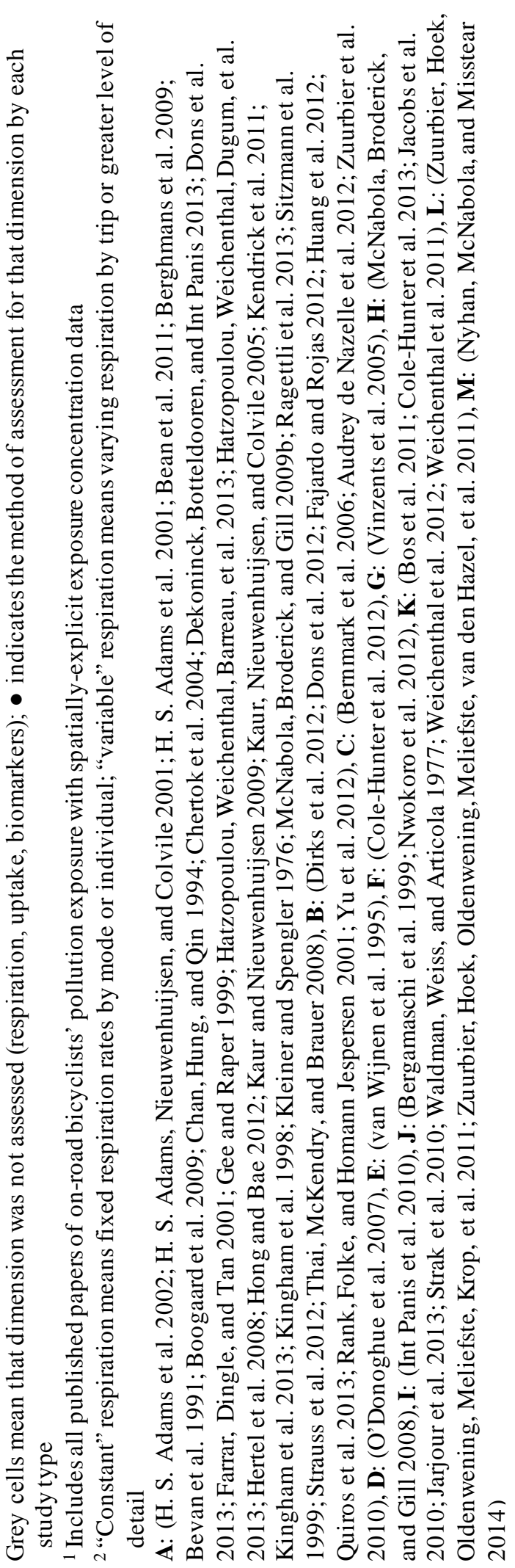


Many studies consider only exposure concentrations and neglect the question of intake dose and the issue of varying respiration and energy expenditure by travel mode and condition (Type A). Similarly, some studies measure exposure concentrations and uptake doses or health biomarkers directly, but do not address the intermediate step of intake or respiration (Types $\mathrm{J}$ and $\mathrm{K}$ ). Of the 19 studies in Table 3 that explicitly consider respiration, 16 use fixed values of $V_{E}$ for each travel mode or individual (Types B-E, G, $\mathrm{H}$, and L). Type B studies (7 of the 19) apply an assumed $V_{E}$ for bicyclists based on other published research. Two studies (Types $\mathrm{D}$ and $\mathrm{H}$ ) use bicycle ergometers in a laboratory to determine representative respiration values by mode. Of the eight studies that model respiration (Types $\mathrm{C}, \mathrm{F}, \mathrm{G}, \mathrm{L}$, and $\mathrm{M}$ ), six use ergometers to develop individual subject functions to estimate on-road $V_{E}$ from field-measured HR; one uses previously developed $V_{E}$-HR functions with field-measured HR; and one estimates respiration from accelerometer-based MET values (see Section 2.4.1). Only two of these eight studies (Types $\mathrm{F}$ and $\mathrm{M}$ ) estimate intake using variable ventilation rates by trip (Cole-Hunter et al., 2012) or at two-minute aggregations (Nyhan, McNabola and Misstear, 2014).

Two studies in Table 3 directly measure on-road bicyclists' minute ventilation in order to estimate intake dose (Types E and I). Van Wijnen et al. (1995) use fixed mode-specific respiration rates that are the averages of measured on-road minute ventilation for a set of test subjects traveling on the same test routes as the concentration measurements, but at different times. Int Panis et al. (2010) use simultaneously monitored on-road respiration and concentration data to estimate intake dose. Combining tidal volume and pollutant concentration measurements, Int Panis et al. calculate breath-by-breath mass intake and sum over trips, thus including both respiration and duration effects on total intake.

Table 3 shows that there has been little assessment of the variability of bicyclists' respiration as they travel in an urban environment. If the variability in respiration is independent of exposure concentrations, then representative averages for each will suffice (assuming linearity). But there is likely to be spatial correlation between pollutant concentrations and bicyclist energy expenditure at locations such as intersections and hills, where both motor vehicles and bicyclists are required to generate more energy. There is also a potential correlation between exposure duration and exposure concentration at congested bottlenecks or busy intersections. At the route level, ColeHunter et al. (2013) found no significant differences in measured HR for routes with low and high proximity to traffic; they conclude that variability in UFP intake dose for bicyclists would be predominantly determined by exposure concentrations, not ventilation characteristics. But a wide range of bicyclists' respiration values have been reported (Section 2.4.1), and the lack of bicyclist intake dose studies considering variable respiration rates leaves the question open.

\subsubsection{Modal Comparisons of Pollution Intake}

Int Panis (2010) argues that comparisons of exposure concentrations by travel mode are "not entirely relevant" because of the dominating effect of breathing differences among modes. Modal comparisons of pollution intake dose go beyond exposure concentrations by including respiration to compare intake dose rates per unit time. More detailed comparisons also consider the intake effects of travel duration differences, assessing 
intake doses per trip or unit travel distance. For faster trips, the time spent in an alternative environment is typically neglected; this aspect may be important when the air quality at the trip destination is poor. Inherent speed differences by mode are problematic for modal comparisons of intake rates by either normalization.

Table 4 summarizes the 12 published modal comparisons that include respiration, showing the median and range for ratios of bicycle to alternative mode intake or uptake doses. Dose ratios are presented separately for the eight studies that compare doses per unit distance and the five studies that compare doses per unit time (one assesses both). For most pollutants, studies that compare doses per unit distance find greater bicycle/car dose ratios than comparisons per unit time, as expected from bicyclists' lower travel speeds. This body of literature is still much smaller than modal comparisons of exposure, but for the most part two to five times higher ventilation rates and slower travel speeds for bicyclists compared to motor vehicle passengers outweigh any beneficial exposure concentration differences. Bicyclists' doses are less consistent when compared to pedestrians, which is not surprising because walking is another active travel mode with elevated respiration. Pedestrians typically have lower respiration rates (McNabola, Broderick and Gill, 2007) but also lower speeds, with counteracting effects on intake rates per unit distance.

Few of the modal comparisons of dose directly measure on-road respiration or model respiration as a function of travel characteristics beyond mode. This is important because travel attributes such as road grade and speed affect respiration and inhalation rates for bicyclists but not motorized modes. Intake doses per trip will be further affected by duration changes with route and destination choices, which are normally not varied in modal comparisons. Furthermore, active travelers tend to have unique demographics (Plaut, 2005), which could systematically impact respiration through physiological attributes such as sex and health condition (W. C. Adams, 1993). 
Table 4. Ratios of intake or uptake doses for bicyclists versus other modes

\begin{tabular}{|c|c|c|c|c|c|}
\hline & \multirow[b]{2}{*}{$\begin{array}{l}\text { Alternative } \\
\text { Mode }\end{array}$} & \multicolumn{2}{|c|}{ Per unit distance 1} & \multicolumn{2}{|c|}{ Per unit time } \\
\hline & & $\mathrm{N}^{2}$ & Median (Range) & $\mathrm{N}$ & Median (Range) \\
\hline \multirow{4}{*}{$\mathrm{CO}$} & Pedestrian & 1 & 0.80 & 0 & \\
\hline & Car/Taxi & 3 & 1.09 (0.36-4.67) & 1 & 0.87 \\
\hline & Bus & 3 & 1.63 (1.07-4.67) & 0 & \\
\hline & Rail & 1 & 7.00 & 0 & \\
\hline \multirow{3}{*}{ VOC $^{3}$} & Pedestrian & 1 & 1.11 & 0 & \\
\hline & Car & 1 & 0.81 & 4 (2 studies) & $0.71(0.50-0.72)$ \\
\hline & Bus & 2 & $1.60(1.25-1.96)$ & 0 & \\
\hline $\mathrm{NO}_{2}$ & Car & 0 & & 1 & 3.08 \\
\hline \multirow{3}{*}{ UFP } & Pedestrian & 2 & $0.68(0.51-0.84)$ & 0 & \\
\hline & Car & 3 & $5.42(1.00-10.42)$ & 1 & 2.09 \\
\hline & Bus & 1 & 1.90 & 1 & 1.87 \\
\hline \multirow{4}{*}{$\mathrm{PM}_{2.5}$} & Pedestrian & 4 & $1.13(0.47-1.97)$ & 1 & 2.09 \\
\hline & Car/Taxi & 5 & 3.36 (1.38-10.88) & 1 & 1.70 \\
\hline & Bus & 4 & 1.77 (1.06-4.78) & 2 & $3.14(1.91-4.36)$ \\
\hline & Rail & 1 & 2.56 & 1 & 2.29 \\
\hline \multirow{4}{*}{$\mathrm{PM}_{10}$} & Pedestrian & 1 & 1.62 & 1 & 1.82 \\
\hline & Car & 1 & 6.75 & 1 & 1.66 \\
\hline & Bus & 1 & 3.21 & 2 & $2.13(1.15-3.10)$ \\
\hline & Rail & 1 & 3.06 & 1 & 2.21 \\
\hline \multirow{3}{*}{$\mathrm{BC}$} & Pedestrian & 1 & 0.81 & 0 & \\
\hline & Car & 1 & 0.84 & 2 & $1.90(1.36-2.44)$ \\
\hline & Bus & 1 & 1.64 & 1 & 1.51 \\
\hline
\end{tabular}

${ }^{1}$ Values are ratios of bicycle to alternative mode doses in mass, particles, or ppb per unit distance (i.e., per km or per trip) or per unit time (i.e., per hour of travel); the table includes all studies that directly compare pollutant intake or uptake between travelers by bicycle and other modes for similar trips.

${ }^{2}$ A single mean value (weighted by number of samples) was computed for studies reporting separate results by routes or times of day. VOC doses per unit time are from two studies, with one reporting three different compounds.

${ }^{3}$ Only reported values for BTEX compounds are included.

Sources, per unit distance: CO: (Audrey de Nazelle et al., 2012; Dirks et al., 2012; Huang et al., 2012); VOC:

(McNabola, Broderick and Gill, 2008; O’Donoghue et al., 2007); UFP: (Audrey de Nazelle et al., 2012; Int Panis et al., 2010; Quiros et al., 2013); $\mathbf{P M}_{2.5}$ : (Audrey de Nazelle et al., 2012; Huang et al., 2012; Int Panis et al., 2010; McNabola, Broderick and Gill, 2008; Nyhan, McNabola and Misstear, 2014; Quiros et al., 2013); PM10: (Int Panis et al., 2010; Nyhan, McNabola and Misstear, 2014); BC: (Audrey de Nazelle et al., 2012)

Sources, per unit time: CO: (van Wijnen et al., 1995); VOC: (Rank, Folke, and Homann Jespersen, 2001; van Wijnen et al. ,1995); NO$_{2}$ : (van Wijnen et al., 1995); UFP: (Zuurbier et al.. 2010); $\mathbf{P M}_{2.5}$ : (Nyhan, McNabola and Misstear, 2014; Zuurbier et al., 2010); PM$_{\mathbf{1 0}}$ : (Nyhan, McNabola and Misstear, 2014; Zuurbier et al., 2010); BC: (Dons et al., 2012; Zuurbier et al., 2010) 


\subsection{BICYCLISTS’ AIR POLLUTION UPTAKE}

A portion of inhaled pollutants are either absorbed (gases) or deposited (particles) onto the lining of the respiratory tract or into the bloodstream. Absorbed/deposited pollutants are then either expelled (through mucociliary clearance or desorption) or transported to body tissues. The air pollution uptake dose is the amount of pollutant that is not exhaled or expelled, but rather incorporated into the body.

Table 5 summarizes the factors that are expected to increase pollutant uptake for bicyclists. The first two factors reflect the exposure in terms of concentration and duration. The next set of factors in Table 5 is attributes of the pollutants that determine uptake dose (independent of travel characteristics). Particle size is important for PM uptake because deposition and clearance rates vary with particle size. UFP deposition is also influenced by the particles' growth characteristics in high humidity conditions such as in lung airways (hygroscopicity). Gas reactivity and solubility in blood and lipids are similarly important because they affect absorption and diffusion rates (Daigle et al., 2003; International Commission on Radiological Protection [ICRP], 1994; Löndahl et al., 2007; McNabola, Broderick and Gill, 2008; Ott, Steinemann and Wallace, 2007; West, 2012).

\section{Table 5. Factors that increase pollutant uptake}

\begin{tabular}{ll}
\hline Factor & Increased uptake with: \\
\hline $\begin{array}{l}\text { Exposure } \\
\text { Concentration }\end{array}$ & $\begin{array}{l}\text { Higher concentrations } \\
\text { Duration }\end{array}$ \\
\hline Pollutant & Songer duration \\
Particle size & More hydrophobic particles \\
Particle hygroscopicity & More blood- and lipid-soluble compounds \\
Gas solubility & \\
\hline Respiration/physiology & Greater ventilation \\
Breath volume flow rate $\left(V_{E}\right)$ & Greater tidal volume \\
Depth of breathing $\left(V_{T}\right)$ & Oral breathing \\
Path of breathing & Greater perfusion \\
Cardiac output (lung perfusion) & Higher metabolic rate \\
Metabolic rate &
\end{tabular}

Table 5 also summarizes the physiology and respiration factors that influence uptake. Intake dose is determined by $\dot{V}_{E}$ and the exposure concentration; uptake dose is further influenced by the depth of respiration $\left(V_{T}\right)$ and the amount of oral breathing. Greater uptake fractions of inhaled PM occur during deeper and more oral breathing (ICRP, 1994), which are associated with higher levels of exertion (Samet et al., 1993; Weisman, 2003). Daigle et al. (2003) found that when subjects' $\dot{V}_{E}$ increased from 11.5 to $38.1 \mathrm{~L} / \mathrm{min}$ the deposition fraction (DF), the portion of particles that are not exhaled after inhalation increased from 0.66 to 0.83 by number of particles and from 0.58 to 0.76 by mass of particles. Thus, a $\dot{V}_{E}$ increase by a factor of 3.3 led to a total deposition increase by a factor of 4.5 due to a higher DF. Löndahl et al. (2007) found only small changes in DF for UFP (by less than 0.03) during exercise when compared to rest ( $\dot{V}_{E}$ of 33.9 
versus $7.8 \mathrm{~L} / \mathrm{min}$ ), but both of these studies found that established models underpredicted the deposition of UFP, especially during exercise.

Uptake rates for gaseous pollutants are also affected by the characteristics of the gas and the level of physical exertion. VOC and CO uptake rates are several times greater during exercise than at rest for a given exposure concentration. But the uptake fraction of inhaled gases tends to decrease with exertion level because gas uptake rates increase more slowly than intake rates with exercise. (Astrand, Engstrom and Ovrum, 1978; Astrand, 1985; Filley, MacIntosh and Wright, 1954; Nadeau et al., 2006; Pezzagno et al.,1988). Diffusion-limited gases such as CO are primarily impacted by the diffusing capacity of the lungs, which can increase by a factor of three during exercise (West, 2012). Uptake rates for perfusion-limited gases such as low-solubility VOC and $\mathrm{NO}_{2}$ increase with ventilation and perfusion of the lungs, gas partial pressure differences between blood and air, and gas solubility in blood (Astrand, 1985; Csanády and Filser, 2001; Farhi, 1967; West, 2012). As blood concentrations approach equilibrium with inspired air, the uptake rate will fall to the steady-state rate of metabolic clearance (Csanády and Filser, 2001; Wallace, Pellizzari and Gordon, 1993). Although exercise increases ventilation and perfusion, it also can decrease the rate at which pollutants are metabolized by reducing blood flow to the liver, reducing the steady-state uptake rate while simultaneously increasing blood concentrations (Astrand, 1985; Csanády and Filser, 2001; Kumagai and Matsunaga, 2000; Nadeau et al., 2006).

Detailed uptake models allow estimation of different locations/tissues of pollutant uptake, which is relevant because of varying susceptibility to negative health effects from air pollution uptake by different tissues. Common uptake models include body compartment and physiologically based pharmacokinetic (PBPK) models for gases and human respiratory tract models for both gases and PM (Heinrich-Ramm et al., 2000; Hofmann, 2011; ICRP, 1994; King et al., 2011; Ott, Steinemann and Wallace, 2007; Wallace et al., 1997; Wallace, Pellizzari and Gordon, 1993). Uptake models are generally validated using much steadier air concentrations than have been observed in on-road environments, so it is not clear how applicable they are for on-road uptake analysis with highly transient exposure concentrations.

Uptake of air pollutants by bicyclists has been studied less than exposure concentrations or intake doses (six of the 57 studies in Table 3 explicitly consider uptake). Vinzents et al. (2005) conservatively estimate deposition as linearly proportional to workload (on average, 43\% higher deposition of PM while bicycling than at rest). Int Panis et al. (2010) use DF that vary with $\dot{V}_{E}$, $V_{T}$, and particle size, based on two previous studies of particle deposition (Chalupa et al., 2004; Daigle et al., 2003). Although other factors in Table 5 were not explicitly modeled, these reference studies used physically active subjects and traffic exhaust particles. Intake doses of UFP were 4.2 to 6.6 times higher for bicyclists than car passengers, while uptake doses were 5.1 to 8.3 times higher - despite lower or roughly equivalent exposure concentrations for bicyclists. $\mathrm{PM}_{2.5}$ comparisons were similar, with intake doses 5.7 to 7.6 times higher for bicyclists than car passengers, but uptake doses were 8.0-12.0 times higher.

McNabola et al. (2008) modeled uptake of VOC and PM 2.5 using the ICRP human respiratory tract model (ICRP, 1994) with on-road measured exposure concentrations and laboratorymeasured respiration characteristics for bicycle, pedestrian, car and bus modes. The ICRP model can include all relevant factors in Table 5 except lung perfusion, though the assumed fraction of 
oral breathing is not reported by McNabola et al. Bicyclists had the highest total lung deposition of $\mathrm{PM}_{2.5}$ and the second-highest absorption of VOC over similar trips to other modes. Breathing characteristics (frequency, tidal volume) and VOC solubility affected the uptake dose and the location of absorption, with more benzene absorbed deep in the lungs for bicyclists and pedestrians. Breathing differences also affected benzene absorption more than 1,3-butadiene absorption because of benzene's lower solubility. McNabola et al. (2007) similarly model VOC uptake by bicyclists using different travel speeds, but with assumed (rather than measured) exposure concentrations. They found that higher bicycling speeds reduce VOC absorption over a fixed travel distance because the increase in respiration rate is smaller than the reduction in exposure duration.

The same ICRP model was also applied by Nyhan et al. (2014) to estimate PM2.5 and PM10 lung deposition for trips by bicycle, foot, bus and train. Their estimates indicate that bicyclists' PM intake and uptake per trip is disproportionately higher than exposure concentrations compared to other modes. But the cross-mode ratios are equivalent for modeled intake and deposition, suggesting that only ventilation rate $V_{E}$ was varied by mode in the uptake model.

Bicyclists' uptake of traffic-related VOC was directly measured by sampling blood and urine concentrations of BTEX compounds (benzene, toluene, ethylbenzene and xylenes) by Bergamaschi et al. (1999). They found significant increases of benzene and toluene in blood for bicyclists in urban areas, and significant increases of toluene and xylenes in urine. Although uptake was directly measured, respiration was not measured and there was no discussion of pollutant intake or inhalation, which inhibits placement of their findings in the larger context of the emissions-health pathway. Nwokoro et al. (2012) directly measured uptake doses of BC by bicyclists and non-bicyclists (pedestrians and public transit riders) in London by sampling airway macrophages. They found significantly higher (63\%) doses of BC for bicyclists, correlated with higher commute exposure concentrations. Bicyclists also had almost twice as long commute durations, and experienced $41 \%$ of daily BC exposure during the commute (as compared to 19\% for non-bicyclists).

The few studies of bicyclists' pollution uptake suggest that PM uptake doses are disproportionally greater for bicyclists than intake doses or exposure concentrations when compared to other modes. Bicyclists' uptake doses of gaseous pollutants are also disproportionately higher than exposure concentrations when compared to other modes, but have yet to be directly compared to intake doses. Uptake dose is the closest measure of health risks for exposed travelers, but connections to health outcomes still require application of a dose-response function that reflects the toxicity of the pollutants, the susceptibility of the travelers and other factors (Cho et al., 2009; ICRP, 1994).

\subsection{HEALTH EFFECTS OF BICYCLISTS’AIR POLLUTION UPTAKE}

Linkages between long-term exposure to traffic-related air pollution and health impacts have been established, as described elsewhere (Bell, 2012; Brook et al., 2010; Brugge, Durant and Rioux, 2007; Health Effects Institute, 2010; Nawrot, Vos et al., 2011; Pope and Dockery, 2006; Samet, 2007). Long-term health effects studies show elevated risk for development of asthma, reduced lung function, increased blood pressure, and cardiac and pulmonary mortality. An 
important gap for traveler health studies, though, is a lack of data on the health effects of chronic high-intensity but short-duration doses (Gunatilaka, Skvortsov and Gailis, 2014; Zuurbier, Hoek, Oldenwening, Meliefste, Krop et al, 2011). Some evidence exists of effects on mortality and cardiovascular/pulmonary hospital admissions for short-term exposure to traffic-related air pollution in general, and particularly PM and UFP (Knibbs, Cole-Hunter and Morawska, 2011; McCreanor et al., 2007; Michaels and Kleinman, 2000; Peters et al., 2004). A recent study indicates increased risk of acute myocardial infarction onset after travel specifically for bicyclists, though the risk is not higher than for other modes (Peters et al., 2013).

Health effects studies of bicyclists' exposure to air pollution have focused on respiratory and cardiovascular effect biomarkers following acute (0.5- to two-hour) exposures to traffic (11 studies of Types K-M in Table 3). Biomarkers are physiological indicators in the pathway of the morbidity and mortality outcomes studied in epidemiology; for example, blood cell counts can be indicators of systemic inflammation and systemic inflammation is linked to cardiovascular disease (Brook et al., 2010). Unfortunately, even when acute health effects are recognized in the form of biomarkers, the broader health significance is often not known, especially in the context of chronic daily exposures.

Studies of bicyclists' biomarkers show inconsistent results, with four of 11 reporting insignificant acute effects and others reporting some cardiovascular or respiratory biomarker changes. No significant changes in bicyclists' respiratory or cardiovascular biomarkers were reported in four studies of acute on-road exposure (Jarjour et al, 2013; Waldman, Weiss and Articola, 1977; Zuurbier, Hoek, Oldenwening, Meliefste, Krop et al., 2011; Zuurbier, Hoek, Oldenwening, Meliefste, van den Hazel et al., 2011). Jacobs et al. (2010) found a significant but small increase in a single indicator of blood inflammation for bicyclists, with "unclear" health implications. Cole-Hunter et al. (2013) found significant differences in nasal and throat irritation between bicyclists in high-exposure and low-exposure routes, but no significant differences for airway inflammation biomarkers. Strak et al. (2010) found mostly insignificant changes in respiratory function biomarkers for bicyclists, though UFP and soot exposure were weakly associated with a biomarker of airway inflammation (exhaled NO) and degraded lung function. Weichenthal et al. (2011) found significant associations between UFP, ozone $\left(\mathrm{O}_{3}\right)$, and $\mathrm{NO}_{2}$ exposures during travel and cardiovascular risk indicators (changes in heart-rate variability), but no strong associations between in-traffic exposure and respiratory biomarkers. Further analysis of individual VOC in the data set found "evidence of possible associations ... for a small number of compounds" with biomarkers of lung inflammation, lung function, and heart-rate variability (Weichenthal et al. 2012). Nyhan et al. (2014) found significant associations between decreased heart-rate variability and $\mathrm{PM}_{2.5}$ and $\mathrm{PM}_{10}$ doses - stronger for bicyclists and pedestrians than other modes. Bos et al. (2011) took a different approach and found that PM exposure during bicycling can suppress a positive exercise-induced health biomarker associated with cognitive performance. Though again, the effects of chronic exposure are still unknown.

This review does not address the health impacts of bicycling-related crashes and physical activity, only air pollution uptake. However, a review of five recent health impact assessments for bicycling concludes that the physical activity benefits of bicycling far outweigh the crash safety and air pollution risks by factors of nine to 96 (Teschke, Reynolds et al., 2012). The air pollution risks in these assessments are based on extrapolations of epidemiological evidence for 
long-term health outcomes, and limited by the continued uncertainty of health effects of chronic daily uptake of air pollution by physically active travelers.

\subsection{SUMMARY}

This is the first review to specifically address bicyclists' health risks from traffic-related air pollution and to explicitly include intake and uptake doses in addition to exposure concentrations. Bicyclists' pollution-exposure concentrations are highly variable, with median increases of up to $102 \%$ (for gaseous hydrocarbons) on high-traffic versus low-traffic routes. Bicyclists' relative exposure concentrations compared to other modes are inconsistent, varying by pollutant, facility, route and city. Bicyclists' exposure concentrations are most affected by wind and proximity to motor-vehicle traffic, though few studies have incorporated detailed, concurrent traffic data.

Bicyclists' pollution intake doses tend to be higher than motorized modes due to their two to five times higher respiration rates. Bicyclists' respiration and intake dose increase with bicycle travel speed and exertion, but only 12 of the 57 studies with spatially explicit, bicyclist exposure concentration data include any measurement of respiration. Furthermore, only three of those studies consider variable bicyclist respiration rates, and there has been almost no assessment of the variability in respiration with trip characteristics (including correlation with exposure concentrations).

Bicyclists' pollution uptake doses are affected by the intake dose, pollutant characteristics, breathing depth and pathway, and other individual and physiological factors. Uptake rates tend to increase with exertion level, affecting bicyclists more than motorized travelers. There are clear links between traffic-related air pollution exposure and negative health outcomes in urban populations. However, the health effects of chronic daily air pollution uptake by bicyclists are still unknown. More research is needed on health impacts of pollution exposure because some studies of bicyclists' biomarkers show significant acute respiratory effects while other studies show insignificant effects.

To reduce exposure concentrations, spatial and temporal separation of bicyclists from motorvehicle traffic can be achieved with separated bicycle facilities, low-volume routes, and off-peak travel. These are potential "win-win” strategies because bicyclists already prefer low-traffic routes and bicycle-specific facilities (Broach, Dill and Gliebe, 2012; Dill, 2009; Kang and Fricker, 2013; Wardman, Tight and Page, 2007). Separated bicycle facilities could also improve safety (Lusk et al., 2011; C. C. Reynolds et al., 2009; Teschke, Harris et al., 2012). Regarding intake doses, other likely mitigation strategies would be to prioritize separation from traffic in locations where bicyclists' respiration is expected to be high (steep grades, for example) or to reduce energy expenditure requirements (by reducing required stops, for example) in locations where pollutant concentrations are known to be high. 


\subsection{RESEARCHGAPS AND OPPORTUNITIES}

This literature review reveals steady progress towards a better understanding of air pollution uptake by bicyclists. However, several significant research gaps deserve attention. Although the literature suggests that traffic-related air pollution uptake is higher for bicyclists than for travelers using motorized modes, persistent uncertainty in the intensity and effects of pollution uptake means that transportation planners and decision makers are unable to consider bicyclists' air pollution risks in a precise way. More research is needed to provide better quantification and understanding of the relative health benefits of alternative bicycle facility designs, bicycle network designs and route options. Some research topics that can bring us closer to achieving these goals include:

- Study of the on-road variability of respiration and air quality for traveling bicyclists, including a broader array of pollutants (e.g., ground-level ozone);

- The impact of bicycle trip attributes such as road grade, road surface, travel speed, and number of stops on respiration rates for bicyclists;

- The impacts of bicycle facility design features on exposure concentrations (distance from motor-vehicle travel lanes, physical barriers, intersection treatments such as "bike boxes", etc.);

- The impacts of traffic-flow characteristics on bicyclists' exposure concentrations, including traffic speeds, volumes, and queuing along arterials or at major intersections;

- Intermodal pollution exposure comparisons that apply more comprehensive and representative modal travel characteristics (trip location and distance, traveler demographics, route preferences) and that consider variable respiration (especially for active travelers);

- Characterization of different bicyclist types (e.g., commuters, recreational riders) and demographic factors that can impact respiration or health effects; these factors include physiology (height, weight, respiratory health), riding style (speed, acceleration, response to grades), and equipment (weight, condition, baggage);

- Analysis of bicyclists' pollutant doses along different types of routes and facilities, to enable health impact assessments; and

- Development of dose-response functions for health effects of chronic short-duration, high-intensity air pollution exposure episodes. 


\subsection{EXPERIMENT AND METHODS}

\subsection{EXPERIMENT}

\subsubsection{Subjects}

Three subjects participated in the data collection; this was considered adequate because the primary focus of the study involved environmental covariates rather than inter-subject covariates. The subjects were recruited from the university student body. Approval for the research was obtained from Portland State University's Human Subjects Research Review Committee (HSRRC).

All subjects were nonsmokers who reported moderate regular physical activity and good respiratory health based on the American Thoracic Society respiratory disease questionnaire $^{1}$. The characteristics of subjects $\mathrm{A}, \mathrm{B}$ and $\mathrm{C}$ were (respectively): male, male and female; age, 34, 28 and 45; bicycle weight (including all gear), 25, 22 and $23 \mathrm{~kg}$; and average post-ride body weight, 80,70 and $75 \mathrm{~kg}$. Breathing zone heights in normal riding position for subjects A, B and C were 1.6, 1.5 and $1.6 \mathrm{~m}$, respectively.

\subsubsection{On-road sampling}

On-road measurements were carried out in Portland, OR, on nine days in April through September, 2013. Subject A participated all nine days; subjects B and C participated two days each. All on-road data collection was performed near the morning peak-travel period (7-10 a.m.). A pre-ride period of 30 minutes at a low-concentration starting location (a $0.8 \mathrm{~km}^{2}$ park) was used. A variety of roadway facilities were used, including off-street paths and mixed-use roadways ranging from local roads to major arterials. The subjects were instructed to adhere to safe riding practices, follow traffic laws, and ride at a pace and exertion level typical for utilitarian travel.

Prescribed riding sample segments were seven to nine kilometers (20-40 minutes) and comprised homogenous facility types. Riding each day involved two to five segments, requiring 1.2-3 hours. Sampling routes are summarized in Table 6. Routes were ridden by an individual (April through August routes) or by paired subjects (September routes). Time-averaged ambient VOC concentrations were measured for the full ride time of each segment.

${ }^{1}$ American Thoracic Society, 1979. "Recommended Respiratory Disease Questionnaires for Use with Adults and Children in Epidemiological Research." 
Table 6. Summary of routes used in breath sampling

\begin{tabular}{|c|c|c|c|c|c|}
\hline Day & Segment 1 & Segment 2 & Segment 3 & Segment 4 & Segment 5 \\
\hline 2 April & $\begin{array}{l}\text { Mixed collectors } \\
\text { and arterials }\end{array}$ & $\begin{array}{l}\text { Mixed collectors } \\
\text { and arterials }\end{array}$ & NA & NA & NA \\
\hline 2 July & Local roads & $\begin{array}{l}\text { Major arterials } \\
\text { (primarily SE } \\
\text { Powell Blvd.) }\end{array}$ & $\begin{array}{l}\text { Major arterials } \\
\text { (Segment } 2 \text { in } \\
\text { reverse) }\end{array}$ & $\begin{array}{l}\text { Local roads } \\
\text { (Segment } 1 \text { in } \\
\text { reverse) }\end{array}$ & $\begin{array}{l}\text { Mixed local } \\
\text { roads and } \\
\text { collectors }\end{array}$ \\
\hline 9 July & \multicolumn{5}{|c|}{ Same as 2 July } \\
\hline 11 July & \multicolumn{5}{|c|}{ Same as 2 July } \\
\hline 22 Aug. & \multicolumn{5}{|c|}{ Same as 2 July, Segments 1-4 } \\
\hline 4 Sept. & $\begin{array}{l}\text { Local roads } \\
\text { (primarily SE } \\
\text { Ankeney St.) }\end{array}$ & $\begin{array}{l}\text { Minor arterial (E } \\
\text { Burnside St.) }\end{array}$ & $\begin{array}{l}\text { Minor arterial } \\
\text { (Segment } 2 \text { in } \\
\text { reverse) }\end{array}$ & $\begin{array}{l}\text { Local roads } \\
\text { (Segment } 1 \text { in } \\
\text { reverse) }\end{array}$ & $\begin{array}{l}\text { Mixed local } \\
\text { roads and } \\
\text { collectors }\end{array}$ \\
\hline 10 Sept. & \multicolumn{5}{|c|}{ Same as 4 September } \\
\hline 11 Sept. & $\begin{array}{l}\text { Mixed local } \\
\text { roads and } \\
\text { collectors }\end{array}$ & $\begin{array}{l}\text { Springwater off- } \\
\text { street path }\end{array}$ & $\begin{array}{l}\text { I-205 off-street } \\
\text { path (s outh } \\
\text { section) }\end{array}$ & Local roads & $\begin{array}{l}\text { Mixed local } \\
\text { roads and } \\
\text { collectors }\end{array}$ \\
\hline 12 Sept. & Local roads & $\begin{array}{l}\text { I-205 off-street } \\
\text { path (north } \\
\text { section) }\end{array}$ & $\begin{array}{l}\text { I-205 off-street } \\
\text { path (Segment } 2 \\
\text { in reverse) }\end{array}$ & $\begin{array}{l}\text { Local roads } \\
\text { (Segment } 1 \text { in } \\
\text { reverse) }\end{array}$ & $\begin{array}{l}\text { Mixed local } \\
\text { roads and } \\
\text { collectors }\end{array}$ \\
\hline
\end{tabular}

On-road location, physiology, and continuous air quality data were collected on 4 additional days in Portland, spanning October 2012 to September 2013. No samples were collected on these days for VOC analysis.

\subsection{INSTRUMENTATION}

\subsubsection{Location}

GPS receivers recorded $1 \mathrm{~Hz}$ location data. Redundant GPS devices and on-bicycle video were used to cross-check the location data. The GPS devices included

- Droid RAZR M smartphone (Motorola, Chicago, IL), logged using the Google MyTracks application

- Citrus smartphone (Motorola, Chicago, IL), logged using the Google MyTracks application

- Joule GPS cycle computer (CycleOps, Madison, WI)

- Portland ACE custom multi-sensor device (Alexander Y. Bigazzi, 2013) with a GPS receiver (Fastrax UP501, u-blox, Thalwil, Switzerland)

\subsubsection{Meteorology}

Temperature and humidity were measured on-road with a HOBO U12 (Onset, Bourne, $\mathrm{MA}$ ), logged at $1 \mathrm{~Hz}$. Wind data were retrieved from an Oregon Department of 
Environmental Quality monitoring station in the data collection area (Station SEL 10139). Wind data were scalar average wind speeds at a five-minute aggregation, measured by an anemometer at a height of 10 meters.

\subsubsection{Air quality monitoring}

Several air quality instruments were mounted to the bicycles used in data collection (Figure 4). The air quality instruments were selected to be highly portable, precise, and provide near-continuous measurements.

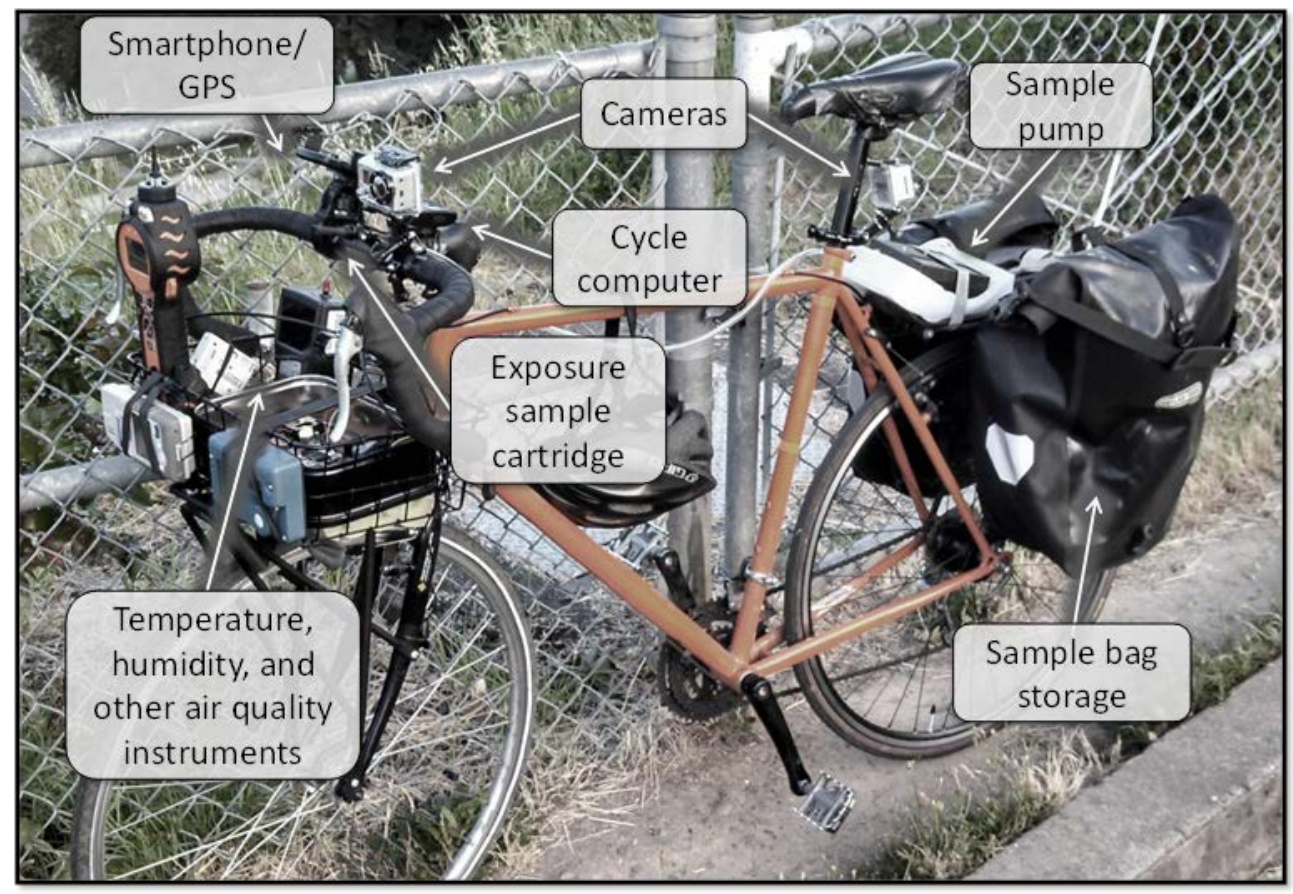

Figure 4. Instrumented bicycle

1 Carbon monoxide (CO): The T15n (Langan Products, San Francisco, CA) uses an electrochemical sensor to measure $\mathrm{CO}$ concentrations at $1 \mathrm{~Hz}$, logged on an internal storage medium using the HOBO platform (OnSet). The Langan device has a range of 0$200 \mathrm{ppm}$, and a resolution of $0.05 \mathrm{ppm}$. It is commonly used for ambulatory CO measurements (Kaur, Nieuwenhuijsen and Colvile, 2007). The Langan instrument used in data collection was calibrated on 2012-05-01; all data were collected within 24 months of calibration, in accordance with manufacturer instructions.

2 Carbon dioxide $\left(\mathbf{C O}_{2}\right)$ : The Telaire 7001 (Telaire, Santa Barbara, CA) uses an electrochemical sensor to measure $\mathrm{CO}_{2}$ concentrations at $1 \mathrm{~Hz}$, logged on an external HOBO data logger (Onset). The Telaire device has a range of $0-2,500 \mathrm{ppm}$, and a resolution of $10 \mathrm{ppm}$. Although $\mathrm{CO}_{2}$ is not a pollutant of concern for human health, it can be a useful surrogate for traffic emissions because of the high $\mathrm{CO}_{2}$ content of exhaust streams (A. Bigazzi et al., 2010). The Telaire instrument used in data collection was calibrated on 2012-07-01; all data were collected within five years of calibration, in accordance with manufacturer instructions. 
3 Particulate matter (PM): The P311 (Airy Technology, Orem, UT) laser particle counter measures PM in three size categories: $\mathrm{PM}_{0.3}, \mathrm{PM}_{2.5}$, and $\mathrm{PM}_{5}$. The Airy has a range of up to four million particles per cubic foot and logs at five-second intervals to an internal medium. The P311 instrument used in data collection was calibrated on 2012-05-28 and 2013-05-09; all data were collected within 12 months of calibration, in accordance with manufacturer instructions.

4 Total volatile organic compounds (TVOC): TVOC concentrations are measured using the PhoCheck Tiger (IonScience, Cambridge, UK). The Tiger measures TVOC using a photoionization detector (PID) with a $10.6 \mathrm{eV}$ lamp, which detects compounds with an ionization potential below $10.6 \mathrm{eV}$. Individual compounds within that range are not distinguished, and the reported concentrations are in isobutylene-equivalent units. The Tiger measures a TVOC concentration range of $1 \mathrm{ppb}$ to 20,000 ppm, with a resolution of $1 \mathrm{ppb}$. The Tiger is lightweight $(0.72 \mathrm{~kg})$ and portable, capable of operating on battery power for over four hours while collecting $1 \mathrm{~Hz}$ measurements. Annual factory calibration and firmware updates keep the instrument accurate, in addition to recalibration after every 100 hours of use. The instrument is zeroed with a carbon filter at the beginning of each collection. The Tiger is a new model of portable PID within the IonScience PhoCheck line, and so has not yet been used in published studies to our knowledge. Earlier models of the PhoCheck were used for air quality studies in motorvehicle environments (Atabi et al., 2013; Chien, 2007; Li et al., 2006). The TVOC instrument used in data collection was calibrated on 2012-04-12 and 2013-05-15; all data were collected within 12 months and 100 operating hours of calibration, in accordance with manufacturer instructions.

\subsubsection{VOC/gas sampling}

Ambient air was sampled through stainless steel adsorption/thermal desorption (ATD) cartridges (Tenax TA plus Carbotrap 1TD) as in Pankow et al. (2011). The pump used was from SKC (Eighty Four, PA), model PCXR8, set at 50 or $75 \mathrm{ml} \mathrm{min}^{-1}$ so as to collect a 2 L sample on each segment. The cartridges were attached to the handlebars (Figure 4) at a height of 1.02 meters. For paired riders, a single ambient sample was obtained for each segment.

At the end of each ride, the ATD cartridges used to sample ambient air were immediately returned to the laboratory. Each cartridge was thermally desorbed (TurboMatrix 650 ATD, Perkin Elmer, Waltham, MA) and analyzed for VOCs using an Agilent (Santa Clara, CA) 7890A gas chromatograph and 5975C mass spectrometer (see Pankow et al,, (1998, 2003, 2004)). Every sample was analyzed on the day collected. Sample concentrations were determined for 75 target compounds, with corrections for travel and lab blanks. Other details are given in Table 7 . 
Table 7. Gas analysis conditions

\begin{tabular}{l|l}
\hline Parameter & Value \\
\hline Cartridge desorption temperature & $280{ }^{\circ} \mathrm{C}$ \\
Cartridge desorption flow rate & $40 \mathrm{~mL} / \mathrm{min}$ \\
Cartridge desorption time & $10 \mathrm{~min}$ \\
Inlet split flow & $5 \mathrm{~mL} / \mathrm{min}$ \\
Secondary trap temperature & $-15^{\circ} \mathrm{C}$ \\
Secondary trap desorption temperature & $295^{\circ} \mathrm{C}$ \\
Secondary trap desorption time & $3 \mathrm{~min}$ \\
Outlet split flow & $6 \mathrm{~mL} / \mathrm{min}$ \\
GC column & $\mathrm{DB}-\mathrm{VRX} 60 \mathrm{~m}, 0.25 \mathrm{~mm}$ id and $1.4 \mathrm{\mu m}$ film thickness \\
GC column flow & $\mathrm{Constant}$ head pressure of 35 psi \\
GC oven temperature program & $45^{\circ} \mathrm{C}$ for $10 \mathrm{~min}$, program to $190{ }^{\circ} \mathrm{C}$ at $12{ }^{\circ} \mathrm{C} / \mathrm{min}$, \\
& hold at $190^{\circ} \mathrm{C}$ for $2 \mathrm{~min}$, then program to $240{ }^{\circ} \mathrm{C}$ at 6 \\
GC transfer line temperature & ${ }^{\circ} \mathrm{C} / \mathrm{min}$, hold at $240 \mathrm{~V}$ for 1 min. \\
MS source temperature & $240{ }^{\circ} \mathrm{C}$ \\
MS quadrupole temperature & $250{ }^{\circ} \mathrm{C}$ \\
Scam range & $150{ }^{\circ} \mathrm{C}$ \\
EM voltage & $34-400$ amu \\
\hline
\end{tabular}

\subsubsection{Physiology}

Heart rate and breathing were measured by a physiology monitoring strap worn around the chest (BioHarness 3, Zephyr, Annapolis, MD) - see Figure 5. The Zephyr BioHarness $3^{2}$ is a relatively new commercial device for mobile physiological monitoring. Data are logged at $1 \mathrm{~Hz}$ and can also be streamed over Bluetooth to a paired device. A custom Android application was written to log the BioHarness data stream with simultaneous GPS data on a smartphone ${ }^{3}$. The BioHarness band stretches around the chest and contains a conductive elastic fabric. Expansion of the chest is monitored by measuring the resistance in the conductive fabric. The breathing rate $\left(f_{b}\right)$ is assessed by detecting inflections in the resistance waveform.

2 http://www.zephyranywhere.com/products/bioharness-3/

${ }^{3}$ See http://alexbigazzi.com/PortlandAce 


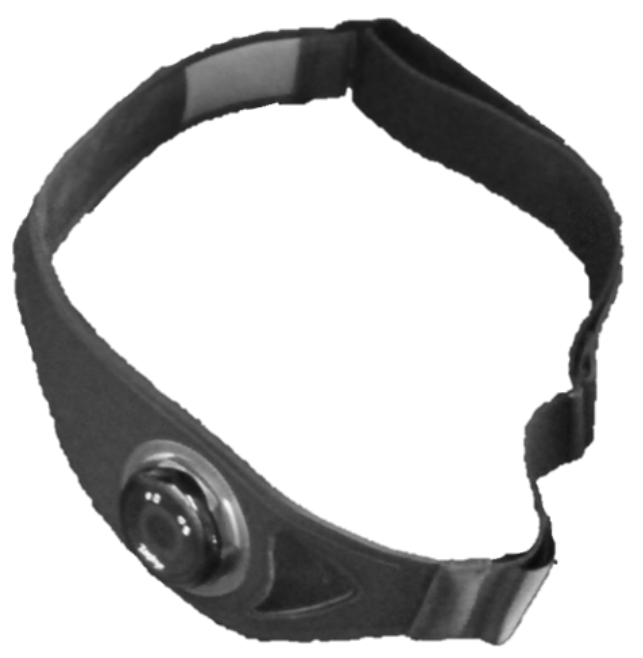

Figure 5. BioHarness physiology monitor

\subsubsection{Traffic and roadway data}

Arterial traffic data for SE Powell Boulevard (one of the high-volume facilities used the study) were obtained from the Portland Bureau of Transportation (PBOT). Powell Boulevard is equipped with Digital Wave Radar (DWR) sensors measuring traffic volume and speed in each lane at mid-block locations near SE $24^{\text {th }}$ and SE $35^{\text {th }}$ avenues. Concurrent traffic data were retrieved at 10-second aggregations for the data collection time periods. DWR data were compared with manual counts by other researchers at $\mathrm{PSU}^{4}$. Eastbound and westbound vehicle counts were compared for five 15-minute periods on May 1, $2013(\mathrm{~N}=10)$. The comparison produced a MPE of $6.1 \%$ and a MAPE of 9.1\%, with larger errors in the WB than EB directions (EB MPE of 2.6\% and MAPE of $5.0 \%$; WB MPE of $9.6 \%$ and MAPE of $13.2 \%$ ).

Average daily traffic (ADT) estimates were available for street links in the City of Portland through a GIS layer obtained from PBOT. The ADT data set was created by the City of Portland in 2005 by interpolating Monday-Thursday count data from the previous five years (prioritizing more recent counts and excluding counts with inconsistent volumes $)^{5}$. The ADT data were validated with 51 arbitrary locations in Southeast Portland for which more recent counts were available (2008-2012). Table 8 presents the results of the validation exercise, showing a reasonable reliability of the ADT data.

${ }^{4}$ Chawalit Tipagornwong and Adam Moore, Portland State University - unpublished correspondence, 2014-01-02

${ }^{5}$ Mary Edin, City of Portland - unpublished correspondence, 2014-02-10 
Table 8. Validation results comparing 2005 ADT map data with more recent (2008-2012) traffic count data

\begin{tabular}{lc}
\hline Number of locations & 51 \\
Correlation coefficient & 0.987 \\
Average ADT & 6,955 \\
Mean error (ADT) & 200 \\
Mean absolute error (ADT) & 808 \\
Mean percent error & $1.1 \%$ \\
Mean absolute percent error & $16.4 \%$ \\
\hline
\end{tabular}

In addition to the ADT GIS layer, two other GIS data sets were obtained for analysis: link-based transportation system plan (TSP) and bicycle network data. Both data sets were obtained from Metro (the metropolitan planning organization for Portland), through the Regional Land Information System (RLIS) ${ }^{6}$.

\subsection{DATA PROCESSING}

\subsubsection{Air quality data processing}

The Langan CO data were adjusted for on-road measured temperature and humidity according to the manufacturer's documentation. The adjustment equation was:

$C_{\text {adjusted }}=\frac{C_{\text {raw }}-1.75^{0.1 C_{\mathrm{raw}}-2}}{1+a\left(C_{\mathrm{raw}}-20\right)}$

where the concentrations $C_{\text {raw }}$ and $C_{\text {adjusted }}$ are in ppm,

$a=\left\{\begin{array}{l}0.0030 \text { when } T>20^{\circ} \mathrm{C} \\ 0.0055 \text { when } T<20^{\circ} \mathrm{C}\end{array}\right.$

and $T$ is the temperature in ${ }^{\circ} \mathrm{C}$.

The Telaire $\mathrm{CO}_{2}$ data were adjusted for on-road measured temperature according to the manufacturer's documentation. The adjustment equation was:

$C_{\text {adjusted }}=C_{\text {raw }}-2(T-25)$

where concentrations are in ppm and temperature $T$ is in ${ }^{\circ} \mathrm{C}$.

In early testing, the PID TVOC data showed inconsistent zero points at startup and a slow decay in the zero reference value over the course of a data collection. The manufacturer's recommendation was to use a "zero at startup" function, which uses the lowest reading

\footnotetext{
${ }^{6} \mathrm{http}: / /$ rlisdiscovery.oregonmetro.gov/
} 
since startup as the (running) zero reference value ${ }^{7}$. While this approach avoids negative values, it creates an untraceable and inconsistent shift in the data values.

As an alternative, a function was written to construct a zero reference curve after data collection was complete. The zero reference curve is the maximum-value convex, monotonically decreasing, piecewise linear curve that can be fit to the data. Adjusted TVOC values were calculated as the raw TVOC readings minus the zero reference curve. Zero readings were taken with a carbon filter at the beginning and end of each collection to serve as anchor points for the zero reference curve. The zero-reading points were removed for analysis, as were the first 15 minutes after the instrument was turned on (the warm-up period suggested by the manufacturer).

High-resolution BTEX concentrations were estimated by disaggregating the segmentlevel VOC data using the TVOC measurements. The BTEX concentration at time $t$ on segment $s$ was calculated utilizing the formula:

$\boldsymbol{C}_{t_{s} s}=\frac{T V O C_{t, s}}{\overline{T V O C}_{s}} \overline{\boldsymbol{C}}_{s}$

where $\bar{C}_{s}$ and $\overline{T V O C}_{s}$ are the average BTEX and TVOC concentrations on segments, respectively. This approach uses the variability information in the TVOC data with the precision information in the GC/MS data. The main assumption is that on-road variation in TVOC is representative of BTEX variation. This disaggregation is likely conservative with respect to sub-segment-level BTEX variability due to the predominance of vehicular sources of BTEX compounds.

\subsubsection{GIS data processing}

All GIS/spatial data analysis was performed in R. The GPS-based location data points were mapped onto GIS roadway network links based on proximity (out to 15 meters). Manual and scripted corrections to the initial mappings were applied at cross-streets and coincident roadways (e.g., parallel paths and overpasses). The link-based GIS roadway network data sets are described above (Section 3.2.6) and include:

1. Roadway facility types from the transportation system plan (TSP)

2. Bicycle network facility designations

3. ADT estimates based on interpolated traffic counts

The bicycle network dataset was restricted to "active" links (excluding "planned" and "recommended”).

The method of initial proximity point-link matching is described in the following steps. The procedure was performed three times - once with each of the ling-based GIS layers above, using the same point location data.

${ }^{7}$ Justin Blackman, Ion Science - unpublished correspondence, 2012-09-11 
1. Create a buffer around each point. The initial buffer size (radius) was 15 meters to allow for GPS error and lateral distance between riding location and the roadway centerline (the approximate location of the link data). The average GPS accuracy recorded for the full data set was 3.6 meters (range, 2-195 meters; $1^{\text {st }}$ and $3^{\text {rd }}$ quartiles, 3 meters). Riding on the edge of a four-lane road with four-meter lanes is an approximately eight-meter offset from the centerline. Together, 12 meters is a reasonable outer buffer, and 15 meters is conservative.

2. Perform a spatial intersect between the buffered points and the link data set to find all the links which intersect the 15-meter buffer of each point.

3. Refine points with multiple links intersecting the buffer. Step through the subset of points with multiple matches in Step 2. For each point, iterate steps 1 and 2 with a decremented buffer size. Use a factor of 0.95 to decrement the buffer size at each iteration. Stop the iteration when each point has zero or one associated link.

The total number of valid $1 \mathrm{~Hz}$ GPS location data points was 104,291 (longitude and latitude fields both present). The results of this point-link mapping process are shown in the following table. Some un-matched data points are due to locations off the network, while some are due to inaccuracy in the GPS data or failure of the matching algorithm.

Table 9. Results of initial point-link matching based on proximity

\begin{tabular}{l|rr}
\hline Dataset & \# points matched & \% points matched \\
\hline TSP & 94,919 & $91.0 \%$ \\
Bicycle network & 54,461 & $52.2 \%$ \\
ADT & 89,160 & $85.5 \%$ \\
\hline
\end{tabular}

The initial point-link matches were further processed to correct for street crossings (at which the cross-street centerline is closer than the travel street centerline) and other matching errors.

1. Discontinuity correction

Identify sequences of data for which the street name field of the matched link changes (or is missing) and then returns to the original street name within 12 observations (seconds). For these sequences, assign the departure link to all intervening data points, up to the point which returns to the street name. Results of the discontinuity correction are shown in Table 10.

Table 10. Discontinuity corrections to point-link matches

\begin{tabular}{l|rrr}
\hline Dataset & $\begin{array}{r}\text { Discontinuities } \\
\text { identified }\end{array}$ & $\begin{array}{r}\text { \# points } \\
\text { corrected }\end{array}$ & $\begin{array}{r}\% \text { points } \\
\text { corrected }\end{array}$ \\
\hline TSP & 3,629 & 8,537 & $8.2 \%$ \\
Bicycle & 884 & 1,603 & $1.5 \%$ \\
network & & & \\
ADT & 3,450 & 8,037 & $7.7 \%$ \\
\hline
\end{tabular}




\section{Manual correction}

The true route of the data collection bicycles was known because of scripted routes, field logs, and on-bicycle video data. After the discontinuity correction, the data were displayed on a map and inspected visually. Points on the map were color-coded for un-matched data, facility type and ADT value. Points identified as erroneously matched were manually re-matched with appropriate links in the relevant GIS data set (or with null values if the true facility was not present in the GIS network). The corrections included errors such as an off-street trail matched to the adjacent road or an overpass matched to the lower road. One of the off-street trails was missing from the TSP data set and all were missing from the ADT data set; these points were corrected to null values. Results of the discontinuity correction are shown in Table 11.

Table 11. Manual corrections to point-link matches

\begin{tabular}{l|rrr}
\hline Dataset & \# corrections & $\begin{array}{r}\text { \# points } \\
\text { corrected }\end{array}$ & $\begin{array}{r}\text { \% points } \\
\text { corrected }\end{array}$ \\
\hline TSP & 63 & 9,453 & $9.1 \%$ \\
Bicycle network & 44 & 1,439 & $1.4 \%$ \\
ADT & 77 & 11,074 & $10.6 \%$ \\
\hline
\end{tabular}

The final results of the matching exercise are shown in Table 12 .

Table 12. Results of point data mapping onto link data sets

\begin{tabular}{l|rrr}
\hline Dataset & $\begin{array}{r}\text { \# location } \\
\text { data points }\end{array}$ & $\begin{array}{r}\text { \# points } \\
\text { matched }\end{array}$ & $\begin{array}{r}\text { \% points } \\
\text { matched }\end{array}$ \\
\hline TSP & 104,291 & 94,027 & $90.2 \%$ \\
Bicycle network & 104,291 & 56,986 & $54.6 \%$ \\
ADT & 104,291 & 87,691 & $84.1 \%$ \\
\hline
\end{tabular}

A "Road Type" field was created for the location data using information in the matched TSP and bicycle network data sets.

1. Initial road types were assigned using a mapping from the TSP data shown in Table 13.

2. Data points identified as a "Multi-Use Trail" in the bicycle network data set or "OffSt. Path" in the TSP data set were classified as "Path" road type.

3. Data points with a "BR" abbreviation in the Segment Name field of the bicycle network data set were classified as "Bridge" road type - to distinguish them from the more separated trails.

The resulting distribution of road-type classifications is shown in Table 14. 
Table 13. Road-type classifications based on TSP classes

\begin{tabular}{l|l}
\hline TSP Classification & Road-Type Classification \\
\hline NA or Unknown & NA \\
Local St. & Local \\
Traffic Access & Minor Collector \\
Neighborhood Collector & Major Collector \\
District Collector & Minor Arterial \\
Major Traffic, Regional/Major & Major Arterial \\
Traffic, or Regional Traffic & \\
\hline
\end{tabular}

Table 14. Distribution of road-type classifications

\begin{tabular}{ccccccccc}
\hline & Path & Bridge & Local & $\begin{array}{c}\text { Minor } \\
\text { Collector }\end{array}$ & $\begin{array}{c}\text { Major } \\
\text { Collector }\end{array}$ & $\begin{array}{c}\text { Minor } \\
\text { Arterial }\end{array}$ & $\begin{array}{c}\text { Major } \\
\text { Arterial }\end{array}$ & NA \\
\hline $\begin{array}{c}N \\
\text { (1-sec data) }\end{array}$ & 10,701 & 2,009 & 49,560 & 7,724 & 5,539 & 8,922 & 16,866 & 2,970 \\
\hline$\%$ of total & $10.3 \%$ & $1.9 \%$ & $47.5 \%$ & $7.4 \%$ & $5.3,1 \%$ & $8.6 \%$ & $16.2 \%$ & $2.9 \%$ \\
\hline
\end{tabular}

Figure 6 shows road type and ADT estimates for all data plotted over an Open Street Map background. Combining the road-type classifications with the ADT estimates produces Figure 7 (note that not all data points with a road-type classification have an associated ADT link, especially the Path road type). Despite the fact that the road type and ADT come from different GIS data sets, the relationships are generally as expected.

A last classification step used the bicycle network link data to separate the two main offstreet paths used in data collection:

1. The "I-205 Path" runs north-south parallel to the freeway, intermittently inside and outside of a soundwall.

2. The "Springwater Path" runs east-west between the river and the I-205 Path, including sections in parkland and sections parallel to a roadway in an industrial area.

Data points at the park reference location (Mt. Tabor Park) were also identified based on the longitude/latitude boundaries. 


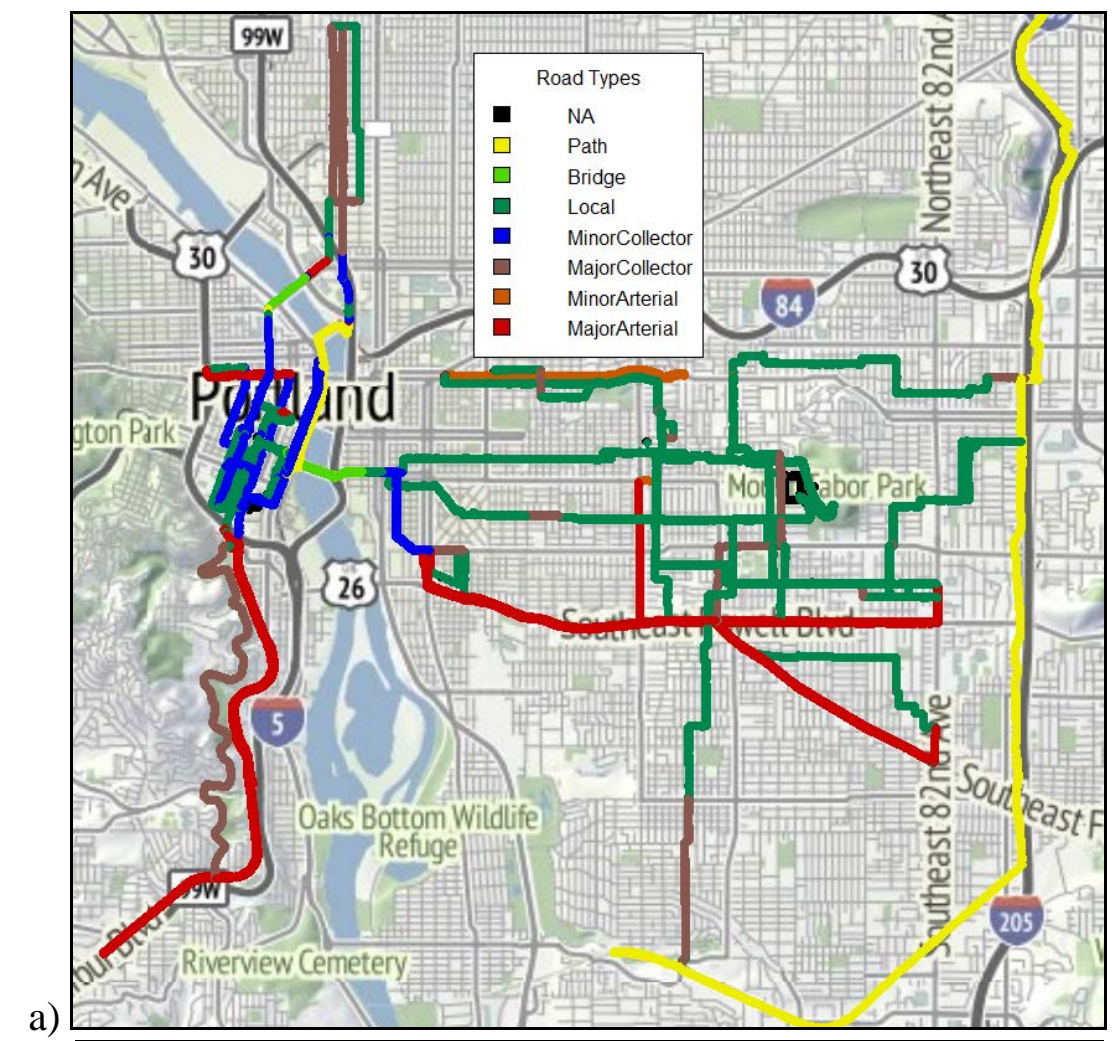

a)

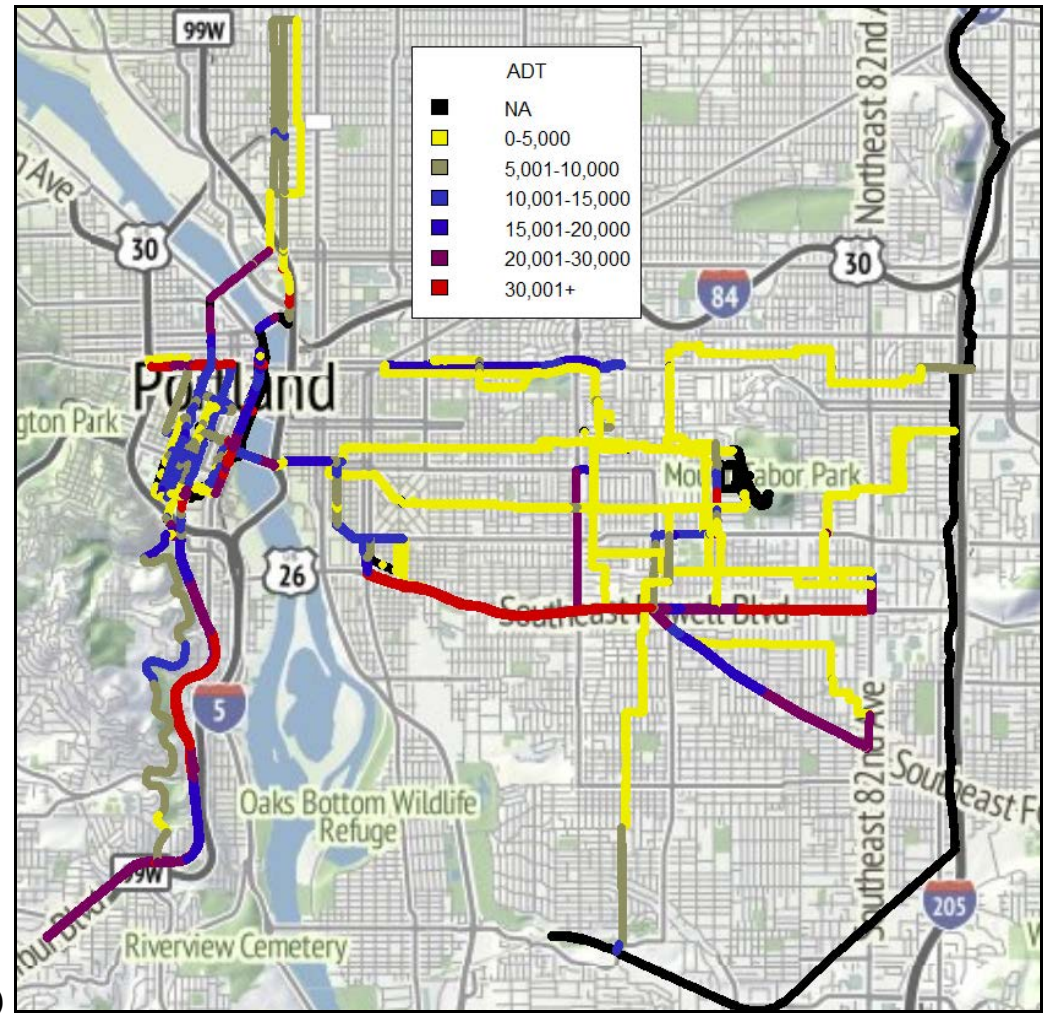

Figure 6. Associated road-type classification (a) and ADT (b) for all location data points (background image from OpenStreetMap) 


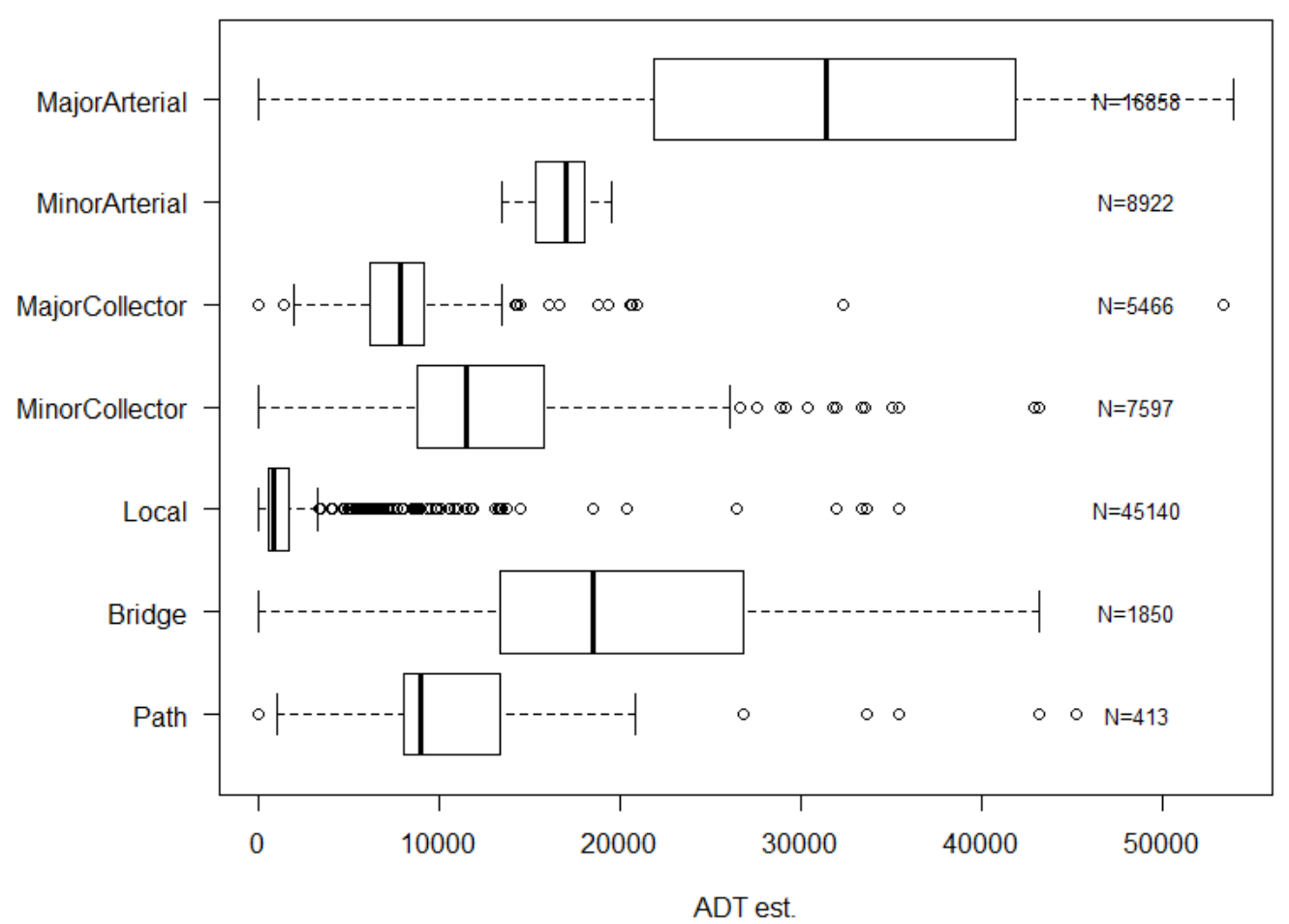

Figure 7. Comparis on of ADT and road type for matched-link location data

To identify crossings of larger roads during travel on paths and local streets, points were identified that had a road-type classification of "Local" or "Path" and had an initial proximity match (single-nearest link before the discontinuity and manual corrections) to a TSP facility type of "Neighborhood Collector," "District Collector" or "Major Traffic." This method identified crossings because, as described above, the data points were closer to the centerline of cross-streets during crossing than the centerline of the traveled roadway ${ }^{8}$.

To capture missed crossings at repeated locations, a buffer of five meters was created around each identified crossing point and a spatial intersect performed on the set of points with road type "Local" and "Path." The intersecting points were added to the pool of crossing points. Lastly, a single point per crossing was selected as the first point in a cluster of crossing points (a cluster being the same crossing link value within a range of 30 seconds). The results of the crossing identification procedure are shown in Table 15 and Figure 8.

\footnotetext{
${ }^{8}$ At a 17 kph bicycling speed, there are 4.7 meters between one-second observations. The closest observation to the cross-street centerline (assuming complete data), would then be 0-2.4 meters, averaging 1.2 meters assuming a uniform distribution. In most situations, 1.2 meters is smaller than the lateral distance from a bicyclist to the centerline. Even a bicyclist riding in the center of the travel lane on a two-lane street with narrow three-meter lanes (i.e., "taking the lane”) would be 1.5 meters from the centerline. Still, the method is not guaranteed to capture every crossing.
} 
Table 15. Unique crossing points identified

\begin{tabular}{|l|c|c|c|}
\hline & \multicolumn{3}{|c|}{ Crossing facility } \\
\hline Travel facility & Neighborhood Collector & District Collector & Major Traffic \\
\hline Local & 141 & 10 & 52 \\
\hline Path & 22 & 2 & 25 \\
\hline
\end{tabular}

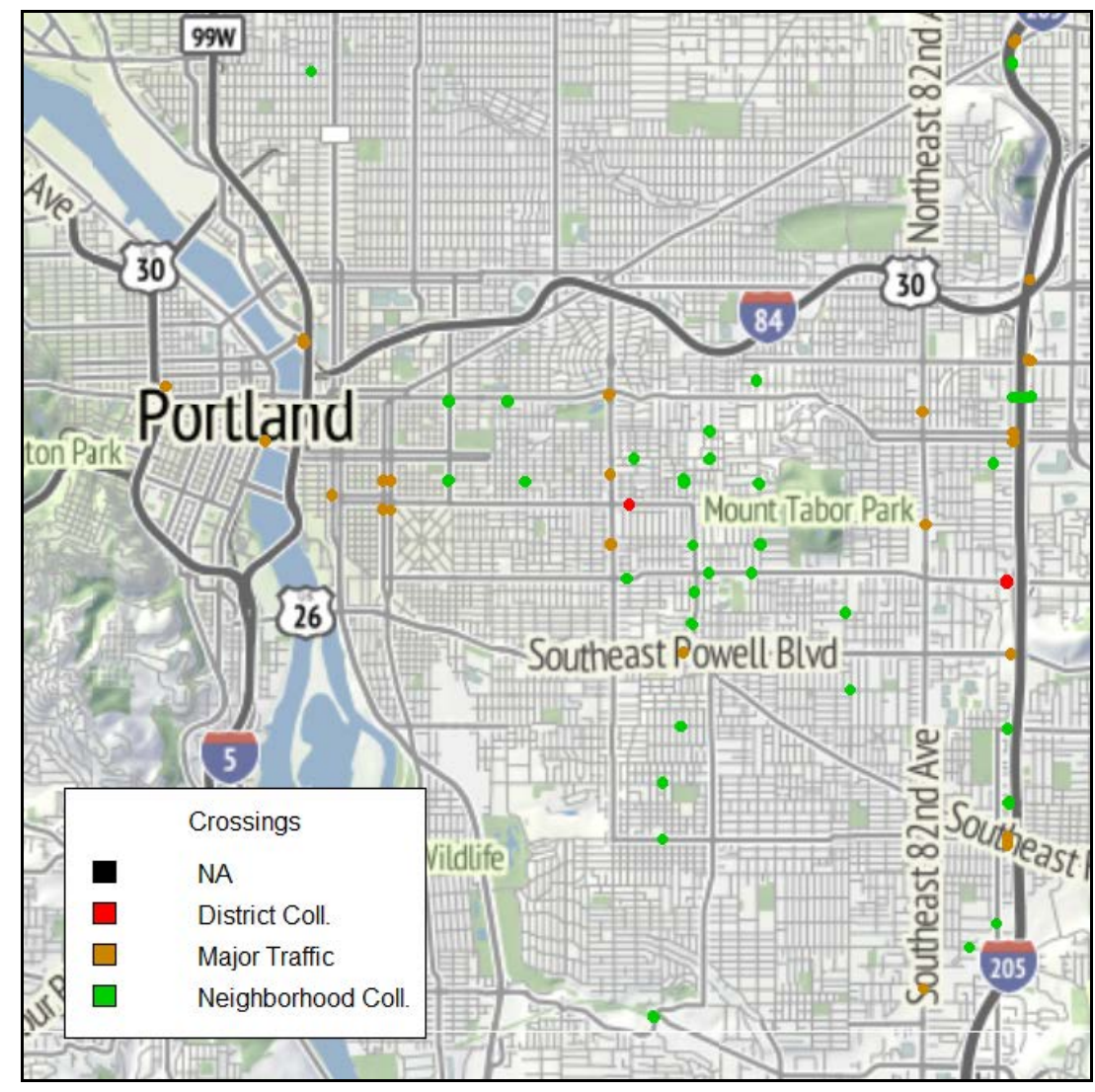

Figure 8. Identified crossings on local roads and paths (background image from OpenStreetMap)

The full data set contained many observations without location/GPS data. Missing GPS data was due to the lack of a GPS device, GPS devices without a satellite fix, or stationary GPS devices (GPS data points were only recorded when new values were present). For example, when the bicyclist was stopped at a traffic signal, the $1 \mathrm{~Hz}$ observations would have missing GPS data, even though the device was tracking location. Additionally, there was imperfect syncing between the GPS satellite time stamps and the device time clock, resulting in occasional one-second observations missing GPS data.

The processed GIS data were combined with the full data set by first integrating the values with present GPS data. GIS fields for records with missing GPS data were then completed with the most recent GIS observation, up to 300 seconds in the past. This process added road-type classifications and ADT data for 44,052 data points $(13.1 \%$ of the full data set) at 4,419 separate discontinuities. 


\subsubsection{Elevation and grade data}

Unfortunately, no GIS data set was available with high-resolution roadway grade or data. In order to calculate grade, $1 \mathrm{~Hz}$ elevation data were extracted from archived data and differentiated in two dimensions. PSU's Department of Geography maintains an online GIS data portal ${ }^{9}$ which can be queried to retrieve elevation data. For the Portland metropolitan region, one meter digital elevation maps (DEM) and digital surface maps (DSM) data are available based on LIDAR readings. An R script ${ }^{10}$ was written to construct URL queries that return DSM and DEM data from GPS data. Extracted DEM data for the data set is shown in Figure 9.

Grade of travel was calculated as $G=\frac{\Delta \text { elevation }}{\text { distance }} 100 \%$ using $1 \mathrm{~Hz}$ elevation and location data. Distance was calculated by a spatial distance function in GIS. Grade was calculated and compared based on elevation values from DEM, DSM and GPS. The GPS-based elevation data did not agree well with the DSM and DEM data sets and were not used. The DSM data were highly erratic because of features such as trees near the road, while the DEM data were smoother but followed the ground contours and missed elevated roadway structures.

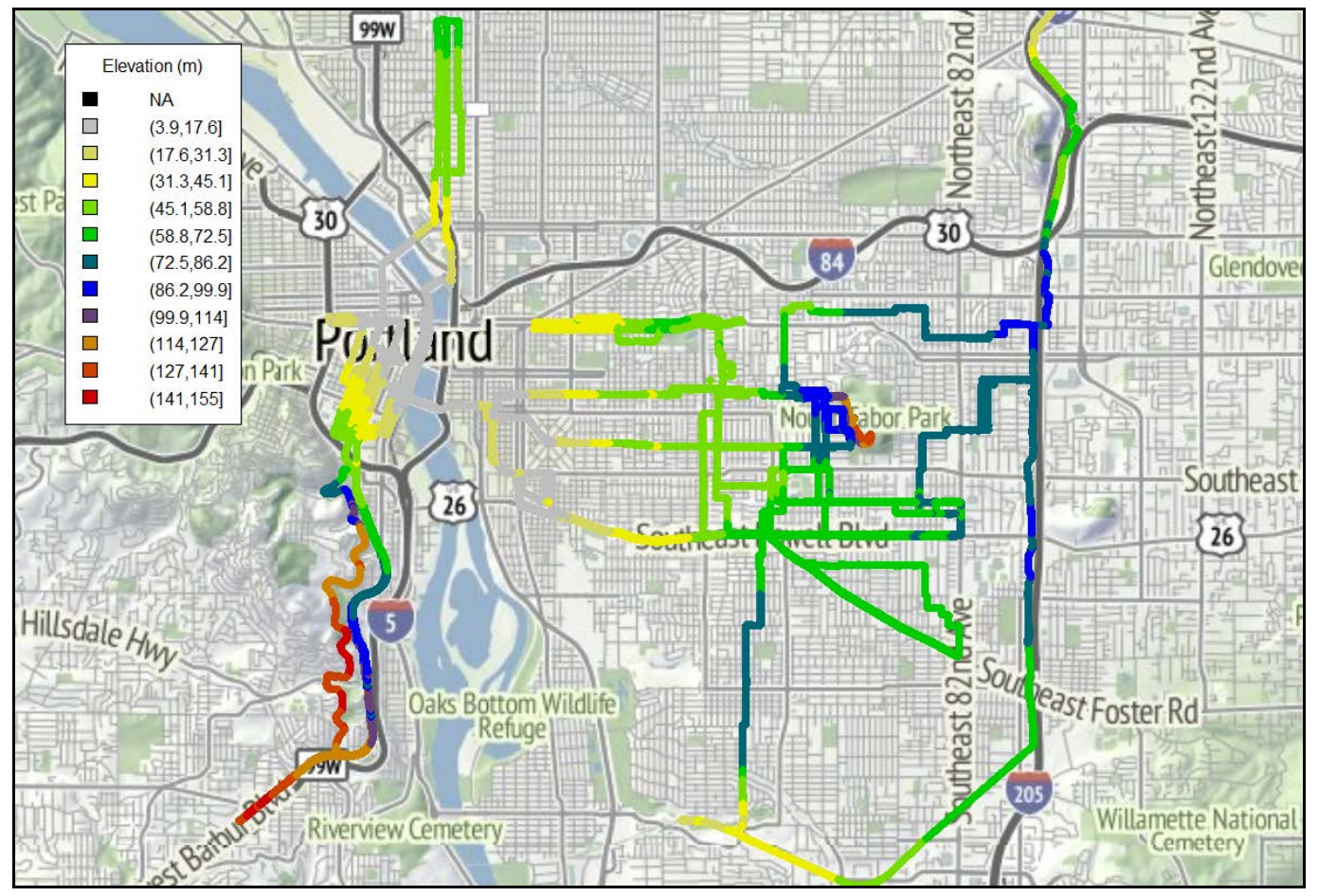

Figure 9. Elevation data from DEM (background image from OpenStreetMap)

The decision was made to use the DEM data and filter the grades for jumps which would indicate a roadway structure over a cut or a bridge transition. Grades over $25 \%$ or under -

\footnotetext{
9 http://atlas.geog.pdx.edu/

${ }^{10}$ Available on GitHub: https://github.com/abigazzi/R/blob/master/getPdxElevation.r
} 
$25 \%$ were removed ( $0.3 \%$ of grade data). In addition, a smoothing algorithm was applied to the grade data (five-second moving average). Estimated grades are mapped in Figure 10. Figure 11 shows the estimated grade versus the travel speed for one-second data. As expected, speed declines with grade; a trendline fits with $R^{2}=0.15, p<0.01$ (speed $=19.42-6,503 G$ with speed in $\mathrm{kph}$ and grade in \%).

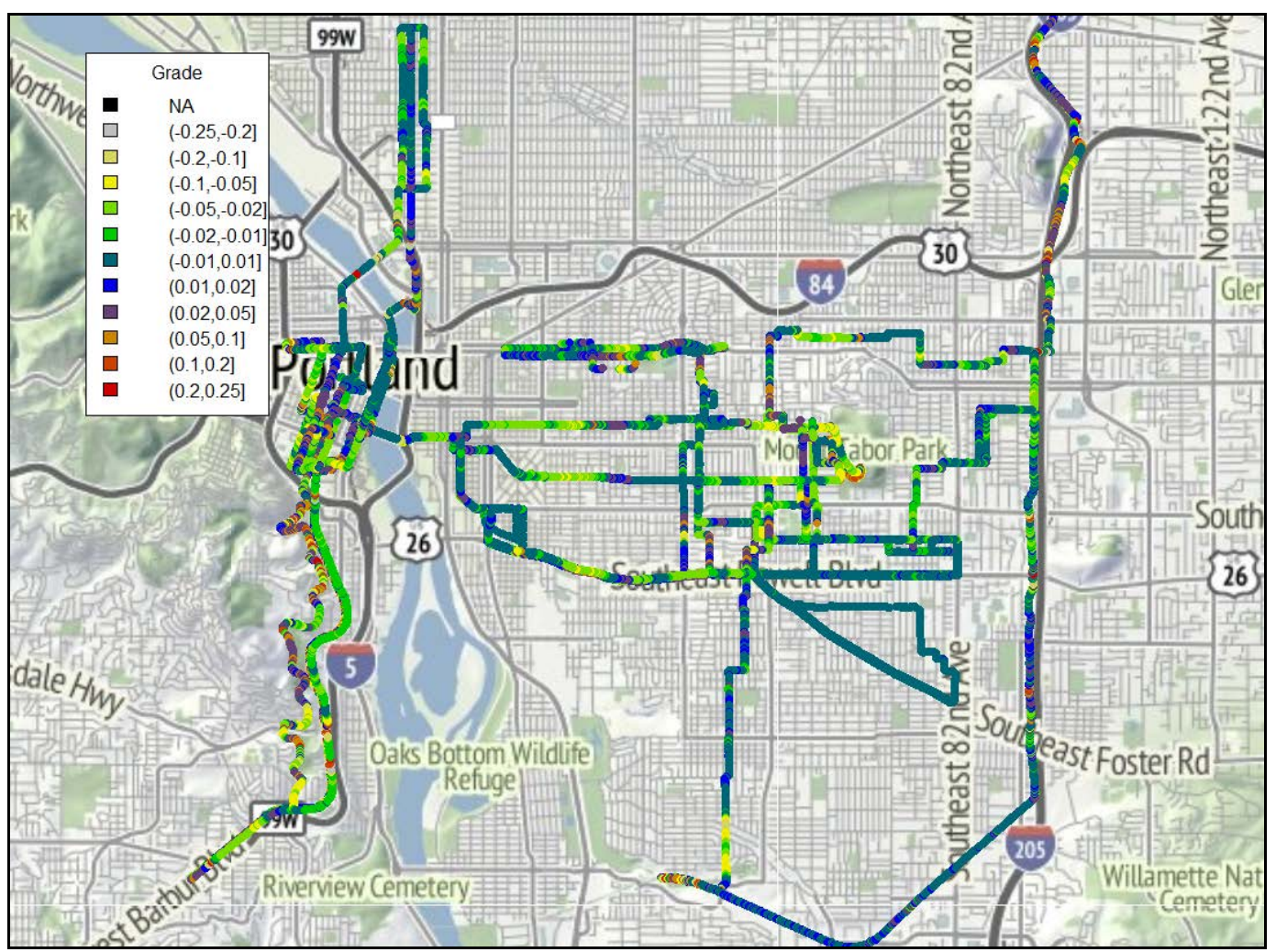

Figure 10. Estimated travel grades (background image from OpenStreetMap) 


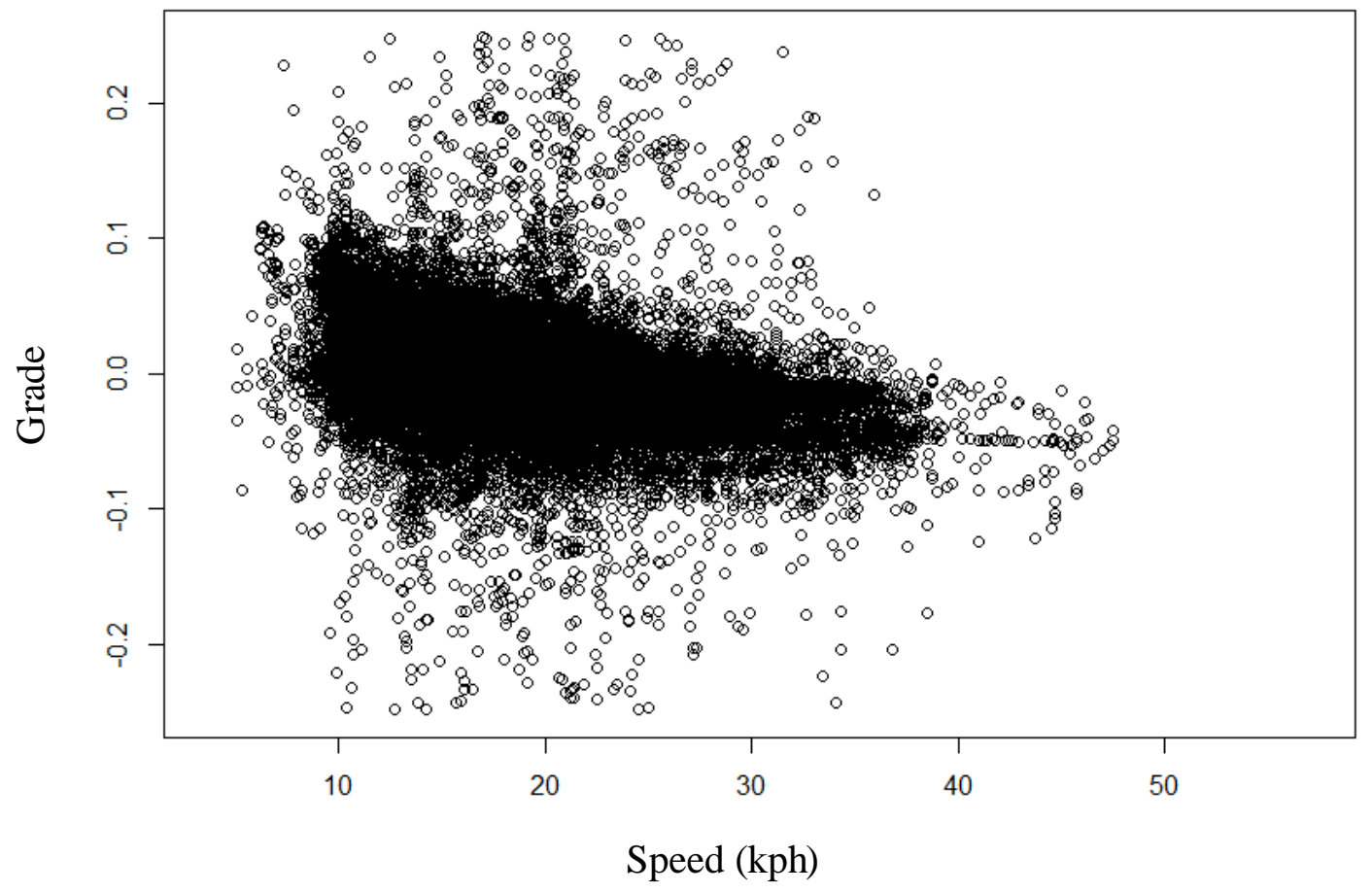

Figure 11. Estimated grade versus travel speed (one-second data) 



\subsection{DATA OVERVIEW}

\subsection{SAMPLE}

A total of 51 ambient air samples were obtained, all between 6:54 and 10:14. On-road segment durations ranged 22-38 minutes and distances ranged 5.6-8.9 kilometers. Including times without VOC samples, 51.3 hours of continuous data were collected with location information, $75 \%$ of it during travel, yielding 135,295 1-second on-road observations and a total distance of approximately 500 kilometers. Much of the modeling is performed at five-second aggregations, leading to 27,059 observations. In terms of individual fields, valid location-specific data were obtained for:

- $\quad 35.9$ hours of TVOC concentrations

- 36.0 hours of CO concentrations

- 33.8 hours of $\mathrm{PM}_{2.5}$ concentrations (at five-second intervals)

- 48.0 hours of heart rate values

The on-road conditions for the VOC sampling times are summarized in Table 16.

Table 16. Sampling conditions for 53 on-road segments by three subjects over nine days

\begin{tabular}{|c|c|c|c|c|}
\hline & Minimum & Median & Mean & Maximum \\
\hline Temperature (C) & 11.0 & 18.9 & 18.6 & 25.3 \\
\hline Relative humidity (\%) & 56.9 & 74.9 & 74.9 & 90.5 \\
\hline Wind speed $\left(\mathrm{m} \mathrm{s}^{-1}\right)$ & 0.6 & 1.6 & 1.8 & 3.6 \\
\hline Segment duration (min) & 22.0 & 25.5 & 25.9 & 38.0 \\
\hline Segment length (km) & 5.6 & 6.6 & 6.8 & 8.9 \\
\hline Mean speed - with stops $\left(\mathrm{km} \mathrm{hr}^{-1}\right)$ & 13.1 & 15.9 & 15.7 & 19.9 \\
\hline Mean speed - without stops $\left(\mathrm{km} \mathrm{hr}^{-1}\right)$ & 14.0 & 17.3 & 17.2 & 20.8 \\
\hline Heart rate $\left(\mathrm{min}^{-1}\right)$ & 58.4 & 86.7 & 87.5 & 112.9 \\
\hline Breath rate $\left(\mathrm{min}^{-1}\right)$ & 18.5 & 24.9 & 24.6 & 30.1 \\
\hline
\end{tabular}

\subsection{SUMMARY OF CONCENTRATIONS}

Table 17 summarizes the measured concentrations of 26 analytes which were above the detection limit of $0.05 \mathrm{ng} \mathrm{l}^{-1}$ in at least $50 \%$ of on-road samples. Previous measurements of bicyclist exposure to VOCs report benzene exposure concentrations ranging from 0.6 to $56 \mathrm{ng} \mathrm{l}^{-1}$ (Bigazzi and Figliozzi, 2014). The mean on-road concentrations in this study (1.67 $\left.\mathrm{ng} \mathrm{l}^{-1}\right)$ is at the lower 
end of that range, and closest in value to the most similar study in space and time (Weichenthal et al., 2012). The on-road BTEX concentrations from this study are similar to recent roadside measurements in London (von Schneidemesser, Monks and Plass-Duelmer, 2010), though much lower than concentrations reported for occupationally exposed workers (Egeghy et al., 2003) and travelers in heavier-polluted cities (Batterman, Peng and Braun, 2002; P. Wang and Zhao, 2008; X. Wang et al., 2002; Zhao et al., 2004). The BTEX concentrations at the park reference location are similar to previously measured ambient concentrations for urban areas in the U.S. (Pankow et al., 2003) and for a Canadian city (Miller et al., 2012). The on-road measured concentration from the continuous instruments is summarized in Table 18.

Table 17. Characterization of ambient concentrations (ng $\left.\mathrm{l}^{-1}\right)$ for on-road segments

\begin{tabular}{|c|c|c|c|c|}
\hline & Minimum & Median & Mean & Maximum \\
\hline trichlorofluoromethane (CFC11) & 0.45 & 0.69 & 0.72 & 1.09 \\
\hline Acetone & 1.46 & 4.52 & 4.82 & 13.40 \\
\hline methylene chloride & 0.27 & 0.65 & 0.79 & 3.49 \\
\hline methyl acetate & ND & 0.12 & 0.13 & 0.40 \\
\hline 1,1,2,-trichloro-1,2,2-trifluoroethane (CFC113) & 0.50 & 0.60 & 0.61 & 0.75 \\
\hline carbon disulfide & ND & 0.05 & 0.08 & 0.53 \\
\hline 2-butanone & 0.53 & 0.80 & 1.05 & 3.33 \\
\hline Chloroform & 0.07 & 0.13 & 0.14 & 0.48 \\
\hline carbon tetrachloride & 0.44 & 0.51 & 0.51 & 0.64 \\
\hline Benzene & 0.19 & 1.35 & 1.67 & 7.43 \\
\hline methyl methacrylate & ND & 0.16 & 0.25 & 3.79 \\
\hline 4-methyl-2-pentanone (MIBK) & ND & 0.10 & 0.11 & 0.39 \\
\hline Toluene & 0.73 & 3.20 & 4.03 & 16.91 \\
\hline 2-hexanone (MBK) & ND & 0.06 & 0.06 & 0.17 \\
\hline tetrachloroethene (PCE) & 0.07 & 0.32 & 0.37 & 1.24 \\
\hline Ethylbenzene & 0.19 & 0.71 & 0.85 & 2.86 \\
\hline$m+p$-xylene & 0.71 & 2.61 & 3.16 & 10.35 \\
\hline ethenylbenzene (styrene) & ND & 0.21 & 1.44 & 32.30 \\
\hline$o$-xylene & 0.27 & 0.93 & 1.14 & 3.78 \\
\hline$n$-propylbenzene & 0.06 & 0.18 & 0.21 & 0.71 \\
\hline 1,3,5-trimethylbenzene & 0.08 & 0.24 & 0.30 & 1.04 \\
\hline 2-ethyltoluene & 0.07 & 0.21 & 0.26 & 0.94 \\
\hline 1,2,4-trimethylbenzene & 0.26 & 0.78 & 0.98 & 3.49 \\
\hline 1-isopropyl-4-methylbenzene & ND & 0.14 & 0.16 & 0.38 \\
\hline 1,2,3-trimethylbenzene & 0.07 & 0.21 & 0.25 & 0.98 \\
\hline Naphthalene & 0.06 & 0.26 & 0.31 & 1.18 \\
\hline
\end{tabular}

$\mathrm{ND}=$ not detected 
Table 18. Characterization of continuous air quality monitoring concentrations

\begin{tabular}{l|rrrr}
\hline & minimum & median & mean & maximum \\
\hline TVOC (ppb isobutylene) & 0.0 & 6.5 & 10.8 & $1,162.2$ \\
CO (ppm) & $-1.10^{*}$ & 0.48 & 0.53 & 20.46 \\
$\mathrm{CO}_{2}(\mathrm{ppm})$ & 373 & 485 & 490 & 730 \\
$\mathrm{PM}_{0.3}(\mathrm{pt} / \mathrm{cc})$ & 8.3 & 60.6 & 74.3 & 439.4 \\
$\mathrm{PM}_{2.5}(\mathrm{pt} / \mathrm{cc})$ & 0.00 & 0.14 & 0.20 & 46.45 \\
$\mathrm{PM}_{5.0}(\mathrm{pt} / \mathrm{cc})$ & 0.00 & 0.02 & 0.03 & 1.78 \\
\hline
\end{tabular}

${ }^{*}$ Electrochemical sensors can produce negative readings due to the linear concentration/voltage assumption

\subsection{CORRELATIONS}

Correlation coefficients for the concentrations of 26 compounds are plotted in Figure 12. An asterisk $(*)$ denotes a significant correlation $(p<0.05)$. For every aromatic hydrocarbon except ethenylbenzene (styrene), concentrations are highly correlated with the concentrations of every other aromatic hydrocarbon. The concentrations of some of the ketones are also highly correlated with the concentrations of the aromatic hydrocarbons. The concentrations of the esters and some of the halocarbons are largely uncorrelated with the concentrations of any of the other compounds. A recent multimodal VOC exposure study in Belgium found similar correlations among concentrations of BTEX and related aromatic compounds (Do et al., 2014). 


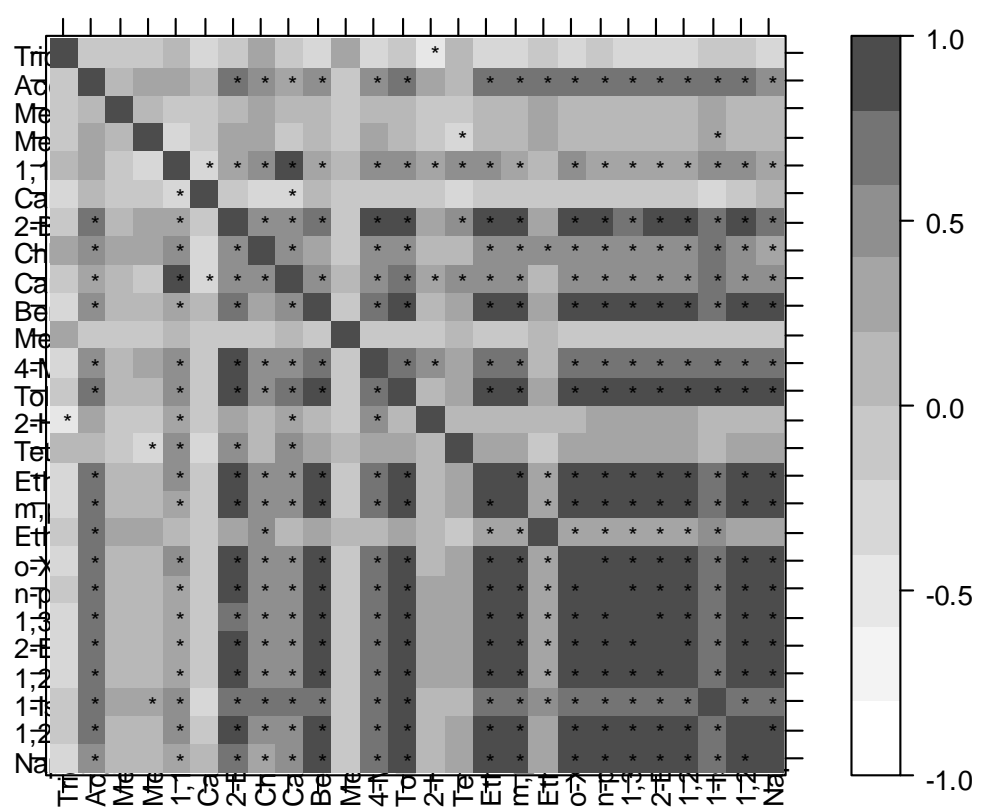

Figure 12. Correlation coefficients for ambient concentrations among 26 compounds (* indicates statistical significance at $p<0.05$ )

Table 19 presents Spearman's rank correlation coefficients for the one-second air monitoring data. The coarse particles are the least correlated with other pollutants. TVOC is positively correlated with $\mathrm{CO}$ and $\mathrm{CO}_{2}$, though the $\mathrm{PM}_{0.3}$ coefficient is negative. $\mathrm{CO}_{2}$ is positively correlated with all other pollutants (as the most general indicator of exhaust presence). 
Table 19. Spearman correlation coefficients between one-second air quality monitoring data (all significant at $p<0.05$ )

\begin{tabular}{|l|l|l|l|l|l|l|}
\hline & $\mathrm{CO}$ & $\mathrm{CO}_{2}$ & TVOC & $\mathrm{PM}_{0.3}$ & $\mathrm{PM}_{2.5}$ & $\mathrm{PM}_{5.0}$ \\
\hline $\mathrm{CO}$ & & 0.09 & 0.16 & 0.26 & -0.01 & -0.10 \\
\hline $\mathrm{CO}_{2}$ & 0.09 & & 0.27 & 0.17 & 0.11 & 0.08 \\
\hline TVOC & 0.16 & 0.27 & & -0.03 & 0.09 & 0.05 \\
\hline $\mathrm{PM}_{0.3}$ & 0.26 & 0.17 & -0.03 & & 0.30 & 0.18 \\
\hline PM $_{2.5}$ & -0.01 & 0.11 & 0.09 & 0.30 & & 0.66 \\
\hline PM $_{5.0}$ & -0.10 & 0.08 & 0.05 & 0.18 & 0.66 & \\
\hline
\end{tabular}

\subsection{CONCENTRATIONS BY LOCATION}

Figure 13 presents exposure concentrations for benzene and toluene from the park reference location and from bicycling on local roads and major arterials $(N=21,25$, and 8 , respectively; note the different vertical scales). The average ADT on the local road segments was 1,359 vehicles per day ${ }^{-1}$ while the average ADT on the major arterial segments was 30,718 vehicles per day $^{-1}$. There is a clear trend of increasing concentrations from bicycling on higher-traffic roadways, though still much overlap among the observations.
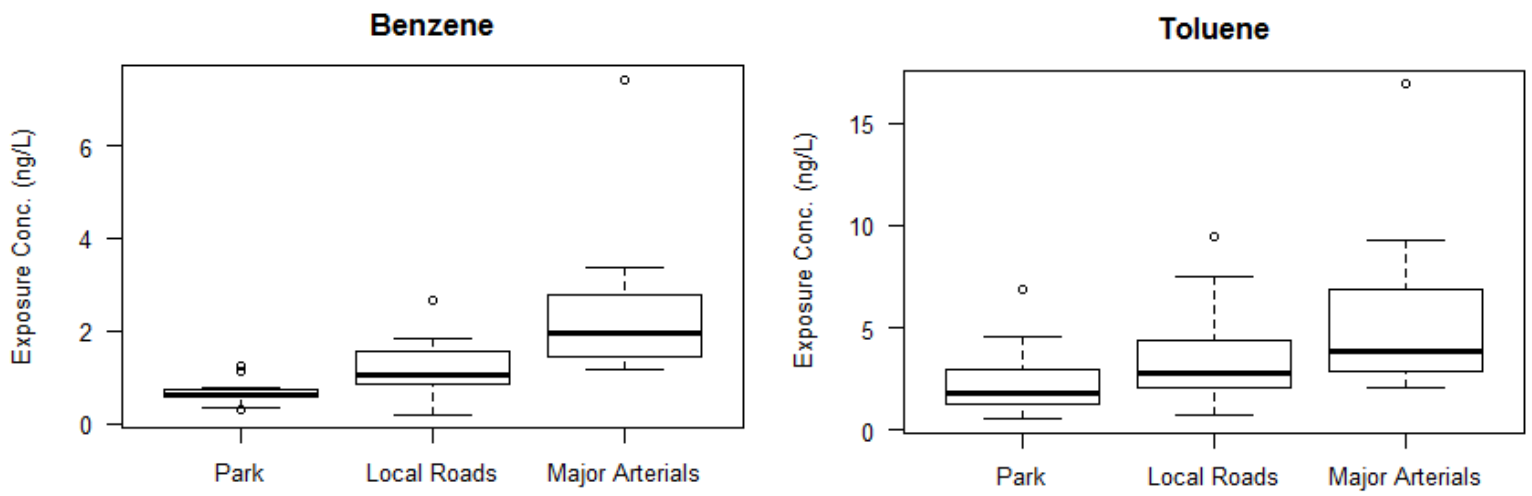

Figure 13. Exposure concentrations by location

Table 20 gives mean concentrations for riding segments on local roads and major arterials, normalized to mean concentrations measured at the park location. Bicycling on higher-traffic roadways led to higher concentrations, with the exception of styrene. Wilcoxon rank-sum tests were used to determine whether the concentrations measured on each roadway type were significantly greater than at the park. Significance levels for accepting the alternative hypothesis that on-road concentrations were greater than at the park are indicated in each cell of Table 20.

Concentrations on major arterials were, on average, 97-317\% greater than at the park location. Excepting styrene, concentrations on major arterials were 48-119\% higher than concentrations on local roads. In terms of fractional changes from the initial park location (i.e., subtracting 1 from the values in Table 20), increases in concentrations were 2.1-3.2 times greater during riding on major arterials than during riding on local roads. 
Table 20. Mean on-road concentrations, normalized to concentrations measured at the park

\begin{tabular}{|c|c|c|}
\hline \multirow{2}{*}{ Compound } & \multicolumn{2}{|c|}{ Mean concentration, normalized to the park } \\
\hline & Local roads & Major arterials \\
\hline benzene & $1.81^{* * *}$ & $3.95^{* * *}$ \\
\hline toluene & $1.51^{* * *}$ & $2.62^{* * *}$ \\
\hline ethylbenzene & $1.79^{* * *}$ & $2.77^{* * *}$ \\
\hline$m+p$-xylene & $1.79^{* * *}$ & $2.65^{* * *}$ \\
\hline ethenylbenzene (styrene) & $3.32^{* * *}$ & $1.97^{* * *}$ \\
\hline o-xylene & $1.80^{* * *}$ & $2.66^{* * *}$ \\
\hline$n$-propylbenzene & $1.86^{* * *}$ & $3.07^{* * *}$ \\
\hline 1,3,5-trimethylbenzene & $2.26^{* * *}$ & $3.99^{* * *}$ \\
\hline 2-ethyltoluene & $2.12^{* * *}$ & $3.77^{* * *}$ \\
\hline 1,2,4-trimethylbenzene & $2.33^{* * *}$ & $4.17^{* * *}$ \\
\hline 1,2,3-trimethylbenzene & $1.96^{* * *}$ & $3.68^{* * *}$ \\
\hline naphthalene & $1.38^{* *}$ & $2.27^{* * *}$ \\
\hline $\begin{array}{l}\text { Significance level of Wilcoxon } \\
\text { road than at the park: } \\
\qquad{ }^{* * *} p<0.01 \\
{ }^{* *} p<0.05 \\
{ }^{*} p<0.10\end{array}$ & ernative hypc & entrations we \\
\hline
\end{tabular}

Concentrations normalized to the park location are shown for various facility types in Figure 14 . Concentrations were lowest at the park and highest on the Springwater Path. The lowest concentrations were on the I-205 Path. The high concentrations on the Springwater Path were confirmed by the continuous on-road data. Inspection of the continuous TVOC data shows that VOC concentrations were extremely high along the Springwater Path coincident with light and medium industry in the same corridor (Figure 15). Likely VOC-emitting businesses in the corridor include metal casting and machining (Precision Castparts Corp., Metal Machinery, LLC), engine services, paint and power-coating, and other light manufacturing. This finding emphasizes the importance of near-road sources of traffic-related air pollutants. 


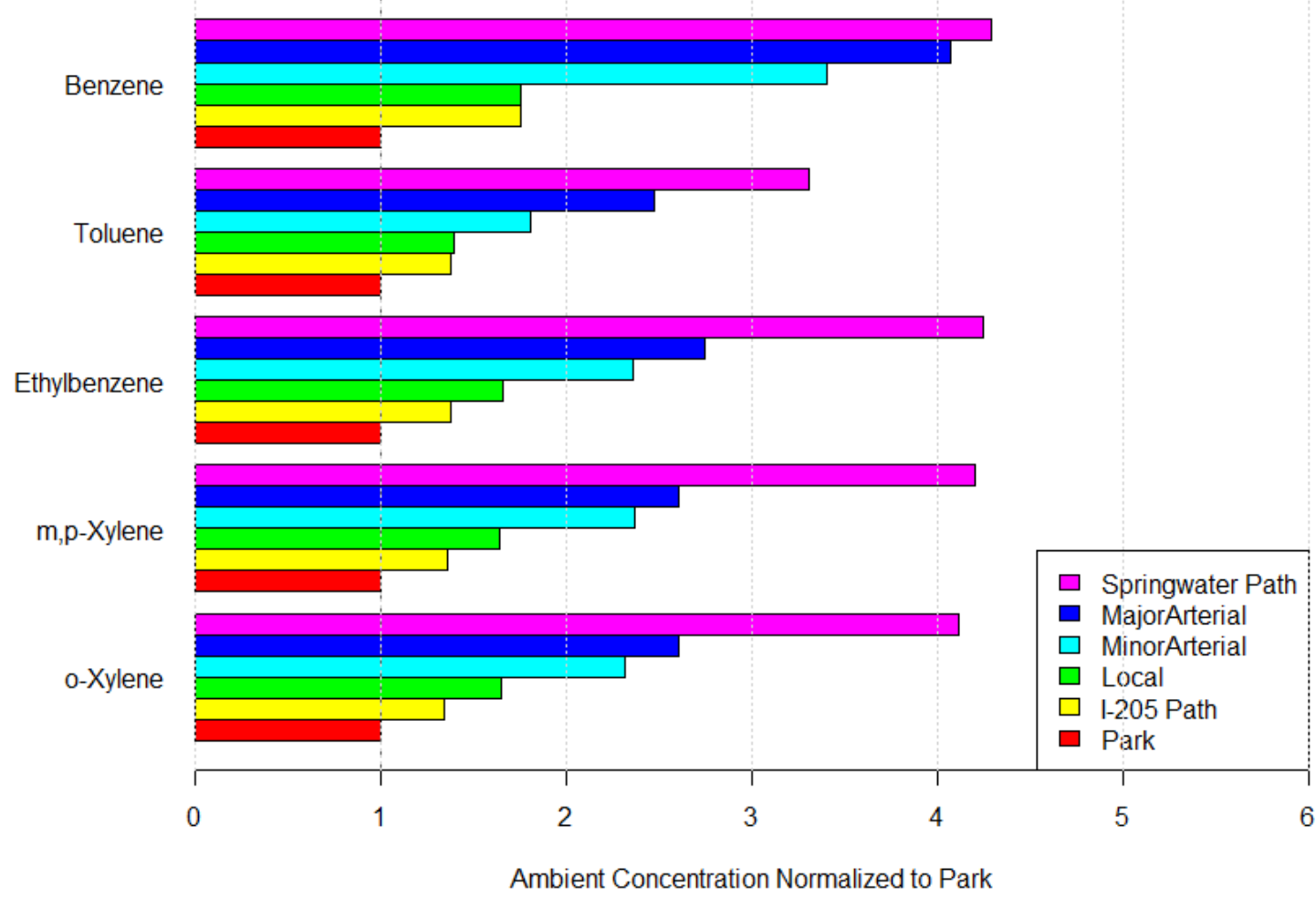

Figure 14. Average ambient concentrations by location, normalized to park location

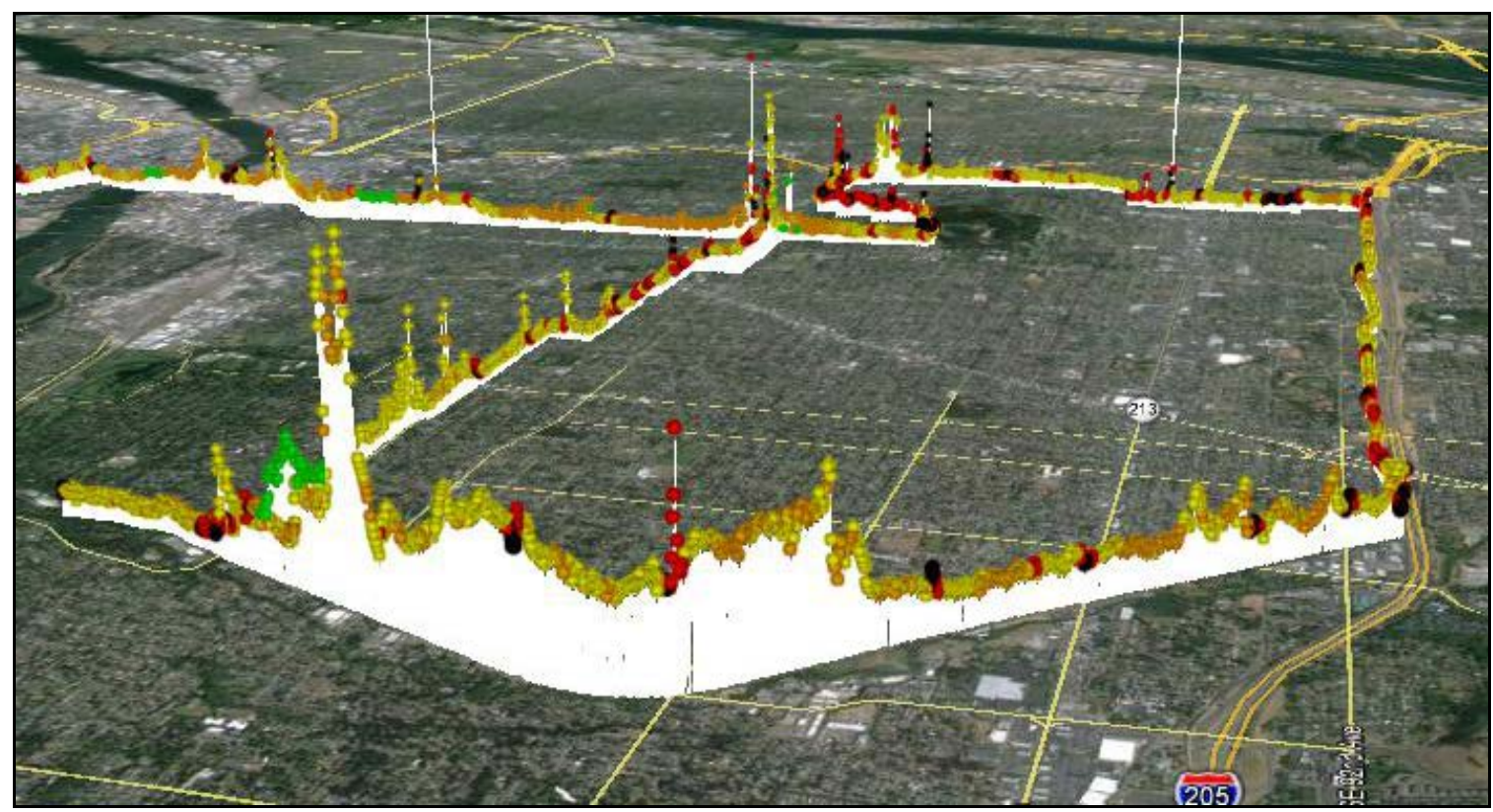

Figure 15. On-road measured TVOC concentration as pin height (travel speed as color, where from black/slow to green/fast); 2013-09-11 data collection 
Average concentrations of BTEX compounds in this study were $50-120 \%$ higher on major arterials than on local roads. This finding agrees well with past studies, which have reported bicyclist BTEX exposure differences of $58-250 \%$ in high-traffic versus low-traffic environments, including cities with higher measured on-road concentrations (see Literature Review). Similar relative effects of roadway type on exposure can be expected in urban areas with higher VOC concentrations, to the extent that motor vehicles emit a proportionate share of aromatic VOC. A higher fraction of industrial VOC sources would mitigate the influence of roadway facility type on exposure while increasing the influence of surrounding land use.

\subsection{EXPOSURE SKEW}

Figure 16 shows Lorenz curves for exposure on the different roadways. The Lorenz curve is a measure of inequality in distributions, widely used in economic analysis of income distributions. Lorenz curves show the proportion of a measured item $(Y)$ occurring in the bottom $(X)$ proportion of a population; in Figure 16, $X=$ observations and $Y=$ cumulative exposure. The degree of inequality is also indicated by the Gini index, which takes a value between 0 (perfect equality) and 1 (perfect inequality). The Gini indices are shown in Table 21, along with the minimum portion of observations that comprise $50 \%$ of total exposure.

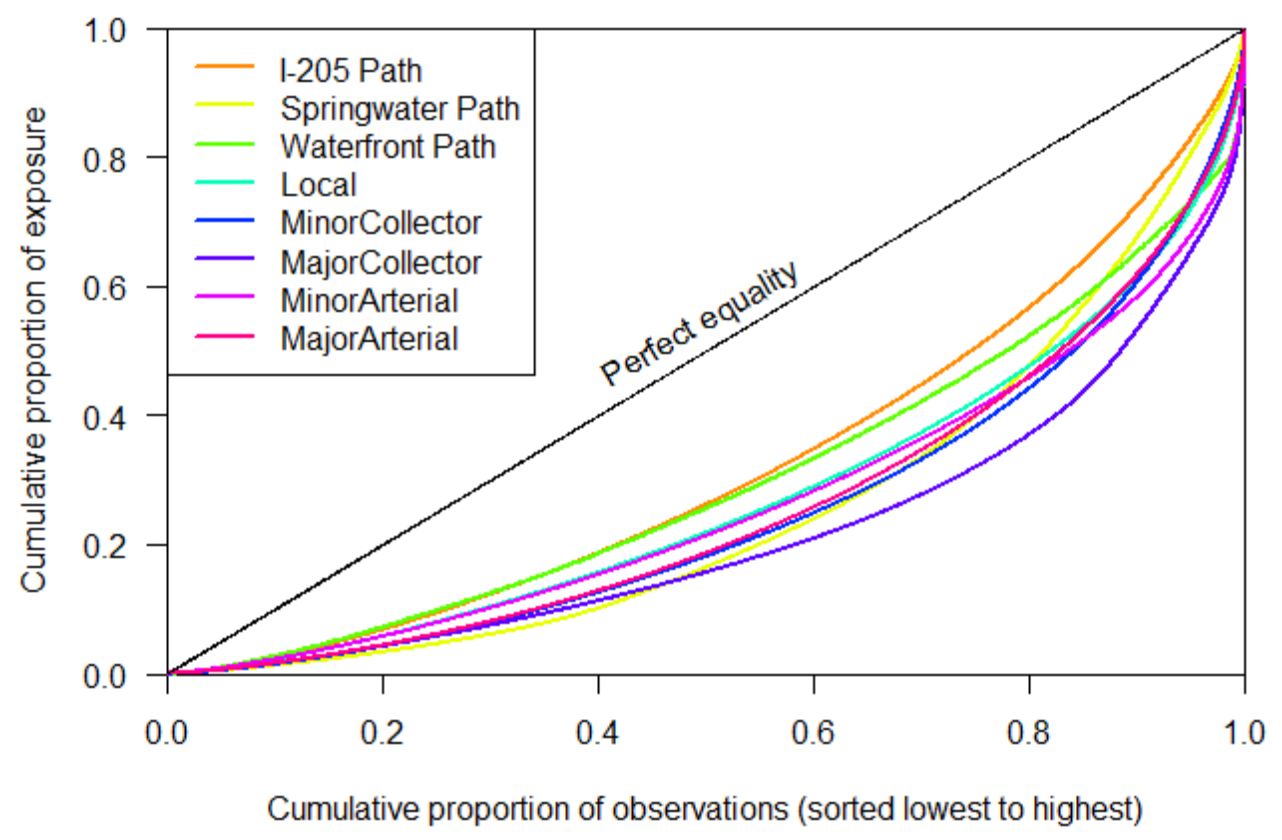

Figure 16. Lorenz curves showing exposure skew by location

Figure 16 and Table 21 show that a large portion of exposure occurred in short periods of time, especially on mixed-traffic roadways. Off-street paths had more consistent (equal) exposure, with the exception of the Springwater Path. Half of cumulative exposure occurred in the highest $12-18 \%$ of on-road observations and $19-30 \%$ of off-road observations. The higher skew on mixed-traffic facilities is likely attributable to nearby vehicle activity (passing vehicles and intersecting roadways). 
Table 21. Gini index of inequality and the minimum portion of the observations representing half of the cumulative exposure, by location

\begin{tabular}{l|rc}
\hline Location & Gini Index & \multicolumn{2}{|c}{$\begin{array}{c}\text { Minimum portion with } \\
\text { 50\% of exposure }\end{array}$} \\
\hline I205 Path & 0.36 & 0.25 \\
Springwater Path & 0.49 & 0.19 \\
Waterfront Path & 0.40 & 0.22 \\
Other Path & 0.40 & 0.23 \\
Local & 0.45 & 0.18 \\
Bridge & 0.29 & 0.30 \\
Minor Collector & 0.50 & 0.16 \\
Major Collector & 0.56 & 0.12 \\
Minor Arterial & 0.47 & 0.16 \\
Major Arterial & 0.49 & 0.17 \\
\hline
\end{tabular}

\subsection{PARALLEL PATH EFFECTS}

Some of the concentrations measurements were taken on parallel facilities with starkly different traffic volumes. In order to test the effect of minor detours on exposure, concentrations on the parallel facilities were directly compared. The four comparisons in this section show that even minor, one- to two-block detours to parallel low-volume streets can significantly reduce exposure concentrations. Representative images for all four pairs of facilities are shown in Figure 17 (screen shots from on-bicycle video data).

East Burnside Street and Southeast Ankeney Street are parallel facilities separated by one block (80 meter) with average ADT on the sampled links of 16,518 and 722, respectively. Burnside is a minor arterial classified as a District Collector in the TSP. Ankeney is a local road classified as a Local Service Traffic Street in the TSP. The facilities were ridden four times each over a distance of 2.8 kilometers on two different days during the morning peak period. Concentrations of BTEX compounds were, on average, 44-88\% higher on Burnside than Ankeney and 59\% higher for the total BTEX concentration. Other concentrations were 51\% (TVOC), 201\% (CO), and 9\% (PM 2.5$)$ higher on Burnside than Ankeney. All differences were significant based on a Wilcoxon rank sum test $(p<0.01)$. 


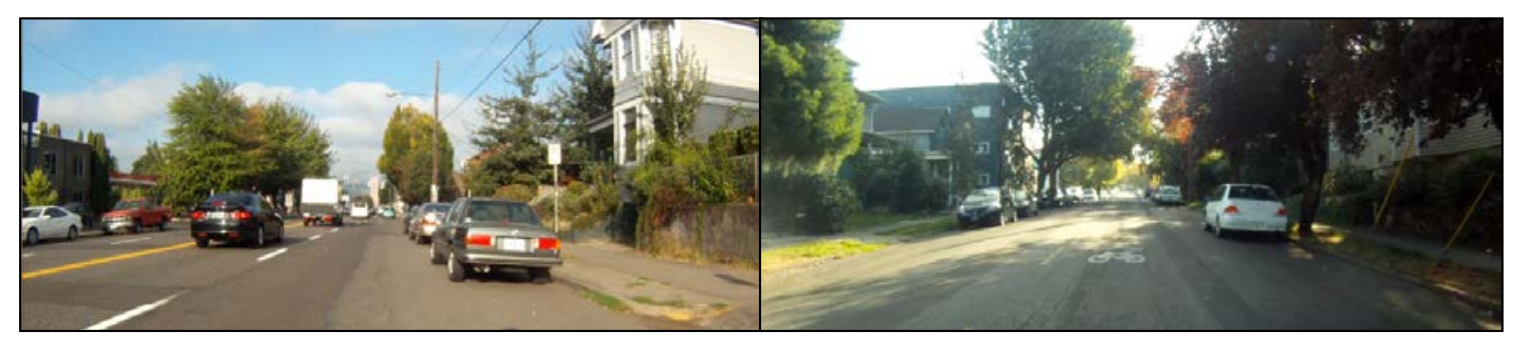

E Burnside St.

SE Ankeney St.

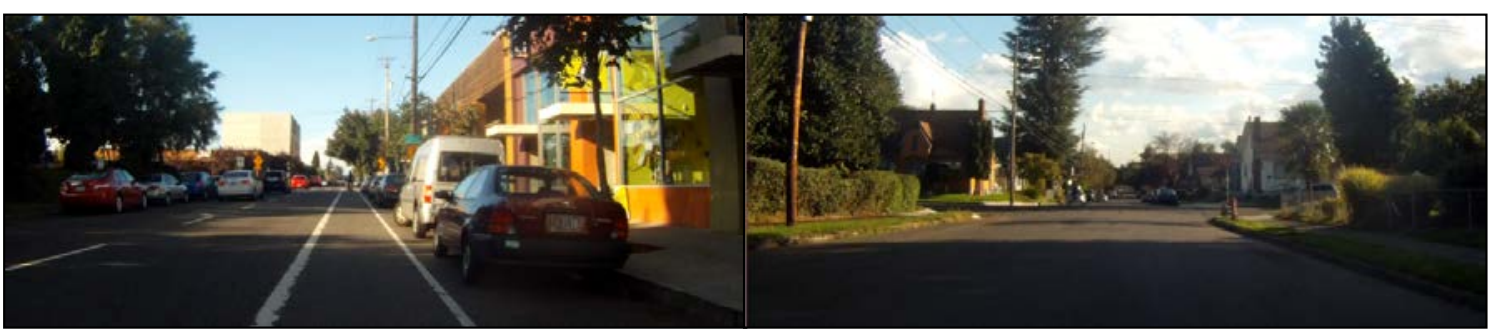

N Williams Ave.

NE Rodney Ave.

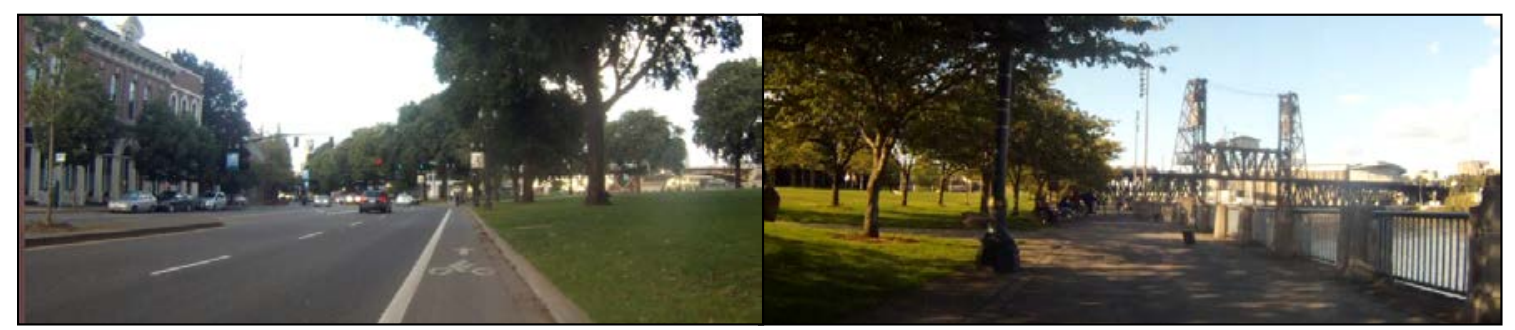

Naito Pkwy.

Riverside Path

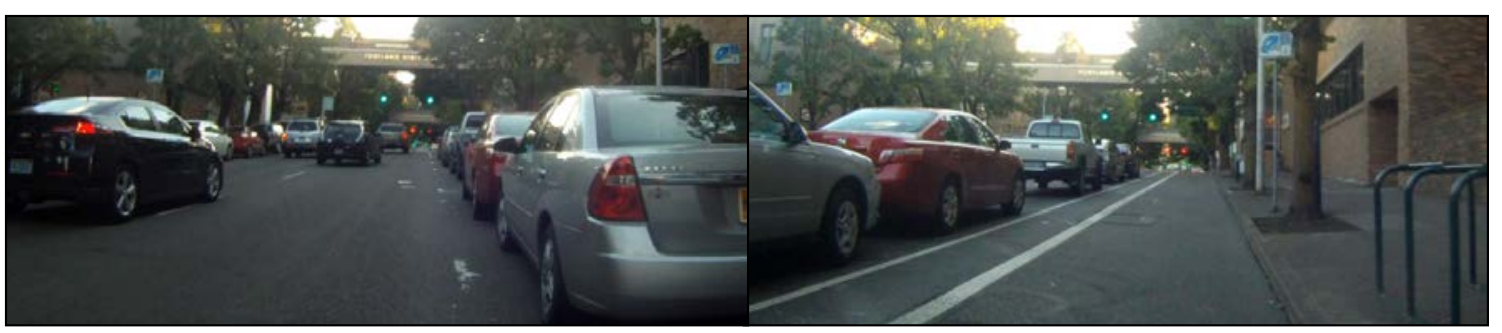

SW Broadway (on-road)

SW Broadway (cycle track)

Figure 17. Parallel facility comparisons (images from on-bicycle video data)

North Williams Avenue and Northeast Rodney Avenue are parallel facilities separated by two blocks with average ADT on the sampled links of 7,358 and 655, respectively ${ }^{19}$. Williams is major collector classified as a Neighborhood Collector in the TSP. Rodney is a local road classified as a Local Service Traffic Street in the TSP. The facilities were ridden three times. Concentrations were on average 329\% (TVOC) and 221\% (CO) higher on Williams than Rodney. The differences were significant based on a Wilcoxon rank sum test $(p<0.01)$. Video data from Williams reveal frequent interactions ("leapfrogging") with buses due to heavy traffic congestion during the data collection period.

\footnotetext{
${ }^{19} \mathrm{~N}$. Williams Ave. has undergone a recent surge in development and traffic volumes are likely higher than reported.
} 
Naito Parkway is a minor collector classified as a Traffic Access Street in the TSP. Average ADT on the sampled links was 19,092. A riverside path in Tom McCall Waterfront Park runs parallel to Naito Parkway for two kilometers, separated by $\sim 70$ meters. The segments were ridden four times. Concentrations were on average 112\% (TVOC), 30\% (CO), and 4\% ( $\mathrm{PM}_{2.5}$ ) higher on Naito than the riverside path. The differences were significant based on a Wilcoxon rank sum test $(p<0.01)$ for TVOC and CO, but not $\mathrm{PM}_{2.5}(p=0.06)$. Unlike the previous comparisons of facilities separated by buildings, the parallel path has only a few trees acting as a barrier to the traffic emissions on Naito. However, being immediately adjacent to the river, the dispersion characteristics are good.

Measurements were taken along a cycle track on Southwest Broadway between Clay Street and Southwest Jackson Street. The seven-block segment (560 meters, 2 minutes) was ridden eight times total: two times each in the cycle track and in the far right traffic lane. Average TVOC concentrations were $9.2 \%$ higher on-road than in the cycle track, though the difference was not significant based on a Wilcoxon rank sum test $(p=0.16)^{20}$. Video data from Broadway showed that vehicle volumes were relatively light during the data collection periods. For comparison, a 2011 study of UFP on the same cycle track measured 8-38\% higher concentrations on-road than in the cycle track based on six sampling periods over eight months of two to seven hours each (Kendrick et al, 2011). The results suggest that cycle tracks are useful to reduce bicyclist exposure concentrations by increasing the separation between bicyclists and motorized traffic, but that cycle tracks are not as effective as parallel paths.

These direct comparisons of exposure concentrations on parallel routes show that minor detours to nearby low-traffic facilities can dramatically reduce exposure concentrations. Hence, provision and usage of low-traffic parallel paths in residential areas is an effective way to reduce bicyclists' exposure.

${ }^{20}$ The morning segments were $46.3 \%$ higher on-road, while the afternoon segments were $10.9 \%$ lower on-road. 


\subsection{MODELING BICYCLIST EXPOSURE}

While more than 40 studies have measured bicyclist pollutant-exposure concentrations, studies including intramodal covariates are still lacking (see Literature Review). Several studies have tested the effects of specific facility types and found lower concentrations on more separated bicycle infrastructure (MacNaughton et al., 2014; Kendrick et al., 2011; Hatzopoulou, Weichenthal, Dugum et al., 2013). A few studies have also tested high-traffic versus low-traffic bicycle routes, finding significant differences in exposure (Jarjour et al., 2013; Cole-Hunter et al., 2012; Weichenthal et al., 2011). High-traffic vs. low-traffic differences are typically larger for the more strongly traffic-related pollutants such as volatile organic compounds (VOC), ultrafine particles (UFP), carbon monoxide (CO), and black carbon particulate matter (BC) (see Literature Review above). But bicyclist exposure research frequently fails to find significant associations between more specific traffic variables and exposure - especially if the traffic variables include all vehicle types and not specifically heavy vehicles (Hatzopoulou, Weichenthal, Dugum et al., 2013; Boogaard, et al. 2009; Kaur and Nieuwenhuijsen, 2009; H. S. Adams, Nieuwenhuijsen and Colvile, 2001). Due to the lack of quantified traffic-exposure relationships, transportation professionals are unable to easily estimate expected exposure reductions when assessing bicyclist routes.

The objective of the models presented here is to model bicyclist exposure concentrations on a wide range of facilities using roadway, traffic and weather variables, with the primary intent of quantifying the impact of $\mathrm{ADT}$ on exposure to VOC, $\mathrm{CO}$ and $\mathrm{PM}_{2.5}$ (fine particulate matter). The literature on travelers' exposure to traffic-related air pollution suggests the potential explanatory variables in Table 22. Many of the variables in Table 22 are unavailable for the present analysis. Also, some available variables are correlated with other variables in the data set. For example, the number of lanes is related to facility type and ADT, and background concentrations are dependent to weather variables. 
Table 22. Potential explanatory variables for modeling exposure

\begin{tabular}{|c|c|c|c|c|c|}
\hline Category & Role & $\begin{array}{l}\text { Explanatory } \\
\text { element }\end{array}$ & Example variables & $\begin{array}{l}\text { Expected } \\
\text { size of } \\
\text { influence }\end{array}$ & $\begin{array}{l}\text { Availability } \\
\text { of data }\end{array}$ \\
\hline Traffic & Emissions & Vehicle volume & $\begin{array}{l}\text { Passing vehicles, } \\
\text { hourly traffic counts, } \\
\text { ADT, facility as proxy }\end{array}$ & High & $\begin{array}{l}\text { Low to } \\
\text { High }\end{array}$ \\
\hline Traffic & $\begin{array}{l}\text { Emissions \& } \\
\text { dispersion }\end{array}$ & Vehicle type & $\begin{array}{l}\text { Classification of } \\
\text { vehicle volume data }\end{array}$ & High & Low-Med \\
\hline Traffic & Emissions & Fuels & $\begin{array}{l}\text { Fuel composition and } \\
\text { characteristics }\end{array}$ & Low-Med & Low-Med \\
\hline Traffic & $\begin{array}{l}\text { Emissions \& } \\
\text { dispersion }\end{array}$ & Vehicle activity & $\begin{array}{l}\text { Speeds, queues, } \\
\text { accelerations, idling, } \\
\text { etc. }\end{array}$ & Low-Med & Med \\
\hline Weather & $\begin{array}{l}\text { Emissions \& } \\
\text { transformations }\end{array}$ & Temperature & Temperature & Med & High \\
\hline Weather & $\begin{array}{l}\text { Emissions \& } \\
\text { transformations }\end{array}$ & Humidity & Relative humidity & Low & High \\
\hline Weather & Dispersion & Wind & $\begin{array}{l}\text { Wind speed \& } \\
\text { variability }\end{array}$ & High & High \\
\hline Weather & Dispersion & $\begin{array}{l}\text { Atmospheric } \\
\text { mixing }\end{array}$ & Mixing layer height & Low-Med & Low-Med \\
\hline Land use & Emissions & $\begin{array}{l}\text { Near-road } \\
\text { industry, auto } \\
\text { services, } \\
\text { restaurants, } \\
\text { residential } \\
\text { combustion, etc. }\end{array}$ & $\begin{array}{l}\# \text { and types of } \\
\text { activities }\end{array}$ & Med-High & Low \\
\hline Land use & Dispersion & $\begin{array}{l}\text { Near-road } \\
\text { structure } \\
\text { geometry }\end{array}$ & $\begin{array}{l}\text { Building/wall height, } \\
\text { set-back }\end{array}$ & Med & Low \\
\hline Land use & Dispersion & $\begin{array}{l}\text { Near-road } \\
\text { vegetation }\end{array}$ & $\begin{array}{l}\text { Number of } \\
\text { trees/plants/shrubs, } \\
\text { size, location, foliage } \\
\text { density, type }\end{array}$ & Low & Low \\
\hline Land use & Dispersion & $\begin{array}{l}\text { Proximity to } \\
\text { other roadways }\end{array}$ & $\begin{array}{l}\text { Crossing or parallel } \\
\text { major road }\end{array}$ & Med & Med \\
\hline Geography & Dispersion & $\begin{array}{l}\text { Near-road } \\
\text { topography }\end{array}$ & $\begin{array}{l}\text { Roadway cuts, bridges, } \\
\text { land berms, hills, etc. }\end{array}$ & Med & Low \\
\hline Geography & Dispersion & $\begin{array}{l}\text { Roadway cross- } \\
\text { sectional } \\
\text { geometry }\end{array}$ & $\begin{array}{l}\text { \# of lanes, lanes } \\
\text { widths, location of } \\
\text { bicyclists }\end{array}$ & Low-Med & Med \\
\hline Geography & Emissions & Road grade & $\%$ grade & Med & Med \\
\hline Background & $\begin{array}{l}\text { Emissions, } \\
\text { transformations, } \\
\text { \& dispersion }\end{array}$ & $\begin{array}{l}\text { Combined } \\
\text { effects of other } \\
\text { region-scale } \\
\text { events and } \\
\text { processes }\end{array}$ & $\begin{array}{l}\text { Measured ambient } \\
\text { concentration }\end{array}$ & Med & Med \\
\hline
\end{tabular}

The measured explanatory variables tested in this analysis are shown in Table 24. As described above, five-second BTEX exposure concentrations are calculated by disaggregating the segmentlevel BTEX concentrations using the 1-Hz TVOC measurements, then aggregating up to five 
seconds. Aggregation was performed using the mode for dummy variables and mean for continuous variables. Traffic, ADT, and grade variables were set at zero when sampling on an off-street path. Grade is the absolute value of the roadway grade in the direction of travel. LogAdt is the natural log-transformed ADT. StopEnRoute is a dummy variable for when the data collection bicycle was stopped during the course of a ride because of traffic signals, stop signs, traffic congestion, etc. (for up to 120 seconds). StartupEnRoute is a dummy variable for the first 10 seconds after a StopEnRoute event. LowSpeed is an indicator of sustained low-speed bicycling (0-12 kph, exclusive). NearCrossing is a dummy variable for when the data collection bicycle was on a local road and within 25 meters of a major road crossing. Crossing Proximity is the distance to a major road crossing. Traffic Speed, Traffic Volume, and Traffic Density are real-time traffic variables from the DWR sensors.

Table 23. Measured explanatory variables

\begin{tabular}{|c|c|c|c|}
\hline Category & Explanatory element & Variable & Units \\
\hline Traffic & Vehicle volume & Coincident ADT, facility type & Vehicles/day, NA \\
\hline Traffic & $\begin{array}{l}\text { Vehicle activity } \\
\text { (congestion) }\end{array}$ & $\begin{array}{l}\text { Traffic volume, density, and minimum } \\
\text { speed at two reference locations on } \\
\text { Powell Blvd. }\end{array}$ & $\begin{array}{l}\text { vphpl, veh/ln-mi, } \\
\text { kph }\end{array}$ \\
\hline Traffic & $\begin{array}{l}\text { Vehicle activity } \\
\text { (congestion) }\end{array}$ & $\begin{array}{l}\text { Bicyclist is traveling at a sustained low } \\
\text { speed ( } 0-12 \mathrm{kph} \text {, exclusive, based on } \\
\text { modeling below) }\end{array}$ & $0 / 1$ \\
\hline Traffic & $\begin{array}{l}\text { Vehicle activity } \\
\text { (idle) }\end{array}$ & $\begin{array}{l}\text { Bicyclists is stopped en route - } \\
\text { presumably at a traffic signal (for up to } \\
120 \text { seconds) }\end{array}$ & $0 / 1$ \\
\hline Traffic & $\begin{array}{l}\text { Vehicle activity } \\
\text { (acceleration) }\end{array}$ & $\begin{array}{l}\text { Bicyclist is in the first } 10 \text { seconds after a } \\
\text { stop en route }\end{array}$ & $0 / 1$ \\
\hline Weather & Temperature & On-road measured temperature & $\mathrm{C}$ \\
\hline Weather & Humidity & On-road measured temperature & $\%$ \\
\hline Weather & Wind speed & $\begin{array}{l}\text { Mean wind speed at a reference ODEQ } \\
\text { station }\end{array}$ & mps \\
\hline Land use & $\begin{array}{l}\text { Proximity to major } \\
\text { roadways }\end{array}$ & $\begin{array}{l}\text { Proximity to a major road crossing, when } \\
\text { riding on a Local Road }\end{array}$ & $\mathrm{m}$ \\
\hline Land use & $\begin{array}{l}\text { Proximity to major } \\
\text { roadways }\end{array}$ & $\begin{array}{l}\text { Bicyclist is near (within } 25 \mathrm{~m} \text { of) a major } \\
\text { road crossing, when riding on a Local } \\
\text { Road }\end{array}$ & $0 / 1$ \\
\hline Geography & Road grade & Grade, absolute grade & $\%$ \\
\hline Background & $\begin{array}{l}\text { Regional emissions, } \\
\text { transformations, and } \\
\text { dispersion }\end{array}$ & $\begin{array}{l}\text { Reference concentration at the park } \\
\text { location before each data collection } \\
\text { period }\end{array}$ & $\mathrm{ng} / \mathrm{L}$ \\
\hline
\end{tabular}

Correlations among the measured explanatory variables and exposure concentrations are shown in Figure 18 using five-second data. The real-time traffic variables are correlated amongst each other, as are weather variables. Background concentrations are positively correlated with temperature and negatively correlated with wind speed and humidity. 


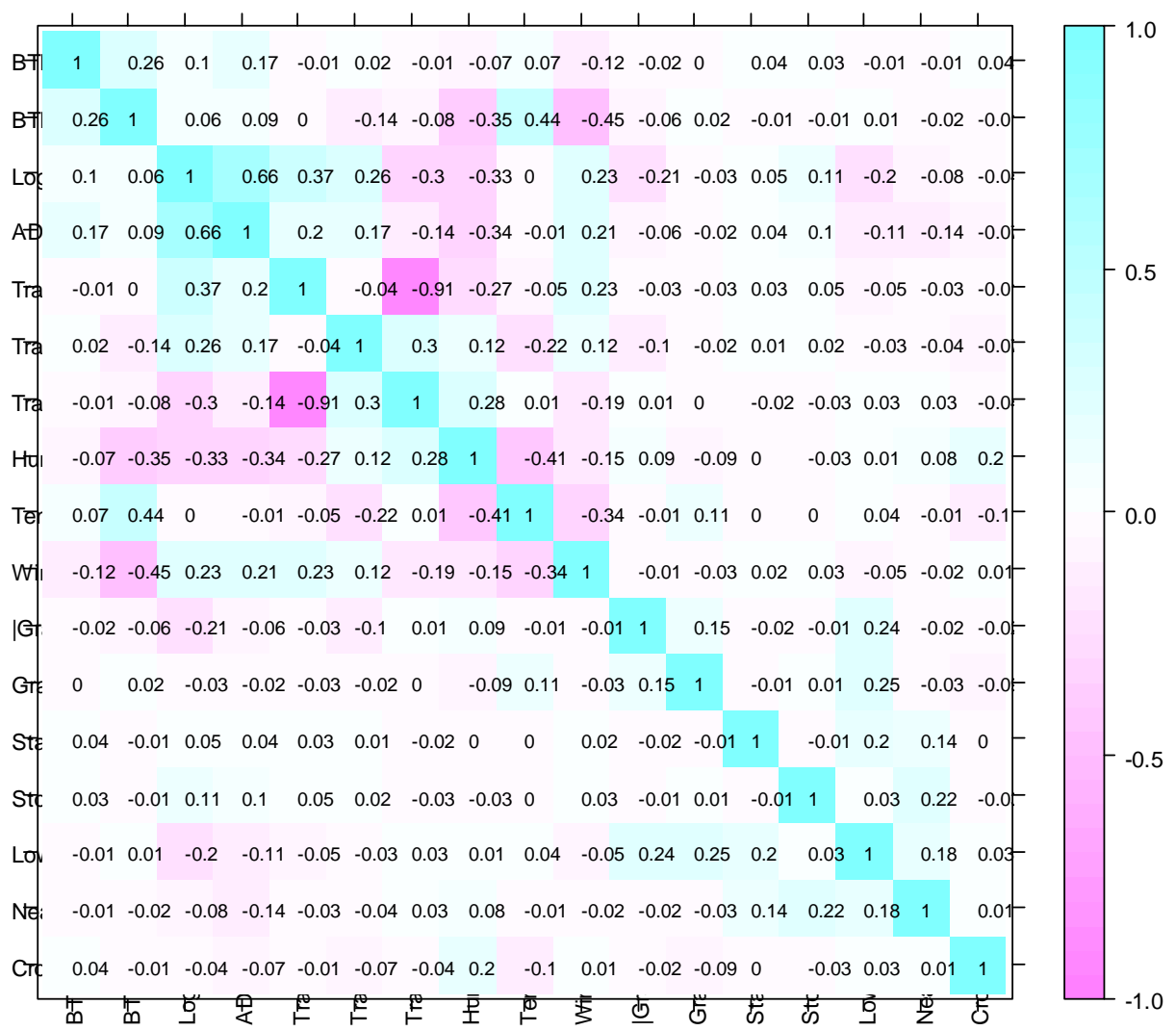

\section{Figure 18 . Correlations among five-second aggregated explanatory variables and BTEX exposure concentrations}

As shown in the Data Overview, distinctly high concentrations were observed at a location on the Springwater Path coincident with polluting near-path industry. In order to separate the nearindustry effects from the more general effects of the path in the model, observations within a geographic bound of the industrial area were identified as shown in Figure 19 (a distance of 2.5 kilometers along the Springwater Path). The subset of observations comprises 99 five-second data points $(0.74 \%$ of the dataset). 


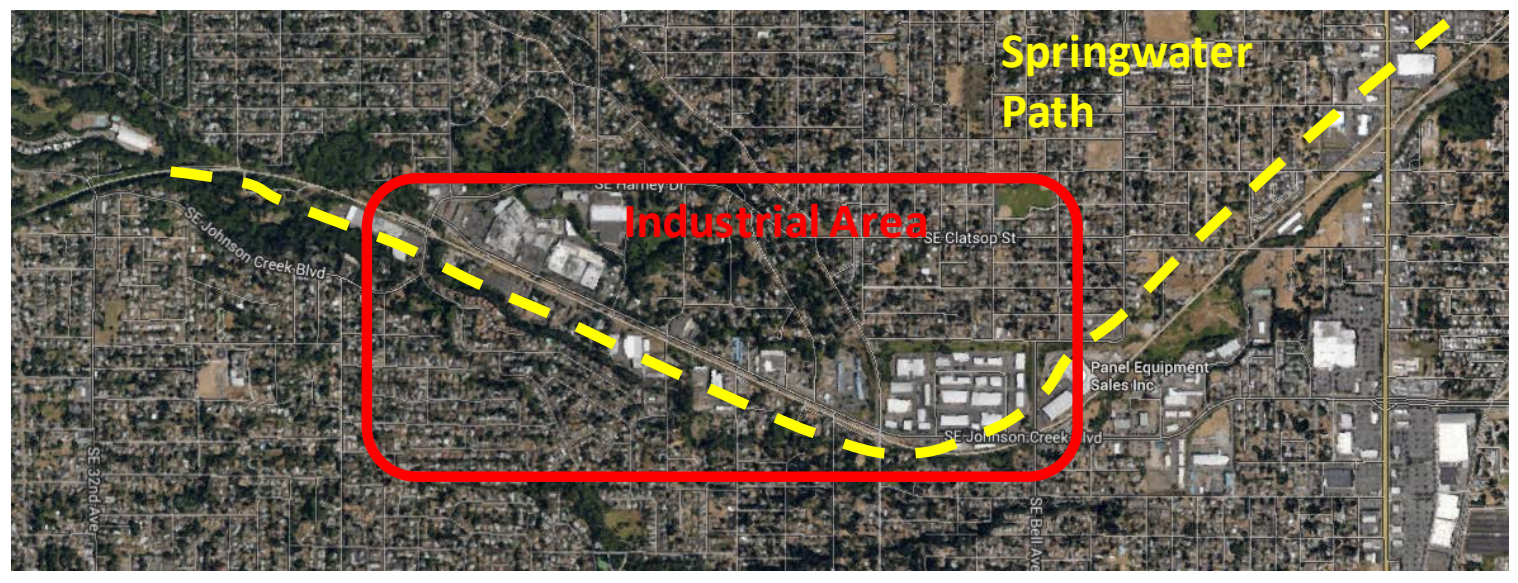

Figure 19. Industrial area along the Springwater Path

A segment-level VOC exposure model was estimated using seemingly unrelated regression (SUR) with a separate equation for each of 10 selected aromatic hydrocarbon compounds. The measured explanatory variables in Table 24 (aggregated at the segment level) were tested by stepwise addition to the model. The model specification is based on theoretical basis, statistical significance, model fit, and judgment. The preferred model was specified:

$$
\begin{aligned}
& \ln C_{i}^{e x}=\beta_{0}+\beta_{1} \ln \left(C_{i}^{b g}\right)+\beta_{2} \text { WindSpeed }_{i}+\beta_{3} \text { TrafficDensity }_{i}+ \\
& \beta_{4} \text { Springwater }_{i}+\beta_{5} \mathrm{I}_{205} \text { Path } \\
& \text { Th }_{i}+\beta_{6} \mathrm{ADT}_{i}+\varepsilon_{i}
\end{aligned}
$$

where $\varepsilon_{i}$ is an error term that is i.i.d. within an equation, but correlates across equations for the same observation $i$. TrafficDensity ${ }_{i}$ is the average concurrent traffic density (in vehicles/lanemile) at two reference locations on Powell Boulevard (set to zero if riding on an off-street path). The SUR model was estimated with $N=\mathbf{5 1 0}$ and 440 degrees of freedom (DF) for the entire system. The overall ordinary least sqaures (OLS) $\mathrm{R}^{2}$ was 0.726 and McElroy's SUR-specific $\mathrm{R}^{2}$ was 0.700. Individual equation statistics are shown in Table 24.

The estimated segment-level SUR model coefficients are shown in Table 25. Coefficients significant at $p<0.05$ are highlighted by bold text. The ADT coefficients suggest a semielasticity of 1.9-3.5\% increases in exposure per 1,000 ADT. The effect on exposure of traffic density (at the reference location) is positive while the effect of wind is negative, both as expected. Background concentrations are also significantly positive. The I-205 Path dummy variable is not significant at $p<0.05$ for four of the compounds due to the only slight increase from background concentrations and the small number of samples on that facility. 
Table 24. Fit characteristics for the SUR system of 10 equations

\begin{tabular}{|c|c|c|c|c|c|c|c|c|}
\hline & & $N$ & $D F$ & $S S R$ & MSE & RMSE & $R^{2}$ & $\begin{array}{r}\text { Adjusted } \\
R^{2}\end{array}$ \\
\hline 1 & Benzene & 51 & 44 & 3.896 & 0.089 & 0.298 & 0.837 & 0.815 \\
\hline 2 & Toluene & 51 & 44 & 7.288 & 0.166 & 0.407 & 0.689 & 0.647 \\
\hline 3 & Ethylbenzene & 51 & 44 & 6.229 & 0.142 & 0.376 & 0.693 & 0.651 \\
\hline 4 & m,p-Xylene & 51 & 44 & 7.017 & 0.159 & 0.399 & 0.651 & 0.603 \\
\hline 5 & $o$-Xylene & 51 & 44 & 6.809 & 0.155 & 0.393 & 0.659 & 0.613 \\
\hline 6 & $n$-propylbenzene & 51 & 44 & 5.111 & 0.116 & 0.341 & 0.728 & 0.690 \\
\hline 7 & 1,3,5-Trimethylbenzene & 51 & 44 & 6.136 & 0.139 & 0.373 & 0.732 & 0.696 \\
\hline 8 & 2-Ethyltoluene & 51 & 44 & 5.383 & 0.122 & 0.350 & 0.774 & 0.743 \\
\hline 9 & 1,2,4-Trimethylbenzene & 51 & 44 & 6.150 & 0.140 & 0.374 & 0.761 & 0.729 \\
\hline 10 & 1,2,3-Trimethylbenzene & 51 & 44 & 6.547 & 0.149 & 0.386 & 0.707 & 0.667 \\
\hline
\end{tabular}

Table 25. Estimated segment-level SUR model coefficients

\begin{tabular}{l|rrrrrrr}
\hline & Intercept & $\ln \left(C^{b g}\right)$ & $\begin{array}{r}\text { Wind } \\
\text { Speed }\end{array}$ & $\begin{array}{r}\text { Traffic } \\
\text { Density }\end{array}$ & Springwater & I-205 & $A D T$ \\
\hline Benzene & 0.194 & $\mathbf{0 . 8 4 9}$ & $\mathbf{- 0 . 1 7 5}$ & $\mathbf{0 . 0 2 8}$ & $\mathbf{1 . 1 7 1}$ & $\mathbf{0 . 6 2 5}$ & $\mathbf{0 . 0 3 5}$ \\
Toluene & $\mathbf{0 . 6 5 2}$ & $\mathbf{0 . 5 9 3}$ & $\mathbf{- 0 . 2 4 4}$ & $\mathbf{0 . 0 1 8}$ & $\mathbf{1 . 2 5 0}$ & $\mathbf{0 . 5 7 9}$ & $\mathbf{0 . 0 1 9}$ \\
Ethylbenzene & -0.117 & $\mathbf{0 . 5 7 7}$ & $\mathbf{- 0 . 1 8 3}$ & $\mathbf{0 . 0 2 3}$ & $\mathbf{1 . 3 9 5}$ & 0.248 & $\mathbf{0 . 0 2 2}$ \\
m,p-Xylene & $\mathbf{0 . 4 9 5}$ & $\mathbf{0 . 5 2 1}$ & $\mathbf{- 0 . 2 0 0}$ & $\mathbf{0 . 0 2 3}$ & $\mathbf{1 . 4 3 5}$ & 0.237 & $\mathbf{0 . 0 2 0}$ \\
o-Xylene & 0.013 & $\mathbf{0 . 5 4 9}$ & $\mathbf{- 0 . 1 9 4}$ & $\mathbf{0 . 0 2 3}$ & $\mathbf{1 . 4 0 9}$ & 0.247 & $\mathbf{0 . 0 1 9}$ \\
n-propylbenzene & $\mathbf{- 0 . 7 9 6}$ & $\mathbf{0 . 5 6 0}$ & $\mathbf{- 0 . 1 7 6}$ & $\mathbf{0 . 0 2 7}$ & $\mathbf{1 . 3 5 7}$ & 0.430 & $\mathbf{0 . 0 2 3}$ \\
1,3,5- & & & & & & & \\
Trimethylbenzene & $\mathbf{- 0 . 8 0 6}$ & $\mathbf{0 . 5 1 4}$ & $\mathbf{- 0 . 1 9 8}$ & $\mathbf{0 . 0 3 4}$ & $\mathbf{1 . 6 4 5}$ & $\mathbf{0 . 5 8 8}$ & $\mathbf{0 . 0 2 7}$ \\
2-Ethyltoluene & $\mathbf{- 0 . 7 1 9}$ & $\mathbf{0 . 5 9 0}$ & $\mathbf{- 0 . 1 8 1}$ & $\mathbf{0 . 0 3 4}$ & $\mathbf{1 . 4 9 7}$ & $\mathbf{0 . 6 4 2}$ & $\mathbf{0 . 0 2 7}$ \\
1,2,4- & -0.249 & $\mathbf{0 . 5 2 9}$ & $\mathbf{- 0 . 1 9 4}$ & $\mathbf{0 . 0 3 6}$ & $\mathbf{1 . 6 6 2}$ & $\mathbf{0 . 6 5 7}$ & $\mathbf{0 . 0 2 9}$ \\
Trimethylbenzene & & & & & & & $\mathbf{0 . 0 2 5}$ \\
1,2,3- & $\mathbf{- 0 . 8 6 6}$ & $\mathbf{0 . 4 9 5}$ & $\mathbf{- 0 . 2 0 0}$ & $\mathbf{0 . 0 2 8}$ & $\mathbf{1 . 4 8 6}$ & $\mathbf{0 . 5 2 2}$ & $\mathbf{0 . 0 2 5}$ \\
Trimethylbenzene & & & & & & & \\
\hline
\end{tabular}

The expected effect on exposure ${ }^{21}$ of the off-street path dummy variables is shown in Table 26. Table 27 shows the changes in SSR with the individual removal of explanatory variables from the model. The strongest explanatory variables are ADT and TrafficDensity.

\footnotetext{
${ }^{21}$ As noted above, an established estimator for the effects of dummy variables on the dependent variable in a semi$\log$ model is $\left[\exp \left(\beta-\frac{1}{2} S E_{\beta}^{2}\right)-1\right] 100 \%$, where $\beta$ is the estimated dummy variable coefficient and $S E_{\beta}$ is its standard error (Jan van Garderen and Shah 2002).
} 
Table 26. Expected effect of path dummy variables on exposure from semi-log SUR model

\begin{tabular}{l|rr}
\hline & I-205 Path & $\begin{array}{r}\text { Springwater } \\
\text { Path }\end{array}$ \\
\hline Benzene & $83.5 \%$ & $208.0 \%$ \\
Toluene & $72.3 \%$ & $219.6 \%$ \\
Ethylbenzene & $24.4 \%$ & $274.0 \%$ \\
m,p-Xylene & $22.7 \%$ & $285.7 \%$ \\
$o$-Xylene & $24.0 \%$ & $276.8 \%$ \\
$n$-propylbenzene & $50.2 \%$ & $265.1 \%$ \\
1,3,5-Trimethylbenzene & $75.0 \%$ & $380.8 \%$ \\
2-Ethyltoluene & $85.3 \%$ & $318.9 \%$ \\
1,2,4-Trimethylbenzene & $87.4 \%$ & $389.4 \%$ \\
1,2,3-Trimethylbenzene & $63.5 \%$ & $308.3 \%$ \\
\hline
\end{tabular}

Table 27. Changes in SUR model system SSR with individual removal of explanatory variables $(\triangle D F=10$ for each)

\begin{tabular}{|c|c|c|c|}
\hline & $\overline{S S R}$ & Change in SSR & $D F$ \\
\hline - & 60.56 & - & 440 \\
\hline $\ln C^{b g}$ & 85.53 & 24.97 & 450 \\
\hline WindSpeed & 70.92 & 10.36 & 450 \\
\hline TrafficDensity & 89.39 & 28.83 & 450 \\
\hline Springwater Path & 79.88 & 19.32 & 450 \\
\hline I-205 Path & 66.89 & 6.33 & 450 \\
\hline ADT & 92.37 & 31.81 & 450 \\
\hline
\end{tabular}

The correlation of residuals among equations is shown in Figure 20. The high correlations support the use of a SUR specification, which is more efficient than individual OLS under crosscorrelated errors. Figure 21 shows model residuals from all 10 SUR equations. Serial correlation in the residuals was checked by regressing $\varepsilon_{i}$ on $\varepsilon_{i-1}$ for each equation using OLS. Significant serial correlation of the residuals was not found: $\mathrm{p}$-values for the lagged residual term were over 0.05 for all 10 equations ( $R^{2}$ ranged from 0.029 to 0.057$)$. 


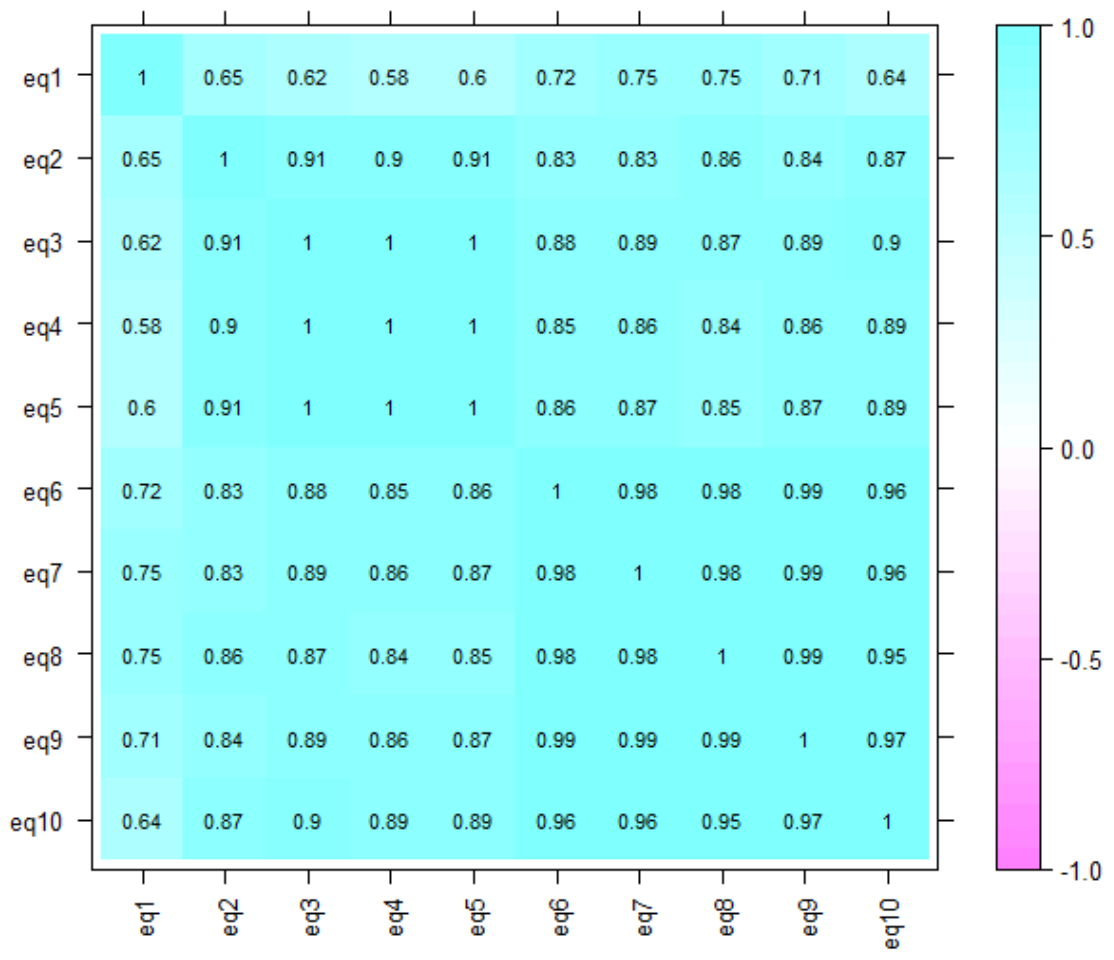

Figure 20. Correlation coefficients of residuals among 10 SUR model equations 


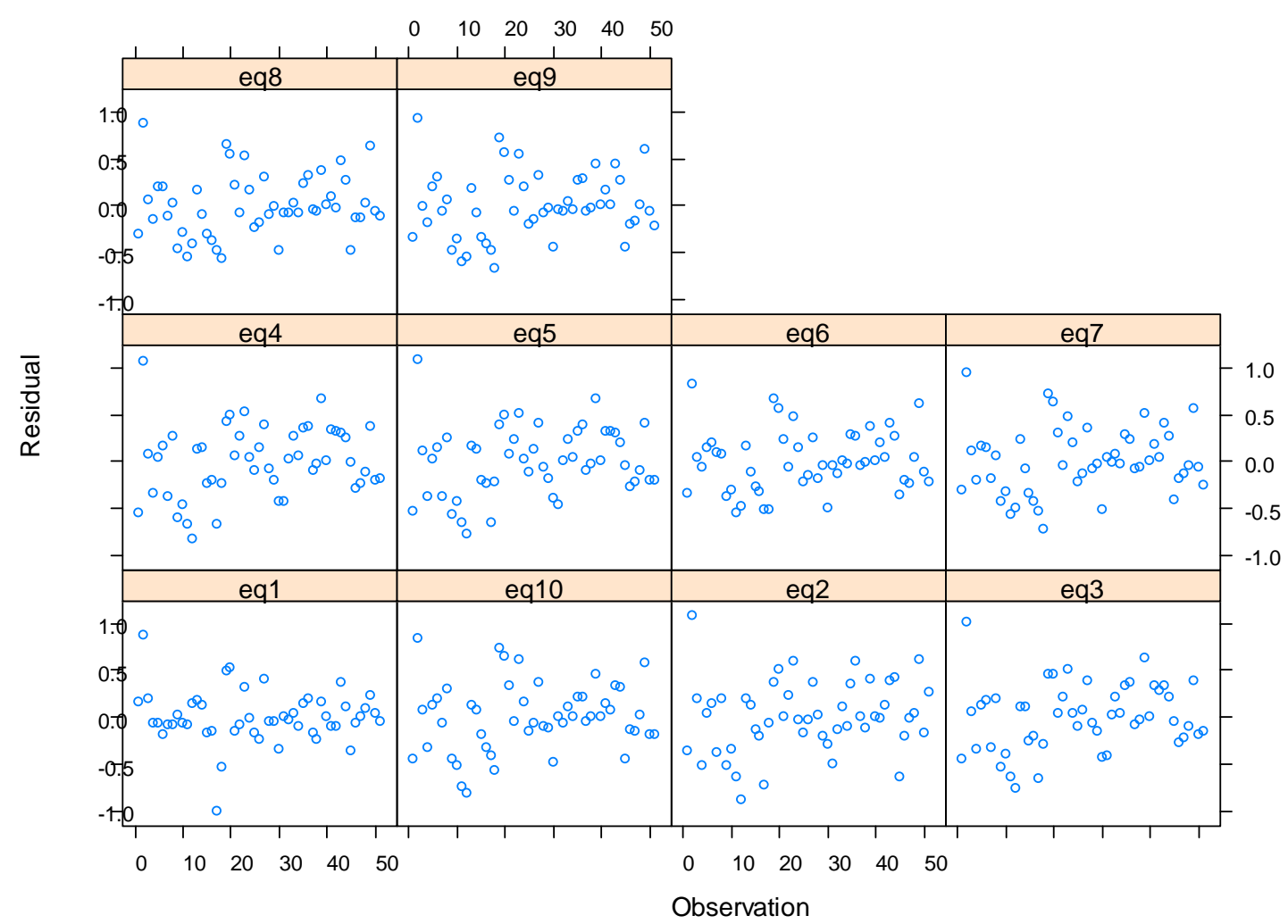

Figure 21. Residuals from 10 SUR model equations

Endogeneity in the background/reference concentration term $\left(\beta_{1}\right)$ was checked by regressing $\varepsilon_{i}$ on $\ln \left(C_{i}^{b g}\right)$ for each equation using OLS. Significant endogeneity was not found: p-values for the background concentration term were over 0.05 for all 10 equations ( $R^{2}$ ranged from $<0.001$ to 0.035).

Heteroscedasticity by facility type was checked by regressing $\varepsilon_{i}^{2}$ on RoadType $e_{i}$ for each equation. RoadType for $_{i}$ the segment-level data is a seven-level factor variable describing the predominant facility type for segment $i$, with the levels Park, I-205 Path, Springwater Path, Local Roads, Minor Arterials, Major Arterials, and Mixed Roadway Types. Significant heteroscedasticity by facility was not found: p-values for F-tests on the RoadType factor variable (change in $D F=6$ ) were over 0.05 for all 10 equations ( $R^{2}$ ranged from 0.058 to 0.143 ).

An alternative specification that applies a natural log transformation to ADT has poorer statistical fit: OLS $R^{2}=0.685$, McElroy $R^{2}=0.625$, $S S R=69.69$. The coefficients on the $\ln (A D T)$ term range from 0.0703 to 0.1055 (all $p<0.01$ ). The coefficient on the TrafficDensity dummy variable is no longer significant in any of the equations at $p<0.05$, while the other coefficients are essentially unchanged. The estimated $\ln (A D T)$ coefficients indicate BTEX exposure elasticity to ADT of 0.076 to 0.106 , slightly smaller than the high-resolution BTEX model (0.128). The segment-level elasticities align with the semi-elasticities in the preferred 
model (1.9-3.5\% per 1,000 ADT, from Table 25) at ADT of 3,000 to 4,000, which would be expected on smaller collector roadways ${ }^{22}$.

Another method to represent the non-linearity of the ADT effect is through a squared term. Adding a term for $A D T^{2}$ (again with $A D T$ in units of 1,000 vehicles per day) to the preferred SUR model described above leads to significant negative coefficients on the $A D T^{2}$ term for four of the 10 compounds at $p<0.05$. The negative coefficients indicate that the marginal effect of increasing $A D T$ tends to diminish on larger roadways (with a maximum effect around 20,000$30,000 \mathrm{ADT}$ ). The non-ADT coefficients are largely unchanged. The SSR falls to 55.54 and the OLS $R^{2}$ increases to 0.749 , but a likelihood ratio test does not reject the restricted (preferred) model at $p<0.05$. Table 28 shows the estimated $A D T$-related coefficients for alternative specifications of the ADT terms in the SUR model (all other variables are specified as in the preferred model in Table 25). ADT interaction with TrafficDensity and WindSpeed variables was tested and found to be not significant at $p<0.05$.

Table 28. Alternative specifications for ADT in the SUR model

\begin{tabular}{l|r|r|rr}
\hline & Linear & Logarithmic & \multicolumn{2}{r}{ Quadratic } \\
\hline & $A D T$ & $\ln (A D T)$ & $A D T$ & $A D T^{2}$ \\
& $(x 1,000)$ & & $(x 1,000)$ & $\left(x 1,000^{2}\right)$ \\
\hline Benzene & $\mathbf{0 . 0 3 5}$ & $\mathbf{0 . 1 0 6}$ & $\mathbf{0 . 0 6 0}$ & -0.001 \\
Toluene & $\mathbf{0 . 0 1 9}$ & $\mathbf{0 . 0 7 6}$ & $\mathbf{0 . 0 7 4}$ & $\mathbf{- 0 . 0 0 2}$ \\
Ethylbenzene & $\mathbf{0 . 0 2 2}$ & $\mathbf{0 . 0 8 5}$ & $\mathbf{0 . 0 8 0}$ & $\mathbf{- 0 . 0 0 2}$ \\
m,p-Xylene & $\mathbf{0 . 0 2 0}$ & $\mathbf{0 . 0 8 2}$ & $\mathbf{0 . 0 8 4}$ & $\mathbf{- 0 . 0 0 2}$ \\
o-Xylene & $\mathbf{0 . 0 1 9}$ & $\mathbf{0 . 0 8 0}$ & $\mathbf{0 . 0 8 3}$ & $\mathbf{- 0 . 0 0 2}$ \\
n-propylbenzene & $\mathbf{0 . 0 2 3}$ & $\mathbf{0 . 0 7 0}$ & $\mathbf{0 . 0 5 1}$ & -0.001 \\
1,3,5-Trimethylbenzene & $\mathbf{0 . 0 2 7}$ & $\mathbf{0 . 0 9 3}$ & $\mathbf{0 . 0 6 6}$ & -0.001 \\
2-Ethyltoluene & $\mathbf{0 . 0 2 7}$ & $\mathbf{0 . 0 8 7}$ & $\mathbf{0 . 0 6 0}$ & -0.001 \\
1,2,4-Trimethylbenzene & $\mathbf{0 . 0 2 9}$ & $\mathbf{0 . 0 9 3}$ & $\mathbf{0 . 0 6 5}$ & -0.001 \\
1,2,3-Trimethylbenzene & $\mathbf{0 . 0 2 5}$ & $\mathbf{0 . 0 8 8}$ & $\mathbf{0 . 0 6 8}$ & -0.001 \\
\hline
\end{tabular}

An alternative specification that replaces the TrafficDensity variable with a MixedTraffic dummy variable (matching the high-resolution exposure model specification) has poorer statistical fit than the preferred specification (McElroy $R^{2}=0.681$ ). The estimated MixedTraffic coefficients are all significant $(p<0.01)$ and range from 0.356 to 0.716 .

Another alternative specification was created by replacing the ADT variable and the two facility dummy variables with a seven-factor RoadType variable ${ }^{23}$. The McElroy $R^{2}$ of the model increases slightly to 0.714 (SSR $=60.29$ ) and the RoadType factor is significant based on an Ftest $(p<0.01)$. Table 29 shows the expected effects of each facility type on exposure (referenced to the Park location), calculated from the estimated coefficients and standard errors from the SUR model including the RoadType factor variable (and controlling for background,

22 Elasticity/Semi-elasticity (per ADT) = Equivalence ADT

${ }^{23}$ Levels: Park, I-205 Path, Springwater Path, Local Road, Minor Arterial, Major Arterial, and Mixed Roadway Types 
wind, and traffic density at the reference location). Significant coefficients at $p<0.05$ are indicated in bold text. The facility type effects are in line with expectations from averages described in the Data Overview.

Table 29. Expected effects of facility types on exposure from semi-log SUR model

\begin{tabular}{l|rrrrrr}
\hline & $\begin{array}{r}\text { Springwater } \\
\text { Path }\end{array}$ & $\begin{array}{r}\text { I-205 } \\
\text { Path }\end{array}$ & $\begin{array}{r}\text { Local } \\
\text { Roads }\end{array}$ & $\begin{array}{r}\text { Mixed } \\
\text { Roadways }\end{array}$ & $\begin{array}{r}\text { Minor } \\
\text { Arterials }\end{array}$ & $\begin{array}{r}\text { Major } \\
\text { Arterials }\end{array}$ \\
\hline Benzene & $\mathbf{1 8 6 \%}$ & $30 \%$ & $\mathbf{6 3 \%}$ & $\mathbf{1 4 5 \%}$ & $\mathbf{1 8 8 \%}$ & $\mathbf{3 5 5 \%}$ \\
Toluene & $\mathbf{2 0 2 \%}$ & $39 \%$ & $27 \%$ & $\mathbf{1 4 2 \%}$ & $\mathbf{9 8 \%}$ & $\mathbf{1 2 2 \%}$ \\
Ethylbenzene & $\mathbf{2 4 8 \%}$ & $-5 \%$ & $\mathbf{4 3 \%}$ & $\mathbf{1 1 5 \%}$ & $\mathbf{1 4 4 \%}$ & $\mathbf{1 5 9 \%}$ \\
m,p-Xylene & $\mathbf{2 6 0 \%}$ & $-5 \%$ & $\mathbf{4 2 \%}$ & $\mathbf{1 1 6 \%}$ & $\mathbf{1 4 8 \%}$ & $\mathbf{1 4 3 \%}$ \\
o-Xylene & $\mathbf{2 4 9 \%}$ & $-6 \%$ & $\mathbf{4 2 \%}$ & $\mathbf{1 1 4 \%}$ & $\mathbf{1 4 4 \%}$ & $\mathbf{1 3 7 \%}$ \\
n-propylbenzene & $\mathbf{2 3 3 \%}$ & $7 \%$ & $\mathbf{5 7 \%}$ & $\mathbf{1 2 6 \%}$ & $\mathbf{1 3 0 \%}$ & $\mathbf{2 1 3 \%}$ \\
1,3,5-Trimethylbenzene & $\mathbf{3 3 2 \%}$ & $16 \%$ & $\mathbf{7 9 \%}$ & $\mathbf{1 6 7 \%}$ & $\mathbf{1 9 2 \%}$ & $\mathbf{2 9 6 \%}$ \\
2-Ethyltoluene & $\mathbf{2 7 5 \%}$ & $21 \%$ & $\mathbf{7 6 \%}$ & $\mathbf{1 7 1 \%}$ & $\mathbf{1 7 4 \%}$ & $\mathbf{2 9 2 \%}$ \\
1,2,4-Trimethylbenzene & $\mathbf{3 4 2 \%}$ & $23 \%$ & $\mathbf{8 8 \%}$ & $\mathbf{1 8 3 \%}$ & $\mathbf{2 0 7 \%}$ & $\mathbf{3 3 4 \%}$ \\
1,2,3-Trimethylbenzene & $\mathbf{2 7 8 \%}$ & $22 \%$ & $\mathbf{6 2 \%}$ & $\mathbf{1 4 1 \%}$ & $\mathbf{1 6 9 \%}$ & $\mathbf{2 3 7 \%}$ \\
\hline
\end{tabular}

An alternative specification was also tested with a different dependent variable of on-road minus background exposure concentrations:

$$
\begin{aligned}
& \ln \left(C_{i}^{e x}\right)-\ln \left(C_{i}^{b g}\right)=\beta_{0}+\beta_{1} \text { WindSpeed }_{i}+\beta_{2} \text { TrafficDensity }_{i}+ \\
& \beta_{3} \text { Springwater }_{i}+\beta_{4} \text { I205Path }_{i}+\beta_{5} \text { ADT }_{i}+\varepsilon_{i}
\end{aligned}
$$

The model results are shown in Table 30, again with significant coefficients at $p<0.05$ in bold text $\left(\mathrm{OLS} R^{2}=0.589\right.$, McElroy $\left.R^{2}=0.599, S S R=70.28\right)$. The Wind Speed coefficients are smaller and mostly not significant, due to the correlation between wind speed and background concentrations. The traffic-related variables are relatively unchanged, lending confidence to the estimated values in the preferred model.

Table 30. Segment-level SUR model coefficients with a differenced (exposure background) dependent variable

\begin{tabular}{l|rrrrrr}
\hline & Intercept & $\begin{array}{r}\text { Wind } \\
\text { Speed }\end{array}$ & $\begin{array}{r}\text { Traffic } \\
\text { Density }\end{array}$ & $\begin{array}{r}\text { Springwater } \\
\text { Path }\end{array}$ & $\begin{array}{r}\text { I-205 } \\
\text { Path }\end{array}$ & $\begin{array}{r}\text { ADT } \\
(x 1,000)\end{array}$ \\
\hline Benzene & 0.232 & $\mathbf{- 0 . 1 5 8}$ & $\mathbf{0 . 0 2 9}$ & $\mathbf{1 . 1 1 5}$ & $\mathbf{0 . 6 5 8}$ & $\mathbf{0 . 0 3 6}$ \\
Toluene & 0.169 & -0.130 & $\mathbf{0 . 0 2 0}$ & $\mathbf{1 . 1 7 9}$ & $\mathbf{0 . 7 9 5}$ & $\mathbf{0 . 0 1 4}$ \\
Ethylbenzene & 0.044 & -0.042 & $\mathbf{0 . 0 2 2}$ & $\mathbf{1 . 2 9 1}$ & 0.291 & $\mathbf{0 . 0 1 9}$ \\
m,p-Xylene & 0.037 & -0.036 & $\mathbf{0 . 0 2 2}$ & $\mathbf{1 . 3 4 7}$ & 0.283 & $\mathbf{0 . 0 1 7}$ \\
o-Xylene & 0.053 & -0.049 & $\mathbf{0 . 0 2 3}$ & $\mathbf{1 . 3 2 2}$ & 0.298 & $\mathbf{0 . 0 1 6}$ \\
n-propylbenzene & 0.101 & -0.082 & $\mathbf{0 . 0 2 7}$ & $\mathbf{1 . 2 0 4}$ & $\mathbf{0 . 5 2 6}$ & $\mathbf{0 . 0 2 3}$ \\
1,3,5-Trimethylbenzene & 0.156 & -0.119 & $\mathbf{0 . 0 3 4}$ & $\mathbf{1 . 5 2 8}$ & $\mathbf{0 . 6 8 0}$ & $\mathbf{0 . 0 2 7}$ \\
2-Ethyltoluene & 0.103 & -0.091 & $\mathbf{0 . 0 3 4}$ & $\mathbf{1 . 3 3 7}$ & $\mathbf{0 . 7 5 7}$ & $\mathbf{0 . 0 2 6}$ \\
1,2,4-Trimethylbenzene & 0.099 & -0.085 & $\mathbf{0 . 0 3 6}$ & $\mathbf{1 . 5 0 3}$ & $\mathbf{0 . 7 6 1}$ & $\mathbf{0 . 0 2 8}$ \\
1,2,3-Trimethylbenzene & 0.073 & -0.066 & $\mathbf{0 . 0 2 9}$ & $\mathbf{1 . 3 7 9}$ & $\mathbf{0 . 7 0 0}$ & $\mathbf{0 . 0 2 2}$ \\
\hline
\end{tabular}




\subsection{CONCLUSIONS}

The concentrations reported in this report are the first VOC exposure measurements for bicyclists in the U.S., and the first quantification of VOC exposure by facility type. The exposure models presented and analyzed above show that roadway and travel variables are important determinants of VOC exposure. Weather and traffic variables explained an approximately equal amount of variance in exposure concentrations for BTEX compounds. BTEX concentrations approximately doubled on high-volume versus low-volume mixed-traffic facilities. Off-road facilities had both very high and very low exposure concentrations; high on-path exposure was coincident with near-path industrial land use.

These results have clear policy and design implications. Selecting travel routes along lowvolume facilities can dramatically decrease exposure to VOC. Route-level exposure differences can be used in both planning and routing applications (Hatzopoulou, Weichenthal, Barreau et al., 2013; Hertel et al., 2008; Sharker and Karimi, 2013). However, bicyclists traveling on off-street paths near industrial areas can have VOC exposure concentrations higher than most mixed-traffic facilities. Distance to traffic is clearly a necessary but not sufficient condition to reduce exposure to BTEX compounds. Roadway characteristics have a strong impact on bicyclists' exposure concentrations, and ADT seems to be a parsimonious approach to characterize the impact of mixed-traffic facilities on bicyclists' exposure. The quantitative estimates of the impact of ADT on exposure concentrations provide a ready tool for analysts to calculate expected differences in exposure levels among routes.

Reduction in exposure concentrations through spatial and temporal separation of bicyclists from motor-vehicle traffic can be achieved with separated bicycle facilities, low-volume routes and off-peak travel. These are potential "win-win" strategies because bicyclists already prefer lowtraffic routes and bicycle-specific facilities (Broach, Dill and Gliebe, 2012; Dill, 2009; Kang and Fricker, 2013). In a survey of Australian commuters, few active travelers changed routes because of air pollution concerns, though most were already on low-traffic routes (Badland and Duncan, 2009) $)^{24}$.

\subsection{SUMMARY OF FINDINGS}

Main findings from the literature review can be summarized as follows:

1) Existing literature focuses on modal comparisons and lacks analysis of intra-modal covariates for exposure and uptake.

2) Exposure differences on high-traffic vs. low-traffic routes vary with pollutant, from $0 \%$ for $\mathrm{PM}_{10}$ to $100 \%$ for VOC.

\footnotetext{
${ }^{24}$ Air pollution exposure during commuting was seen as a health risk by $45 \%$ of respondents, with no significant differences by mode. Air pollution was only seen as a barrier to walking and biking for $13 \%$ of respondents (much smaller than the results for infrastructure barriers).
} 
3) On-road ventilation is rarely studied with exposure; typically bicyclist ventilation rates are two to five times higher than those of motorists.

4) Uptake doses and health outcomes for bicyclists are poorly understood.

Main findings from the analysis of empirical data can be summarized as follows:

1) On-road concentrations of aromatic hydrocarbons were highly correlated among compounds.

2) Concentrations of BTEX compounds were $50-120 \%$ higher on major arterials than local roads.

3) Concentrations on off-street paths were very high in locations coincident with near-path industrial land use, and low elsewhere.

4) Significant concentration reductions were measured for minor, one-block detours to parallel low-volume facilities.

5) BTEX exposure concentrations increased 2\% per 1,000 ADT.

6) BTEX exposure concentrations increased with temperature and decreased with wind speed; on-road exposure had elasticity-to-background concentrations of 0.7 .

\subsection{SKETCH-LEVEL TABLE FOR DESIGN GUIDANCE}

This section presents summary guidance for transportation professionals to compare the expected pollution impacts of different bicycle facilities. As stated in the Introduction, this information was missing from the design guidance in Portland 2030 Bicycle Master Plan. Table 31 presents a list of basic principles about bicyclist pollution risks that would be useful for practitioners to understand. Table 32 presents summary information about the effects of different bicycle facilities on air pollution risks for bicyclists. The information in both tables was distilled from literature and the findings of this research. More information on the development of these tables can be found in Bigazzi (2014). 
Table 31. Principles about bicyclist pollution risks for transportation professionals

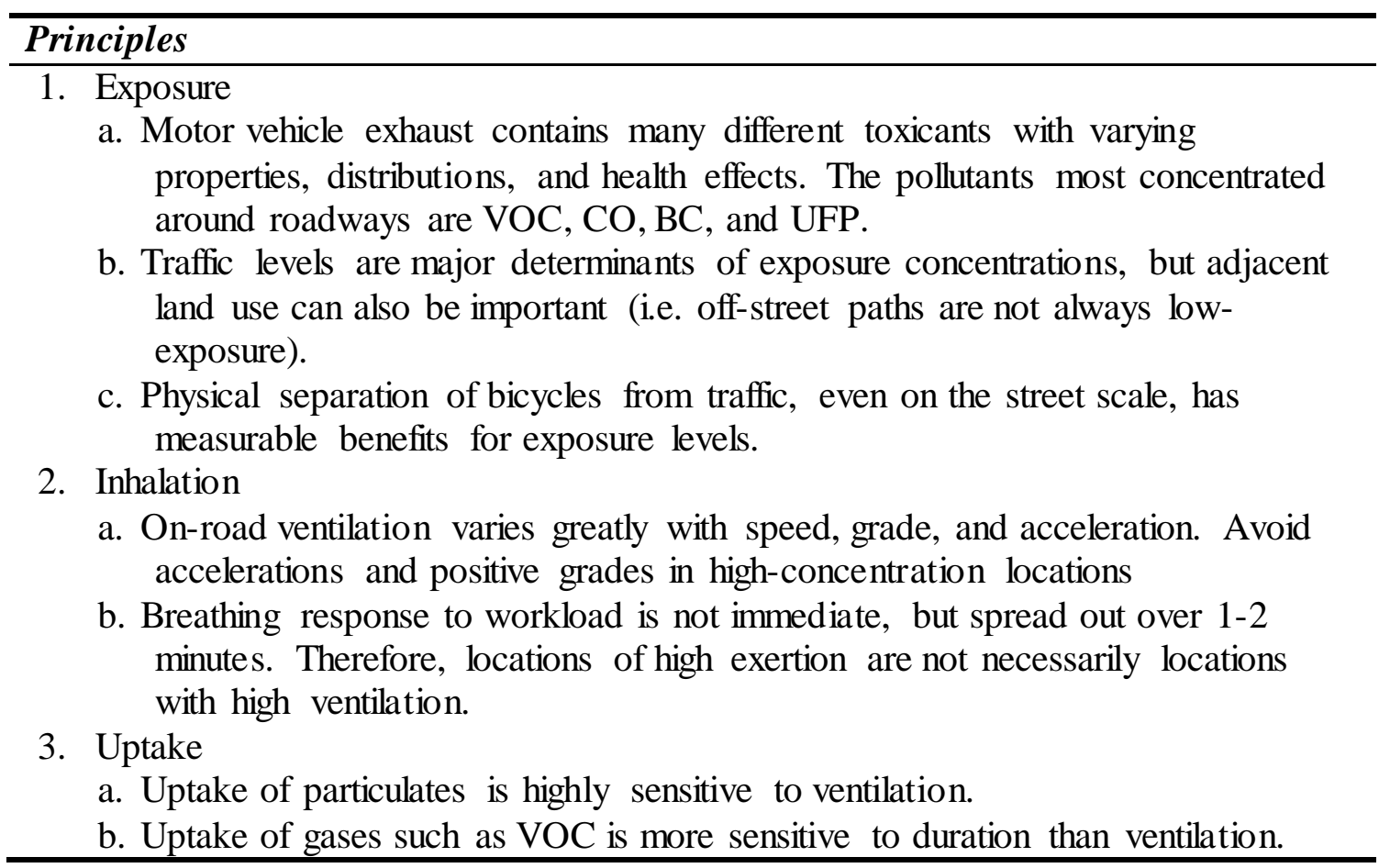


Table 32. Bikeway design considerations for air pollution risks

\begin{tabular}{|c|c|}
\hline Facility & Air Pollution Considerations \\
\hline Bike lane & $\begin{array}{l}\text { - Bike lanes on high-volume streets lead to high exposure } \\
\text { concentrations; each 10,000 ADT is associated with } \sim 20 \% \\
\text { higher BTEX exposure concentrations } \\
\text { - Provides some lateral separation, with concentration benefits } \\
\text { versus in-lane riding } \\
\text { - Dedicated right-of-way can reduce exposure duration during } \\
\text { motor-vehicle congestion (exposure concentrations are } 20-30 \% \\
\text { higher during stop-and-go riding) }\end{array}$ \\
\hline $\begin{array}{l}\text { Bike boulevard/ } \\
\text { Neighborhood } \\
\text { greenway }\end{array}$ & $\begin{array}{l}\text { - Low exposure concentrations due to low ADT (only 40\% } \\
\text { higher BTEX exposure than background) } \\
\text { - Additional exposure concentration benefits from traffic } \\
\text { calming/volume reductions } \\
\text { - Fewer stops leads to lower inhalation doses (e.g., turning stop } \\
\text { signs) }\end{array}$ \\
\hline Cycle track & $\begin{array}{l}\text { - Lateral separation reduces exposure } \\
\text { o } 8 \text {-38\% lower UFP exposure concentrations than in the } \\
\text { position of a bicycle lane (Kendrick et al., 2011) } \\
\text { o } \sim 30 \% \text { lower CO for a three-meter increased distance from } \\
\text { roadway centerline (Grange et al., 2014) } \\
\text { - Fewer stops leads to lower inhalation doses }\end{array}$ \\
\hline Off-street path & $\begin{array}{l}\text { - Generally low exposure concentrations } \\
\text { o } \sim 50-60 \% \text { higher BTEX than background for the I-205 and } \\
\text { Springwater Paths, similar to mixed-traffic facilities of 0- } \\
5,000 \text { ADT } \\
\text { o } 25 \% \text { lower BC and } \mathrm{NO}_{2} \text { than bike lanes (MacNaughton et } \\
\text { al., 2014) } \\
\text { - Nearby industrial land use can increase exposure dramatically } \\
\text { (by 300\% in a 2.5-kilometer industrial area of the Springwater } \\
\text { Path) } \\
\text { - Fewer stops leads to lower inhalation doses }\end{array}$ \\
\hline
\end{tabular}

\subsection{TRANSFERABILITY OF FINDINGS}

Some findings of the research presented in this report are context-specific, while others are more broadly applicable. Where possible, results have been compared with empirical and theoretical values in the literature to provide outside validation. As discussed in the Literature Review, exposure concentrations are highly context-specific. The measured exposure concentrations in this study agree well with recently reported near-road concentrations in the U.S., Canada and Western Europe (see Data Overview), but these concentrations will likely only be relevant for cities in developed countries with similar vehicle fleets. Extrapolation of exposure concentrations to other U.S. and Canadian cities is reasonable for perhaps a decade, and might also be possible 
for cities in other OECD countries and longer time scales. But developing-world cities will likely have vastly different exposure concentrations, as will Portland in 40 years.

The relative contribution of traffic and facility type to on-road exposure can vary by location and pollutant. A higher fraction of non-traffic (e.g., industrial) pollution sources in a city will reduce the relative importance of roadway facility type on exposure and increase the influence of surrounding land use, background concentrations and possibly weather. In much larger cities, background concentrations are likely to be higher, but traffic volumes on arterials are likely higher as well. Thus, relative exposure on "high-traffic" and "low-traffic" routes might be similar, although the absolute concentrations change. In terms of different VOCs, smaller roadway effects on exposure to alkanes and aldehydes can be expected than the effects on exposure to aromatics explored in this research (alkanes and aldehydes tend to be more disperse). $\mathrm{CO}$ and UFP are expected to be highly concentrated around roadways, whereas larger PM is more disperse.

\subsection{LIMITATIONS}

This section summarizes the main limitations of this research. Several types of secondary data which could have improved models of exposure were not readily available, including the fraction of ADT that is heavy vehicles (trucks and buses) for each link in the network, real-time traffic data on each link in the network (as opposed to static traffic data and real-time data from a single corridor), and near-road land use (including explicit data on point and area sources of air pollutants).

Other data were estimated or roughly quantified, and some uncertainty is likely due to error in these values. The link ADT data were based on interpolation from traffic counts that could have been up to 13 years old. Although a validity check showed good agreement with more recent counts, the ADT data might not have been a good indicator of traffic volumes during data collection.

Land-use regression was beyond the scope of study: exposure was modeled primarily using roadway, traffic and weather variables. The natural laboratory of Portland presented some limitations on the range of facilities which could be studied; for example, the largest arterial facility had around 40,000 ADT. Lastly, in order to prioritize environmental and travel covariates, only three healthy adult subjects participated in the research, which limited the range of physiological characteristics among the participants.

\subsection{FUTURE RESEARCH}

This section concludes with some prime topics for future research. More ubiquitous pollution exposure data would help inform bicyclist route-choice decisions and bicycle-network planning. High-precision exposure measurements are expensive, but new low-cost technologies provide low-precision alternatives which could be combined with high-precision measurements to create detailed urban on-road pollution maps. Finally, in order to compare pollution-exposure risks among toxicants and with other health effects such as crashes and physical activity, quantitative 
dose-response relationships are needed that pertain to commuting exposures. Biomarker studies have found some acute impacts of pollution exposure during commuting, and long-term epidemiology studies have quantified the expected health outcomes of changes in annual average $\mathrm{PM}_{2.5}$ and $\mathrm{PM}_{10}$ concentrations. However, researchers' current ability to translate daily commuting dose estimates into health outcomes (e.g., mortality, mobility) is severely limited. 


\subsection{REFERENCES}

Adams, H. S., M. J. Nieuwenhuijsen, and R. N. Colvile. 2001. "Determinants of Fine Particle (PM2. 5) Personal Exposure Levels in Transport Microenvironments, London, UK.” Atmospheric Environment 35 (27): 4557-66.

Adams, H. S., M. J. Nieuwenhuijsen, R. N. Colvile, M. A. S. McMullen, and P. Khandelwal. 2001. "Fine Particle (PM2. 5) Personal Exposure Levels in Transport

Microenvironments, London, UK.” Science of the Total Environment, The 279 (1-3): 2944.

Adams, H. S., M. J. Nieuwenhuijsen, R. N. Colvile, M. J. Older, and M. Kendall. 2002.

"Assessment of Road Users' Elemental Carbon Personal Exposure Levels, London, UK.” Atmospheric Environment 36 (34): 5335-42.

Adams, W. C. 1993. Measurement of Breathing Rate and Volume in Routinely Performed Daily Activities. U.S. Environmental Protection Agency. http:/hero.epa.gov/index.cfm?action=reference.details \&reference_id=77086.

Ainsworth, Barbara E., William L. Haskell, Stephen D. Herrmann, Nathanael Meckes, David R. Bassett, Catrine Tudor-Locke, Jennifer L. Greer, Jesse Vezina, Melicia C. Whitt-Glover, and Arthur S. Leon. 2011a. "The Compendium of Physical Activities Tracking Guide." Healthy Lifestyles Research Center, College of Nursing \& Health Innovation, Arizona State University. https://sites.google.com/site/compendiumo fphysicalactivities/home.

— 2011b. "2011 Compendium of Physical Activities: A Second Update of Codes and MET Values." Medicine and Science in Sports and Exercise 43 (8): 1575-81.

Astrand, I. 1985. "Uptake of Solvents from the Lungs.” British Journal of Industrial Medicine 42 (4): 217-18. doi:10.1136/oem.42.4.217.

Astrand, I., J. Engstrom, and P. Ovrum. 1978. "Exposure to Xylene and Ethylbenzene: I.” Uptake, Distribution and Elimination in Man. Stand J Work Environ Health 4: 185-94.

Atabi, Farideh, F. Moattar, N. Mansouri, A. A. Alesheikh, and S. A. H. Mirzahosseini. 2013. "Assessment of Variations in Benzene Concentration Produced from Vehicles and Gas Stations in Tehran Using GIS.” International Journal of Environmental Science and Technology 10 (2): 283-94.

Badland, Hannah M., and Mitch J. Duncan. 2009. "Perceptions of Air Pollution during the Work-Related Commute by Adults in Queensland, Australia.” Atmospheric Environment 43 (36): 5791-95. doi:10.1016/j.atmosenv.2009.07.050.

Batterman, Stuart A, Chung-Yu Peng, and James Braun. 2002. "Levels and Composition of Volatile Organic Compounds on Commuting Routes in Detroit, Michigan.” Atmospheric Environment 36 (39-40): 6015-30. doi:10.1016/S1352-2310(02)00770-7.

Bean, T., N. Carslaw, M. Ashmore, A. Gillah, and C. Parkinson. 2011. "How Does Exposure to Nitrogen Dioxide Compare between on-Road and off-Road Cycle Routes?” Journal of Environmental Monitoring 13 (4): 1039. doi:10.1039/c0em00332h.

Bell, ML. 2012. Assessment of the Health Impacts of Particulate Matter Characteristics. Research Report 161. Boston, MA: Health Effects Institute. http:/ukpmc.ac.uk/abstract/MED/22393584. 
Bergamaschi, Enrico, Angelita Brustolin, Giuseppe De Palma, Paola Manini, Paola Mozzoni, Roberta Andreoli, Stefania Cavazzini, and Antonio Mutti. 1999. "Biomarkers of Dose and Susceptibility in Cyclists Exposed to Monoaromatic Hydrocarbons.” Toxicology Letters 108 (2-3): 241-47. doi:10.1016/S0378-4274(99)00095-8.

Berghmans, P., N. Bleux, Luc Int Panis, V.K. Mishra, R. Torfs, and M. Van Poppel. 2009. "Exposure Assessment of a Cyclist to PM10 and Ultrafine Particles." Science of The Total Environment 407 (4): 1286-98. doi:10.1016/j.scitotenv.2008.10.041.

Bernmark, Eva, Christina Wiktorin, Magnus Svartengren, Marie Lewné, and Samuel Åberg. 2006. "Bicycle Messengers: Energy Expenditure and Exposure to Air Pollution." Ergonomics 49 (14): 1486-95. doi:10.1080/00140130600708206.

Bevan, Michael A. J., Christopher J. Proctor, Joanna Baker-Rogers, and Nigel D. Warren. 1991. "Exposure to Carbon Monoxide, Respirable Suspended Particulates and Volatile Organic Compounds While Commuting by Bicycle.” Environmental Science \& Technology 25 (4): 788-91. doi:10.1021/es00016a026.

Bigazzi, Alexander, J.W.C. Van Lint, G. Klunder, U. Stelwagen, and N. Ligterink. 2010. "Traffic Data for Local Emissions Monitoring at a Signalized Intersection." In Intelligent Transportation Systems (ITSC), 2010 13th International IEEE Conference on, 210-15.

Bigazzi, Alexander Y. 2013. "The Portland ACE Documentation: A Portable, Low-Cost, and Networked Device for Assessing Cyclists’ Exposure”. Portland State University. http:/alexbigazzi.com/Portland Ace/.

Bigazzi, Alexander Y., and Miguel A. Figliozzi. 2014. "Review of Urban Bicyclists' Intake and Uptake of Traffic-Related Air Pollution.” Transport Reviews 34 (2): 221-45. doi:10.1080/01441647.2014.897772.

Bigazzi, Alexander York. 2014. "Bicyclists Uptake of Traffic-Related Air Pollution: Effects of the Urban Transportation System”. Portland, Oregon: Portland State University.

Boogaard, Hanna, Frank Borgman, Jaap Kamminga, and Gerard Hoek. 2009. "Exposure to Ultrafine and Fine Particles and Noise during Cycling and Driving in 11 Dutch Cities.” Atmospheric Environment 43 (27): 4234-42. doi:10.1016/j.atmosenv.2009.05.035.

Bos, I., L. Jacobs, T.S. Nawrot, B. de Geus, R. Torfs, L. Int Panis, B. Degraeuwe, and R. Meeusen. 2011. "No Exercise-Induced Increase in Serum BDNF after Cycling near a Major Traffic Road.” Neuroscience Letters 500 (2): 129-32. doi:10.1016/j.neulet.2011.06.019.

Broach, Joseph, Jennifer Dill, and John Gliebe. 2012. "Where Do Cyclists Ride? A Route Choice Model Developed with Revealed Preference GPS Data.” Transportation Research Part A: Policy and Practice 46 (10): 1730-40. doi:10.1016/j.tra.2012.07.005.

Brook, Robert D., Sanjay Rajagopalan, C. Arden Pope, Jeffrey R. Brook, Aruni Bhatnagar, Ana V. Diez-Roux, Fernando Holguin, et al. 2010. "Particulate Matter Air Pollution and Cardiovascular Disease An Update to the Scientific Statement From the American Heart Association.” Circulation 121 (21): 2331-78. doi:10.1161/CIR.0b013e3181dbece1.

Brugge, D., J. Durant, and C. Rioux. 2007. "Near-Highway Pollutants in Motor Vehicle Exhaust: A Review of Epidemiologic Evidence of Cardiac and Pulmonary Health Risks.” Environmental Health 6: 23-34.

Chalupa, David C, Paul E Morrow, Gunter Oberdorster, Mark J Utell, and Mark W Frampton. 2004. "Ultrafine Particle Deposition in Subjects with Asthma." Environmental Health Perspectives 112 (8): 879-82. 
Chan, L.Y., W.T. Hung, and Y. Qin. 1994. "Vehicular Emission Exposure of Bicycle Commuters in the Urban Area of Guangzhou, South China (PRC).” Environment International 20 (2): 169-77. doi:10.1016/0160-4120(94)90134-1.

Chertok, Michael, Alexander Voukelatos, Vicky Sheppeard, and Chris Rissel. 2004. "Comparison of Air Pollution Exposure for Five Commuting Modes in Sydney - Car, Train, Bus, Bicycle and Walking.” Health Promotion Journal of Australia 15 (1): 63-67.

Chien, Yeh-Chung. 2007. "Variations in Amounts and Potential Sources of Volatile Organic Chemicals in New Cars.” Science of the Total Environment 382 (2): 228-39.

Cho, Seung-Hyun, Haiyan Tong, John K McGee, Richard W Baldauf, Q Todd Krantz, and M Ian Gilmour. 2009. "Comparative Toxicity of Size-Fractionated Airborne Particulate Matter Collected at Different Distances from an Urban Highway.” Environmental Health Perspectives 117 (11): 1682-89. doi:10.1289/ehp.0900730.

City of Portland. 2010. Portland Bicycle Plan for 2030. Portland, Oregon: Bureau of Transportation. http://www.portlandoregon. gov/transportation/44597.

City of Portland, and Multnomah County. 2009. Climate Action Plan 2009. Portland, Oregon: Bureau of Planning and Sustainability. http//www.portlandoregon.gov/bps/article/268612.

Clifford, M. J., R. Clarke, and S. B. Riffat. 1997. "Local Aspects of Vehicular Pollution.” Atmospheric Environment 31 (2): 271-76. doi:10.1016/1352-2310(96)00205-1.

Cole-Hunter, Tom, Lidia Morawska, Ian Stewart, Matthew Hadaway, Rohan Jayaratne, and Colin Solomon. 2013. "Utility of an Alternative Bicycle Commute Route of Lower Proximity to Motorised Traffic in Decreasing Exposure to Ultra-Fine Particles, Respiratory Symptoms and Airway Inflammation -- a Structured Exposure Experiment.” Environmental Health 12 (1). doi:10.1186/1476-069X-12-29.

Cole-Hunter, Tom, Lidia Morawska, Ian Stewart, Rohan Jayaratne, and Colin Solomon. 2012. "Inhaled Particle Counts on Bicycle Commute Routes of Low and High Proximity to Motorised Traffic.” Atmospheric Environment 61 (December). doi:10.1016/j.atmosenv.2012.06.041.

CROW. 2007. Design Manual for Bicycle Traffic. The Netherlands.

Csanády, Gy.A., and J.G. Filser. 2001. "The Relevance of Physical Activity for the Kinetics of Inhaled Gaseous Substances.” Archives of Toxicology 74 (11): 663-72. doi:10.1007/s002040000158.

Daigle, Christopher C, David C Chalupa, F Raymond Gibb, Paul E Morrow, Günter Oberdörster, Mark J Utell, and Mark W Frampton. 2003. "Ultrafine Particle Deposition in Humans during Rest and Exercise.” Inhalation Toxicology 15 (6): 539-52. doi:10.1080/08958370304468.

De Geus, Bas, S. de Smet, J. Nijs, and R. Meeusen. 2007. "Determining the Intensity and Energy Expenditure during Commuter Cycling.” British Journal of Sports Medicine 41 (1): 8-12. doi:10.1136/bjsm.2006.027615.

De Hartog, Jeroen Johan, Hanna Boogaard, Hans Nijland, and Gerard Hoek. 2010. "Do the Health Benefits of Cycling Outweigh the Risks?” Environmental Health Perspectives 118 (8): 1109-16. doi:10.1289/ehp.0901747.

De Nazelle, A., M. J Nieuwenhuijsen, J. M Antó, M. Brauer, D. Briggs, C. Braun-Fahrlander, N. Cavill, et al. 2011. "Improving Health through Policies That Promote Active Travel: A Review of Evidence to Support Integrated Health Impact Assessment.” Environment International. 
De Nazelle, Audrey, Scott Fruin, Dane Westerdahl, David Martinez, Anna Ripoll, Nadine Kubesch, and Mark Nieuwenhuijsen. 2012. "A Travel Mode Comparison of Commuters' Exposures to Air Pollutants in Barcelona.” Atmospheric Environment 59 (November): 151-59. doi:10.1016/j.atmosenv.2012.05.013.

De Nazelle, Audrey, Daniel A. Rodríguez, and Douglas Crawford-Brown. 2009. "The Built Environment and Health: Impacts of Pedestrian-Friendly Designs on Air Pollution Exposure.” Science of The Total Environment 407 (8): 2525-35. doi:10.1016/j.scitotenv.2009.01.006.

Dekoninck, Luc, Dick Botteldooren, and Luc Int Panis. 2013. “An Instantaneous Spatiotemporal Model to Predict a Bicyclist's Black Carbon Exposure Based on Mobile Noise Measurements.” Atmospheric Environment 79 (November): 623-31. doi:10.1016/j.atmosenv.2013.06.054.

Department for Transport. 2013. Briefing on the Government's Ambition for Cycling. London, UK: Department for Transport.

Di Prampero, P. E., G. Cortili, P. Mognoni, and F. Saibene. 1979. "Equation of Motion of a Cyclist.” Journal of Applied Physiology 47 (1): 201-6.

Dill, Jennifer. 2009. "Bicycling for Transportation and Health: The Role of Infrastructure." Journal of Public Health Policy 30: S95-S110. doi:10.1057/jphp.2008.56.

Dill, Jennifer, and Theresa Carr. 2003. "Bicycle Commuting and Facilities in Major U.S. Cities: If You Build Them, Commuters Will Use Them.” Transportation Research Record: Journal of the Transportation Research Board 1828 (-1): 116-23. doi:10.3141/1828-14.

Dirks, K. N., P. Sharma, J. A. Salmond, and S. B. Costello. 2012. "Personal Exposure to Air Pollution for Various Modes of Transport in Auckland, New Zealand.” Open Atmospheric Science Journal 6 (1): 84-92.

Do, Duc Hoai, Herman Van Langenhove, Stephen Izuchukwu Chigbo, Abebech Nuguse Amare, Kristof Demeestere, and Christophe Walgraeve. 2014. "Exposure to Volatile Organic Compounds: Comparison among Different Transportation Modes.” Atmospheric Environment 94 (September): 53-62. doi:10.1016/j.atmosenv.2014.05.019.

Dons, Evi, Luc Int Panis, Martine Van Poppel, Jan Theunis, and Geert Wets. 2012. "Personal Exposure to Black Carbon in Transport Microenvironments.” Atmospheric Environment 55 (August): 392-98. doi:10.1016/j.atmosenv.2012.03.020.

Dons, Evi, Philip Temmerman, Martine Van Poppel, Tom Bellemans, Geert Wets, and Luc Int Panis. 2013. "Street Characteristics and Traffic Factors Determining Road Users' Exposure to Black Carbon.” Science of The Total Environment 447 (March): 72-79. doi:10.1016/j.scito tenv.2012.12.076.

Egeghy, P. P., L. Hauf-Cabalo, R. Gibson, and S. M. Rappaport. 2003. "Benzene and Naphthalene in Air and Breath as Indicators of Exposure to Jet Fuel.” Occupational and Environmental Medicine 60 (12): 969-76. doi:10.1136/oem.60.12.969.

Elen, Bart, Jan Peters, Martine Poppel, Nico Bleux, Jan Theunis, Matteo Reggente, and Arnout Standaert. 2013. "The Aeroflex: A Bicycle for Mobile Air Quality Measurements." Sensors 13 (1): 221-40. doi:10.3390/s130100221.

El-Fadel, M., and L. Abi-Esber. 2009. "In-Vehicle Exposure to Carbon Monoxide Emissions from Vehicular Exhaust: A Critical Review.” Critical Reviews in Environmental Science and Technology 39 (8): 585-621. doi:10.1080/10643380701798264. 
Fajardo, Oscar A., and Nestor Y. Rojas. 2012. "Particulate Matter Exposure of Bicycle Path Users in a High-Altitude City.” Atmospheric Environment 46 (January): 675-79. doi:10.1016/j.atmosenv.2011.09.047.

Farhi, L.E. 1967. "Elimination of Inert Gas by the Lung." Respiration Physiology 3 (1): 1-11. doi:10.1016/0034-5687(67)90018-7.

Faria, E. W., D. L. Parker, and I. E. Faria. 2005a. "The Science of Cycling: Physiology and Training-Part 1.” Sports Medicine 35 (4): 285-312. . 2005b. "The Science of Cycling: Factors Affecting Performance-Part 2." Sports Medicine 35 (4): 313-37.

Farrar, D., P. Dingle, and R. Tan. 2001. "Exposure to Nitrogen Dioxide in Buses, Taxis, and Bicycles in Perth, Western Australia.” Bulletin of Environmental Contamination and Toxicology 66 (4): 433-38. doi:10.1007/s001280024.

Filley, Giles F., Donald J. MacIntosh, and George W. Wright. 1954. "Carbon Monoxide Uptake and Pulmonary Diffusing Capacity in Subjects at Rest and During Exercise.” Journal of Clinical Investigation 33 (4): 530-39.

Forastiere, Francesco, and Nera Agabiti. 2013. "Assessing the Link between Air Pollution and Heart Failure.” The Lancet, July. doi:10.1016/S0140-6736(13)61167-8.

Fruin, Scott A., D. Westerdahl, T. Sax, C. Sioutas, and P. M. Fine. 2008. "Measurements and Predictors of on-Road Ultrafine Particle Concentrations and Associated Pollutants in Los Angeles.” Atmospheric Environment 42 (2): 207-19.

Gee, Ivan L., and David W. Raper. 1999. "Commuter Exposure to Respirable Particles inside Buses and by Bicycle.” Science of The Total Environment 235 (1-3): 403-5. doi:10.1016/S0048-9697(99)00247-8.

Gordon, Mark, Ralf M. Staebler, John Liggio, Shao-Meng Li, Jeremy Wentzell, Gang Lu, Patrick Lee, and Jeffrey R. Brook. 2012. "Measured and Modeled Variation in Pollutant Concentration near Roadways.” Atmospheric Environment 57 (September): 138-45. doi:10.1016/j.atmosenv.2012.04.022.

Gotschi, Thomas. 2011. "Costs and Benefits of Bicycling Investments in Portland, Oregon." Journal of Physical Activity and Health 8 (1): S49-S58.

Grange, Stuart K., Kim N. Dirks, Seosamh B. Costello, and Jennifer A. Salmond. 2014. "Cycleways and Footpaths: What Separation Is Needed for Equivalent Air Pollution Dose between Travel Modes?” Transportation Research Part D: Transport and Environment 32 (October): 111-19. doi:10.1016/j.trd.2014.07.014.

Gulliver, J., and D. J. Briggs. 2004. "Personal Exposure to Particulate Air Pollution in Transport Microenvironments.” Atmospheric Environment 38 (1): 1-8.

Gunatilaka, Ajith, Alex Skvortsov, and Ralph Gailis. 2014. "A Review of Toxicity Models for Realistic Atmospheric Applications.” Atmospheric Environment 84 (February): 230-43. doi:10.1016/j.atmosenv.2013.11.051.

Hall, Jane V., Victor Brajer, and Frederick W. Lurmann. 2008. "Measuring the Gains from Improved Air Quality in the San Joaquin Valley.” Journal of Environmental Management 88 (4): 1003-15. doi:10.1016/j.jenvman.2007.05.002.

Hamer, Mark, and Yoichi Chida. 2008. "Active Commuting and Cardiovascular Risk: A MetaAnalytic Review.” Preventive Medicine 46 (1): 9-13. doi:10.1016/j.ypmed.2007.03.006.

Hatzopoulou, Marianne, Scott Weichenthal, Guillaume Barreau, Mark Goldberg, William Farrell, Dan Crouse, and Nancy Ross. 2013. “A Web-Based Route Planning Tool to 
Reduce Cyclists’ Exposures to Traffic Pollution: A Case Study in Montreal, Canada.” Environmental Research 123 (May): 58-61. doi:10.1016/j.envres.2013.03.004.

Hatzopoulou, Marianne, Scott Weichenthal, Hussam Dugum, Graeme Pickett, Luis MirandaMoreno, Ryan Kulka, Ross Andersen, and Mark Goldberg. 2013. “The Impact of Traffic Volume, Composition, and Road Geometry on Personal Air Pollution Exposures among Cyclists in Montreal, Canada.” Journal of Exposure Science and Environmental Epidemiology 23 (1): 46-51. doi:10.1038/jes.2012.85.

Health Effects Institute. 2010. Traffic-Related Air Pollution: A Critical Review of the Literature on Emissions, Exposure, and Health Effects. Special Report Special Report 17. Boston, MA: Health Effects Institute.

Heinrich-Ramm, R., M. Jakubowski, B. Heinzow, J. Molin Christensen, E. Olsen, and O. Hertel. 2000. "Biological Monitoring for Exposure to Volatile Organic Compounds (VOCs) (IUPAC Recommendations 2000).” Pure and Applied Chemistry 72 (3): 385-436. doi:10.1351/pac200072030385.

Hertel, Ole, Martin Hvidberg, Matthias Ketzel, Lars Storm, and Lizzi Stausgaard. 2008. “A Proper Choice of Route Significantly Reduces Air Pollution Exposure -- A Study on Bicycle and Bus Trips in Urban Streets.” Science of The Total Environment 389 (1): 5870. doi:10.1016/j.scitotenv.2007.08.058.

Hill, L. Bruce, and James Gooch. 2010. A Multi-City Investigation of Exposure to Diesel Exhaust in Multiple Commuting Modes. CATF Special Report 2007-1. Boston, MA: Clean Air Task Force.

Hoehner, Christine M., Carolyn E. Barlow, Peg Allen, and Mario Schootman. 2012. "Commuting Distance, Cardiorespiratory Fitness, and Metabolic Risk.” American Journal of Preventive Medicine 42 (6): 571-78. doi:10.1016/j.amepre.2012.02.020.

Hofmann, Werner. 2011. "Modelling Inhaled Particle Deposition in the Human lung-A Review.” Journal of Aerosol Science 42 (10): 693-724. doi:10.1016/j.jaerosci.2011.05.007.

Hong, E-Sok, and C.-H. Bae. 2012. "Exposure of Bicyclists to Air Pollution in Seattle, Washington Hybrid.” Transportation Research Record: Journal of the Transportation Research Board 2270 (-1): 59-66. doi:10.3141/2270-08.

Huang, Jing, Furong Deng, Shaowei Wu, and Xinbiao Guo. 2012. "Comparisons of Personal Exposure to PM2.5 and CO by Different Commuting Modes in Beijing, China.” Science of The Total Environment 425 (May): 52-59. doi:10.1016/j.scitotenv.2012.03.007.

Int Panis, Luc. 2011. “Cycling: Health Benefits and Risks.” Environmental Health Perspectives 119 (3): A114. doi:10.1289/ehp.1003227.

Int Panis, Luc, Bas de Geus, Grégory Vandenbulcke, Hanny Willems, Bart Degraeuwe, Nico Bleux, Vinit Mishra, Isabelle Thomas, and Romain Meeusen. 2010. "Exposure to Particulate Matter in Traffic: A Comparison of Cyclists and Car Passengers.” Atmospheric Environment 44 (19): 2263-70. doi:10.1016/j.atmosenv.2010.04.028.

International Commission on Radiological Protection Task Group. 1994. "Human Respiratory Tract Model for Radiological Protection.” Annals of the ICRP 24 (1-3): 1-480.

Jacobs, Lotte, Tim Nawrot, Bas de Geus, Romain Meeusen, Bart Degraeuwe, Alfred Bernard, Muhammad Sughis, Benoit Nemery, and Luc Int Panis. 2010. "Subclinical Responses in Healthy Cyclists Briefly Exposed to Traffic-Related Air Pollution: An Intervention Study.” Environmental Health 9 (1): 64. doi:10.1186/1476-069X-9-64. 
Jan van Garderen, Kees, and Chandra Shah. 2002. "Exact Interpretation of Dummy Variables in Semilogarithmic Equations.” Econometrics Journal 5 (1): 149-59. doi:10.1111/1368423X.00078.

Jarjour, Sarah, Michael Jerrett, Dane Westerdahl, Audrey de Nazelle, Cooper Hanning, Laura Daly, Jonah Lipsitt, and John Balmes. 2013. "Cyclist Route Choice, Traffic-Related Air Pollution, and Lung Function: A Scripted Exposure Study.” Environmental Health 12 (February). doi:10.1186/1476-069X-12-14.

Johnson, T. 2002. A Guide to Selected Algorithms, Distributions, and Databases Used in Exposure Models Developed by The Office Of Air Quality Planning and Standards. CR827033. Research Triangle Park, NC: U.S. Environmental Protection Agency, Office of Research and Development. Google Scholar.

Kang, Lei, and Jon D. Fricker. 2013. "Bicyclist Commuters' Choice of on-Street versus offStreet Route Segments.” Transportation. doi:10.1007/s11116-013-9453-X.

Karner, Alex A., Douglas S. Eisinger, and Deb A. Niemeier. 2010. "Near-Roadway Air Quality: Synthesizing the Findings from Real-World Data.” Environmental Science \& Technology 44 (14): 5334-44. doi:10.1021/es100008x.

Kaur, S., M. Nieuwenhuijsen, and R. Colvile. 2005. "Personal Exposure of Street Canyon Intersection Users to PM2. 5, Ultrafine Particle Counts and Carbon Monoxide in Central London, UK.” Atmospheric Environment 39 (20): 3629-41.

Kaur, S., and M. J. Nieuwenhuijsen. 2009. "Determinants of Personal Exposure to PM2.5, Ultrafine Particle Counts, and CO in a Transport Microenvironment." Environmental Science \& Technology 43 (13): 4737-43. doi:10.1021/es803199z.

Kaur, S., M.J. Nieuwenhuijsen, and R.N. Colvile. 2007. "Fine Particulate Matter and Carbon Monoxide Exposure Concentrations in Urban Street Transport Microenvironments.” Atmospheric Environment 41 (23): 4781-4810. doi:10.1016/j.atmosenv.2007.02.002.

Kendrick, Christine, Adam Moore, Ashley Haire, Alexander Bigazzi, Miguel Andres Figliozzi, Christopher Monsere, and Linda George. 2011. "Impact of Bicycle Lane Characteristics on Exposure of Bicyclists to Traffic-Related Particulate Matter.” Transportation Research Record: Journal of the Transportation Research Board 2247 (December): 2432. doi:10.3141/2247-04.

King, Julian, Karl Unterkofler, Gerald Teschl, Susanne Teschl, Helin Koc, Hartmann Hinterhuber, and Anton Amann. 2011. "A Mathematical Model for Breath Gas Analysis of Volatile Organic Compounds with Special Emphasis on Acetone.” Journal of Mathematical Biology 63 (5): 959-99. doi:10.1007/s00285-010-0398-9.

Kingham, Simon, Ian Longley, Jenny Salmond, Woodrow Pattinson, and Kreepa Shrestha. 2013. "Variations in Exposure to Traffic Pollution While Travelling by Different Modes in a Low Density, Less Congested City.” Environmental Pollution 181 (October): 211-18. doi:10.1016/j.envpol.2013.06.030.

Kingham, Simon, Julia Meaton, Andrew Sheard, and Olivia Lawrenson. 1998. "Assessment of Exposure to Traffic-Related Fumes during the Journey to Work.” Transportation Research Part D: Transport and Environment 3 (4): 271-74. doi:10.1016/S13619209(98)00005-4.

Kleiner, Beth C., and John D. Spengler. 1976. "Carbon Monoxide Exposures of Boston Bicyclists.” Journal of the Air Pollution Control Association 26 (2): 147-49. doi:10.1080/00022470.1976.10470239. 
Knibbs, Luke D., Tom Cole-Hunter, and Lidia Morawska. 2011. “A Review of Commuter Exposure to Ultrafine Particles and Its Health Effects.” Atmospheric Environment 45 (16): 2611-22. doi:10.1016/j.atmosenv.2011.02.065.

Kumagai, Shinji, and Ichiro Matsunaga. 2000. "A Lung Model Describing Uptake of Organic Solvents and Roles of Mucosal Blood Flow and Metabolism in the Bronchioles." Inhalation Toxicology 12 (6): 491-510. doi:10.1080/089583700402888.

Li, Tian-Tian, Yu-Hua Bai, Zhao-Rong Liu, Jin-Feng Liu, Guang-Shan Zhang, and Jin-Long Li. 2006. "Air Quality in Passenger Cars of the Ground Railway Transit System in Beijing, China.” Science of The Total Environment 367 (1): 89-95. doi:10.1016/j.scitotenv.2006.01.007.

Löndahl, Jakob, Andreas Massling, Joakim Pagels, Erik Swietlicki, Elvira Vaclavik, and Steffen Loft. 2007. "Size-Resolved Respiratory-Tract Deposition of Fine and Ultrafine Hydrophobic and Hygroscopic Aerosol Particles During Rest and Exercise.” Inhalation Toxicology 19 (2): 109-16.

Lusk, Anne C., Peter G. Furth, Patrick Morency, Luis F. Miranda-Moreno, Walter C. Willett, and Jack T. Dennerlein. 2011. "Risk of Injury for Bicycling on Cycle Tracks versus in the Street.” Injury Prevention 17 (2): 131-35.

MacNaughton, Piers, Steven Melly, Jose Vallarino, Gary Adamkiewicz, and John D. Spengler. 2014. "Impact of Bicycle Route Type on Exposure to Traffic-Related Air Pollution." Science of The Total Environment 490 (August): 37-43. doi:10.1016/j.scitotenv.2014.04.111.

Martin, J. C., D. L. Milliken, J. E. Cobb, K. L. McFadden, and A. R. Coggan. 1998. "Validation of a Mathematical Model for Road Cycling Power.” Journal of Applied Biomechanics 14: 276-91.

McCreanor, James, Paul Cullinan, Mark J. Nieuwenhuijsen, James Stewart-Evans, Eleni Malliarou, Lars Jarup, Robert Harrington, et al. 2007. "Respiratory Effects of Exposure to Diesel Traffic in Persons with Asthma.” New England Journal of Medicine 357 (23): 2348-58. doi:10.1056/NEJMoa071535.

McNabola, A., B. M. Broderick, and L. W. Gill. 2007. "Optimal Cycling and Walking Speed for Minimum Absorption of Traffic Emissions in the Lungs." Journal of Environmental Science and Health. Part A, Toxic/hazardous Substances \& Environmental Engineering 42 (13): 1999-2007. . 2008. "Relative Exposure to Fine Particulate Matter and VOCs between Transport Microenvironments in Dublin: Personal Exposure and Uptake.” Atmospheric Environment 42 (26): 6496-6512.

McNabola, A., B.M. Broderick, and L.W. Gill. 2009a. "The Impacts of Inter-Vehicle Spacing on in-Vehicle Air Pollution Concentrations in Idling Urban Traffic Conditions.” Transportation Research Part D: Transport and Environment 14 (8): 567-75. doi:10.1016/j.trd.2009.08.003.

McNabola, A., Brian M. Broderick, and Laurence W. Gill. 2009b. “A Principal Components Analysis of the Factors Effecting Personal Exposure to Air Pollution in Urban Commuters in Dublin, Ireland.” Journal of Environmental Science and Health, Part A: Toxic/Hazardous Substances and Environmental Engineering 44 (12): 1219-26. doi:10.1080/10934520903139928.

Michaels, R. A., and M. T. Kleinman. 2000. "Incidence and Apparent Health Significance of Brief Airborne Particle Excursions.” Aerosol Science and Technology 32 (2): 93-105. 
Miller, Lindsay, Xiaohong Xu, Alice Grgicak-Mannion, Jeffrey Brook, and Amanda Wheeler. 2012. "Multi-Season, Multi-Year Concentrations and Correlations amongst the BTEX Group of VOCs in an Urbanized Industrial City.” Atmospheric Environment 61 (December): 305-15. doi:10.1016/j.atmosenv.2012.07.041.

Nadeau, V., G. Truchon, M. Brochu, and R. Tardif. 2006. "Effect of Physical Exertion on the Biological Monitoring of Exposure of Various Solvents Following Exposure by Inhalation in Human Volunteers: I. Toluene.” Journal of Occupational and Environmental Hygiene 3 (9): 481-89.

Nankervis, Max. 1999. "The Effect of Weather and Climate on Bicycle Commuting." Transportation Research Part A: Policy and Practice 33 (6): 417-31. doi:10.1016/S0965-8564(98)00022-6.

Nawrot, Tim S., Laura Perez, Nino Künzli, Elke Munters, and Benoit Nemery. 2011. 'Public Health Importance of Triggers of Myocardial Infarction: A Comparative Risk Assessment.” The Lancet 377 (9767): 732-40. doi:10.1016/S0140-6736(10)62296-9.

Nawrot, Tim S., Robin Vos, Lotte Jacobs, Stijn E. Verleden, Shana Wauters, Veerle Mertens, Christophe Dooms, et al. 2011. "The Impact of Traffic Air Pollution on Bronchiolitis Obliterans Syndrome and Mortality after Lung Transplantation.” Thorax 66 (9): 748-54. doi:10.1136/thx.2010.155192.

Nwokoro, Chinedu, Clare Ewin, Clare Harrison, Mubin Ibrahim, Isobel Dundas, Iain Dickson, Naseem Mushtaq, and Jonathan Grigg. 2012. "Cycling to Work in London and Inhaled Dose of Black Carbon.” European Respiratory Journal 40 (5): 1091-97. doi:10.1183/09031936.00195711.

Nyhan, Marguerite, A. McNabola, and Bruce Misstear. 2014. “Comparison of Particulate Matter Dose and Acute Heart Rate Variability Response in Cyclists, Pedestrians, Bus and Train Passengers.” Science of The Total Environment 468-469 (January): 821-31. doi:10.1016/j.scitotenv.2013.08.096.

O’Donoghue, R. T., L. W. Gill, R. J. McKevitt, and B. Broderick. 2007. "Exposure to Hydrocarbon Concentrations While Commuting or Exercising in Dublin.” Environment International 33 (1): 1-8.

Olds, T. S. 2001. "Modelling Human Locomotion: Applications to Cycling.” Sports Medicine 31 (7): 497-509.

Oregon Department of Environmental Quality. 2011. Benzene in Oregon's Air. Fact Sheet. http//www.deq.state.or.us/aq/factsheets/06-AQ-018_benzene.pdf. . 2012. Fact Sheet: Portland Air Toxics Solutions Report and Recommendations. http://www.deq.state.or.us/aq/factsheets/12aq035patsReport.pdf.

Ott, Wayne, Anne C. Steinemann, and Lance A. Wallace. 2007. Exposure Analysis. Boca Raton, Florida, USA: CRC Press.

Pankow, J. F, W. Luo, D. A Bender, L. M Isabelle, J. S Hollingsworth, C. Chen, W. E Asher, and J. S Zogorski. 2003. "Concentrations and Co-Occurrence Correlations of 88 Volatile Organic Compounds (VOCs) in the Ambient Air of 13 Semi-Rural to Urban Locations in the United States.” Atmospheric Environment 37 (36): 5023-46.

Pankow, J. F., W. Luo, L. M. Isabelle, D. A. Bender, and R. J. Baker. 1998. "Determination of a Wide Range of Volatile Organic Compounds in Ambient Air Using Multisorbent Adsorption/thermal Desorption and Gas Chromatography/mass Spectrometry." Analytical Chemistry 70 (24): 5213-21. 
Pankow, J. F., W. Luo, A. N. Melnychenko, K. C. Barsanti, L. M. Isabelle, C. Chen, A. B. Guenther, and T. N. Rosenstiel. 2011. "Volatilizable Biogenic Organic Compounds (VBOCs) with Two Dimensional Gas Chromatography-Time of Flight Mass Spectrometry (GC × GC-TOFMS): Sampling Methods, VBOC Complexity, and Chromatographic Retention Data.” Atmos. Meas. Tech. Discuss. 4 (3): 3647-84. doi:10.5194/amtd-4-3647-2011.

Pankow, J. F., W. Luo, A. D. Tavakoli, C. Chen, and L. M. Isabelle. 2004. "Delivery Levels and Behavior of 1, 3-Butadiene, Acrylonitrile, Benzene, and Other Toxic Volatile Organic Compounds in Mainstream Tobacco Smoke from Two Brands of Commercial Cigarettes.” Chemical Research in Toxicology 17 (6): 805-13.

Peters, Annette, Stephanie von Klot, Murray A. Mittleman, Christine Meisinger, Allmut Hörmann, Bernhard Kuch, and H. Erich Wichmann. 2013. "Triggering of Acute Myocardial Infarction by Different Means of Transportation.” European Journal of Preventive Cardiology 20 (5): 750-58. doi:10.1177/2047487312446672.

Peters, Annette, S. Von Klot, M. Heier, I. Trentinaglia, A. Hörmann, H. E Wichmann, and H. Löwel. 2004. "Exposure to Traffic and the Onset of Myocardial Infarction." New England Journal of Medicine 351 (17): 1721-30.

Pezzagno, G., M. Imbriani, S. Ghittori, and E. Capodaglio. 1988. "Urinary Concentration, Environmental Concentration, and Respiratory Uptake of Some Solvents: Effect of the Work Load.” American Industrial Hygiene Association Journal 49 (11): 546-52.

Piechocki-Minguy, A., H. Plaisance, C. Schadkowski, I. Sagnier, J.Y. Saison, J.C. Galloo, and R. Guillermo. 2006. "A Case Study of Personal Exposure to Nitrogen Dioxide Using a New High Sensitive Diffusive Sampler.” Science of The Total Environment 366 (1): 55-64. doi:10.1016/j.scito tenv.2005.08.009.

Plaut, Pnina O. 2005. "Non-Motorized Commuting in the US." Transportation Research Part D: Transport and Environment 10 (5): 347-56. doi:10.1016/j.trd.2005.04.002.

Pope, C. A. III, and D. W. Dockery. 2006. "Health Effects of Fine Particulate Air Pollution: Lines That Connect.” Journal of the Air \& Waste Management Association 56 (6): 70942.

Pucher, John, Ralph Buehler, and Mark Seinen. 2011. "Bicycling Renaissance in North America? An Update and Re-Appraisal of Cycling Trends and Policies.” Transportation Research Part A: Policy and Practice 45 (6): 451-75. doi:10.1016/j.tra.2011.03.001.

Pucher, John, Jennifer Dill, and Susan Handy. 2010. "Infrastructure, Programs, and Policies to Increase Bicycling: An International Review.” Preventive Medicine 50, Supplement (January): S106-S125. doi:10.1016/j.ypmed.2009.07.028.

Pucher, John R., and Ralph Buehler. 2012. City Cycling. Cambridge, MA, USA: MIT Press. Quiros, David C., Eon S. Lee, Rui Wang, and Yifang Zhu. 2013. "Ultrafine Particle Exposures While Walking, Cycling, and Driving along an Urban Residential Roadway.” Atmospheric Environment 73 (July): 185-94. doi:10.1016/j.atmosenv.2013.03.027.

Ragettli, Martina S., Elisabetta Corradi, Charlotte Braun-Fahrländer, Christian Schindler, Audrey de Nazelle, Michael Jerrett, Regina E. Ducret-Stich, Nino Künzli, and Harish C. Phuleria. 2013. "Commuter Exposure to Ultrafine Particles in Different Urban Locations, Transportation Modes and Routes.” Atmospheric Environment 77 (October): 376-84. doi:10.1016/j.atmosenv.2013.05.003. 
Ragland, David R., Offer Grembek, Phyllis Orrick, and Grace Felschundneff. 2013. "Roadway and Infrastructure Design and Its Relation to Pedestrian and Bicyclist Safety: Basic Principles, Applications, and Benefits.” In Washington, D.C.

Rank, J., J. Folke, and P. Homann Jespersen. 2001. "Differences in Cyclists and Car Drivers Exposure to Air Pollution from Traffic in the City of Copenhagen.” Science of the Total Environment, The 279 (1-3): 131-36.

Reynolds, Conor C. O., M. Winters, F. Ries, and B. Gouge. 2010. Active Transportation in Urban Areas: Exploring Health Benefits and Risks. National Collaborating Centre for Environmental Health. http:/www.nspacts.ca/docs/DNS\%20article\%20Active_Transportation_in_Urban_Areas June_2010.pdf.

Reynolds, Conor CO, M. Anne Harris, Kay Teschke, Peter A. Cripton, and Meghan Winters. 2009. "The Impact of Transportation Infrastructure on Bicycling Injuries and Crashes: A Review of the Literature." Environmental Health 8 (1): 47-65.

Rojas-Rueda, D., A. de Nazelle, M. Tainio, and M. J. Nieuwenhuijsen. 2011. "The Health Risks and Benefits of Cycling in Urban Environments Compared with Car Use: Health Impact Assessment Study.” BMJ 343 (aug04 2): d4521-d4521. doi:10.1136/bmj.d4521.

Rosenbaum, Arlene, Ed Carr, and Jonathan Cohen. 2004. Air Dispersion Modeling Component of the Portland Air Toxics Assessment (PATA). U.S. EPA.

Samet, Jonathan M. 2007. “Traffic, Air Pollution, and Health.” Inhalation Toxicology 19 (12): 1021-27. doi:10.1080/08958370701533541.

Samet, Jonathan M., William E. Lambert, David S. James, Christine M. Mermier, and Thomas W. Chick. 1993. Assessment of Heart Rate As a Predictor of Ventilation. Investigator's Report 59. Research Report. Health Effects Institute.

Shah, Anoop SV, Jeremy P Langrish, Harish Nair, David A McAllister, Amanda L Hunter, Ken Donaldson, David E Newby, and Nicholas L Mills. 2012. "Global Association of Air Pollution and Heart Failure: A Systematic Review and Meta-Analysis.” The Lancet 382 (9897): 1039-48. doi:10.1016/S0140-6736(13)60898-3.

Sharker, Monir H., and Hassan A. Karimi. 2013. "Computing Least Air Pollution Exposure Routes.” International Journal of Geographical Information Science 28 (2): 343-62. doi:10.1080/13658816.2013.841317.

Sitzmann, B., M. Kendall, J. Watt, and I. Williams. 1999. "Characterisation of Airborne Particles in London by Computer-Controlled Scanning Electron Microscopy.” Science of The Total Environment 241 (1-3): 63-73. doi:10.1016/S0048-9697(99)00326-5.

Steinle, Susanne, Stefan Reis, and Clive Eric Sabel. 2013. "Quantifying Human Exposure to Air pollution-Moving from Static Monitoring to Spatio-Temporally Resolved Personal Exposure Assessment.” Science of The Total Environment 443 (January): 184-93. doi:10.1016/j.scitotenv.2012.10.098.

Strak, Maciej, Hanna Boogaard, Kees Meliefste, Marieke Oldenwening, Moniek Zuurbier, Bert Brunekreef, and Gerard Hoek. 2010. "Respiratory Health Effects of Ultrafine and Fine Particle Exposure in Cyclists.” Occupational and Environmental Medicine 67 (2): 11824. doi:10.1136/oem.2009.046847.

Strauss, Jillian, Luis Miranda-Moreno, Dan Crouse, Mark S. Goldberg, Nancy A. Ross, and Marianne Hatzopoulou. 2012. "Investigating the Link between Cyclist Volumes and Air Pollution along Bicycle Facilities in a Dense Urban Core.” Transportation Research Part D: Transport and Environment 17 (8): 619-25. doi:10.1016/j.trd.2012.07.007. 
Teschke, Kay, M. Anne Harris, Conor C. O. Reynolds, Meghan Winters, Shelina Babul, Mary Chipman, Michael D. Cusimano, et al. 2012. "Route Infrastructure and the Risk of Injuries to Bicyclists: A Case-Crossover Study.” American Journal of Public Health 102 (12): 2336-43. doi:10.2105/AJPH.2012.300762.

Teschke, Kay, Conor C. O. Reynolds, Francis J. Ries, Brian Gouge, and Meghan Winters. 2012. “Bicycling: Health Risk or Benefit?” UBC Medical Journal 3 (2). http:/prophet.library.ubc.ca/ojs/index.php/ubcmj/article/view/2494.

Thai, Amy, Ian McKendry, and Michael Brauer. 2008. "Particulate Matter Exposure along Designated Bicycle Routes in Vancouver, British Columbia.” Science of The Total Environment 405 (1-3): 26-35. doi:10.1016/j.scitotenv.2008.06.035.

Tiwary, Abhishek, Alan Robins, Anil Namdeo, and Margaret Bell. 2011. "Air Flow and Concentration Fields at Urban Road Intersections for Improved Understanding of Personal Exposure.” Environment International 37 (5): 1005-18. doi:10.1016/j.envint.2011.02.006.

U.S. Environmental Protection Agency. 2009. Metabolically Derived Human Ventilation Rates: A Revised Approach Based Upon Oxygen Consumption Rates. EPA/600/R-06/129F. National Center for Environmental Assessment. Washington, D.C.: U.S. Environmental Protection Agency. http:/cfpub.epa.gov/ncea/cfm/recordisplay.cfm?deid=202543\#Download.

Vallero, Daniel. 2008. Fundamentals of Air Pollution. 4th ed. Burlington, MA: Elsevier Academic Press.

Van Wijnen, J. H, A. P Verhoeff, H. W.A Jans, and M. Bruggen. 1995. "The Exposure of Cyclists, Car Drivers and Pedestrians to Traffic-Related Air Pollutants.” International Archives of Occupational and Environmental Health 67 (3): 187-93.

Vinzents, Peter S., Peter Møller, Mette Sørensen, Lisbeth E. Knudsen, Ole Hertel, Finn Palmgren Jensen, Bente Schibye, and Steffen Loft. 2005. "Personal Exposure to Ultrafine Particles and Oxidative DNA Damage.” Environmental Health Perspectives 113 (11): 1485-90. doi:10.1289/ehp.7562.

Von Schneidemesser, Erika, Paul S. Monks, and Christian Plass-Duelmer. 2010. "Global Comparison of VOC and CO Observations in Urban Areas.” Atmospheric Environment 44 (39): 5053-64. doi:10.1016/j.atmosenv.2010.09.010.

Waldman, Michael, Sharlene Weiss, and William Articola. 1977. A Study of the Health Effects of Bicycling in an Urban Atmosphere. Washington, D.C.: U.S. Department of Transportation. http://trid.trb.org/view.aspx?id=68085.

Wallace, Lance A., W. C. Nelson, E. D. Pellizzari, and J. H. Raymer. 1997. "Uptake and Decay of Volatile Organic Compounds at Environmental Concentrations: Application of a FourCompartment Model to a Chamber Study of Five Human Subjects.” Journal of Exposure Analysis and Environmental Epidemiology 7 (2): 141-63.

Wallace, Lance A., E. D. Pellizzari, and S. Gordon. 1993. "A Linear Model Relating Breath Concentrations to Environmental Exposures: Application to a Chamber Study of Four Volunteers Exposed to Volatile Organic Chemicals." Journal of Exposure Analysis and Environmental Epidemiology 3 (1): 75-102.

Wang, P., and W. Zhao. 2008. "Assessment of Ambient Volatile Organic Compounds (VOCs) near Major Roads in Urban Nanjing, China.” Atmospheric Research 89 (3): 289-97. doi:10.1016/j.atmosres.2008.03.013. 
Wang, Xin-ming, Guo-ying Sheng, Jia-mo Fu, Chuen-yu Chan, Shun-Cheng Lee, Lo Yin Chan, and Zhi-shi Wang. 2002. "Urban Roadside Aromatic Hydrocarbons in Three Cities of the Pearl River Delta, People’s Republic of China.” Atmospheric Environment 36 (33): 5141-48. doi:10.1016/S1352-2310(02)00640-4.

Wardman, Mark, Miles Tight, and Matthew Page. 2007. "Factors Influencing the Propensity to Cycle to Work.” Transportation Research Part A: Policy and Practice 41 (4): 339-50. doi:10.1016/j.tra.2006.09.011.

Weichenthal, Scott, Ryan Kulka, Patrick Bélisle, Lawrence Joseph, Aimee Dubeau, Christina Martin, Daniel Wang, and Robert Dales. 2012. "Personal Exposure to Specific Volatile Organic Compounds and Acute Changes in Lung Function and Heart Rate Variability among Urban Cyclists.” Environmental Research 118 (October): 118-23. doi:10.1016/j.envres.2012.06.005.

Weichenthal, Scott, Ryan Kulka, Aimee Dubeau, Christina Martin, Daniel Wang, and Robert Dales. 2011. "Traffic-Related Air Pollution and Acute Changes in Heart Rate Variability and Respiratory Function in Urban Cyclists.” Environmental Health Perspectives 119 (10): 1373-78. doi:10.1289/ehp.1003321.

Weisman, Idelle M. 2003. "Erratum ATS/ACCP Statement on Cardiopulmonary Exercise Testing.” American Journal of Respiratory and Critical Care Medicine 167 (10): 145152.

West, John Burnard. 2012. Respiratory Physiology: The Essentials. 9th ed. Baltimore, MD: Lippincott Williams \& Wilkins.

Whitt, F. R. 1971. "A Note on the Estimation of the Energy Expenditure of Sporting Cyclists." Ergonomics 14 (3): 419-24. doi:10.1080/00140137108931261.

Wilson, David Gordon. 2004. Bicycling Science. 3rd ed. Cambridge, MA: MIT Press.

Winters, Meghan, M. A. Harris, Conor C. O. Reynolds, P. A. Cripton, M. Chipman, M. D. Cusimano, J. Brubacher, S. M. Friedman, M. Monro, and L. Vernich. 2013. "Bicyclists' Injuries and the Cycling Environment: The Impact of Route Infrastructure.” In Washington, D.C. http://docs.trb.org/prp/13-2995.pdf.

Yu, Qi, Yi Lu, Shan Xiao, Junxiu Shen, Xun Li, Weichun Ma, and Limin Chen. 2012. “Commuters' Exposure to PM1 by Common Travel Modes in Shanghai." Atmospheric Environment 59 (November): 39-46. doi:10.1016/j.atmosenv.2012.06.001.

Zhao, L., X. Wang, Q. He, H. Wang, G. Sheng, L. Y. Chan, J. Fu, and D. R. Blake. 2004. "Exposure to Hazardous Volatile Organic Compounds, $\mathrm{PM}<\mathrm{Sub}>10</$ sub $>$ and CO While Walking along Streets in Urban Guangzhou, China.” Atmospheric Environment 38 (36): 6177-84.

Zuurbier, Moniek, G. Hoek, M. Oldenwening, V. Lenters, K. Meliefste, P. Van Den Hazel, and B. Brunekreef. 2010. "Commuters' Exposure to Particulate Matter Air Pollution Is Affected by Mode of Transport, Fuel Type, and Route.” Environmental Health Perspectives 118 (6): 783-89.

Zuurbier, Moniek, G. Hoek, M. Oldenwening, K. Meliefste, P. van den Hazel, and B. Brunekreef. 2011. "Respiratory Effects of Commuters' Exposure to Air Pollution in Traffic.” Epidemiology 22 (2): 219-27.

Zuurbier, Moniek, Gerard Hoek, Peter Hazel, and Bert Brunekreef. 2009. "Minute Ventilation of Cyclists, Car and Bus Passengers: An Experimental Study.” Environmental Health 8 (1): 48-57. doi:10.1186/1476-069X-8-48. 
Zuurbier, Moniek, Gerard Hoek, Marieke Oldenwening, Kees Meliefste, Esmeralda Krop, Peter van den Hazel, and Bert Brunekreef. 2011. "In-Traffic Air Pollution Exposure and CC16, Blood Coagulation, and Inflammation Markers in Healthy Adults.” Environmental Health Perspectives 119 (10): 1384-89. doi:10.1289/ehp.1003151. 